\title{
POSTIRRADIATION EXAMINATIONS OF FUEL PINS FROM THE GCFR F-1 SERIES OF MIXED-OXIDE FUEL PINS AT 5.5 at. $\%$ BURNUP
} by

R. V. Strain and C. E. Johnson

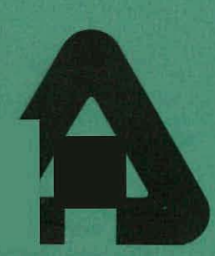




\section{DISCLAIMER}

This report was prepared as an account of work sponsored by an agency of the United States Government. Neither the United States Government nor any agency Thereof, nor any of their employees, makes any warranty, express or implied, or assumes any legal liability or responsibility for the accuracy, completeness, or usefulness of any information, apparatus, product, or process disclosed, or represents that its use would not infringe privately owned rights. Reference herein to any specific commercial product, process, or service by trade name, trademark, manufacturer, or otherwise does not necessarily constitute or imply its endorsement, recommendation, or favoring by the United States Government or any agency thereof. The views and opinions of authors expressed herein do not necessarily state or reflect those of the United States Government or any agency thereof. 


\section{DISCLAIMER}

Portions of this document may be illegible in electronic image products. Images are produced from the best available original document. 
The facilities of Argonne National Laboratory are owned by the United States Government. Under the terms of a contract (W-31-109-Eng-38) between the U. S. Department of Energy, Argonne Universities Association and The University of Chicago, the University employs the staff and operates the Laboratory in accordance with policies and programs formulated, approved and reviewed by the Association.

\section{MEMBERS OF ARGONNE UNIVERSITIES ASSOCIATION}

The University of Arizona Carnegie-Mellon University Case Western Reserve University The University of Chicago University of Cincinnati Illinois Institute of Technology University of Illinois Indiana University Iowa State University The University of Iowa
Kansas State University The University of Kansas Loyola University Marquette University Michigan State University The University of Michigan University of Minnesota University of Missouri Northwestern University University of Notre Dame
The Ohio State University

Ohio University

The Pennsylvania State University

Purdue University

Saint Louis University

Southern Illinois Univer sity

The University of Texas at Austin

Washington University

Wayne State University

The University of Wisconsin

\section{NOTICE}

This report was prepared as an account of work sponsored by the United States Government. Neither the United States nor the United States Department of Energy, nor any of their employees, nor any of their contractors, subcontractors, or their employees, makes any warranty, express or implied, or assumes any legal liability or responsibility for the accuracy, completeness or usefulness of any information, apparatus, product or process disclosed, or represents that its use would not infringe privately-owned rights. Mention of commercial products, their manufacturers, or their suppliers in this publication does not imply or connote approval or disapproval of the product by Argonne National Laboratory or the U. S. Department of Energy.

Printed in the United States of America Available from

National Technical Information Service

U. S. Department of Commerce

5285 Port Royal Road

Springfield, Virginia 22161

Price: Printed Copy $\$ 6.00 ;$ Microfiche $\$ 3.00$ 


\section{ARGONNE NATIONAL LABORATORY \\ 9700 South Cass Avenue \\ Argonne, Illinois 60439}

\section{POSTIRRADIATION EXAMINA TIONS OF FUEL PINS \\ FROM THE GCFR $F=1$ SERIES \\ OF MIXED-OXIDE FUEL PINS \\ AT $\sim 5.5$ at. $\%$ BURNUP}

by

R. V. Strain* and C. E. Johnson**

Materials Science Division

May 1978

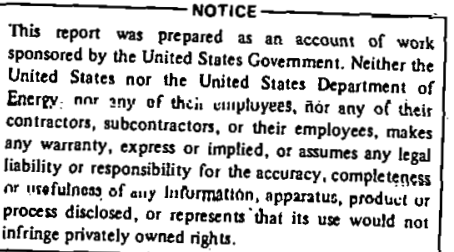

infringe privately owned rights.

\footnotetext{
* Now with EBR-II Project

**Chemical Engineering Division
} 
THIS PAGE

\section{WAS INTENTIONALLY LEFT BLANK}


TABLE OF CONTENTS

$\underline{\text { Page }}$

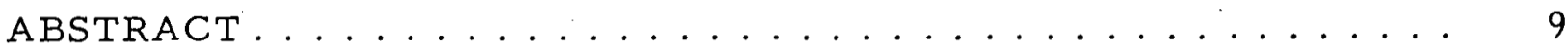

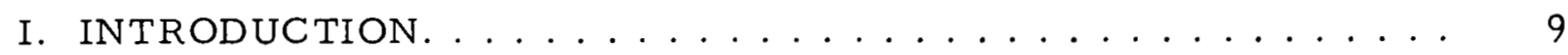

A. Capsule and Fuel-pin Descriptions.............. 10

B. Irradiation Conditions . . . . . . . . . . . . 12

C. Disassembly and Examination of the Capsule . . . . . . . . 16

D. Nondestructive Examination of the Fuel Pins . . . . . . . . 17

1. Neutron Radiography . . . . . . . . . . . . . . . 17

2. Visual and Photographic Examinations ........... 17

3. Gamma Spectroscopy. . . . . . . . . . . . . . . . . . . 19

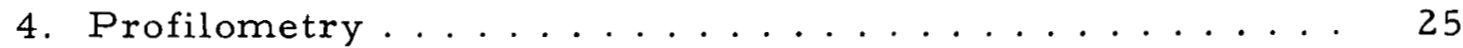

5. Eddy-current Inspection. . . . . . . . . . . 25

E. Destructive Examinations . . . . . . . . . . . . 30

1. Gas Sampling and Analysis ............... 30

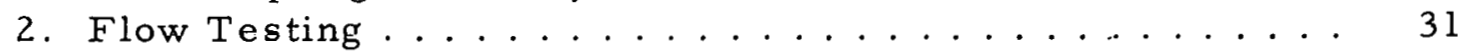

3. Fuel-pin Sectioning ................. 33

4. Burnup Analyses. . . . . . . . . . . . . . . . 35

(a) Metallographic Examinations............. 35

(b) Fuel-density Determinations ............ 41

(c) Electron-microprobe Examinations of the Fuel. . . . 46

(d) Fuel-Cladding Chemical Interaction ......... 51

(e) Cladding Microstructure. . . . . . . . . . . 57

(f) Cladding-density Determinations . . . . ..... 68

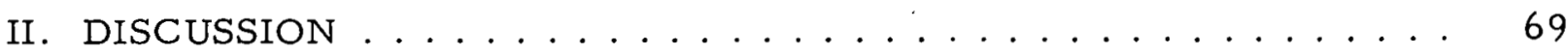

A. Volatile Fission-product Migration. . . . . . . . . . . 69

B. Fuel Melting. . . . . . . . . . . . . . . . . . 72

C. Actinide Redistribution. . . . . . . . . . . . 75

D. Rádial Uxygen Fotential . . . . . . . . . . . . . 75

E. Cladding Characterization. . . . . . . . . . . 78

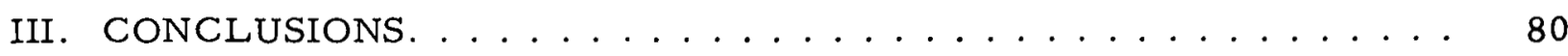

APPENDIX: Results of Fuel-density Measurements Made with

Quantitative Metallography. . . . . . . . . . 84

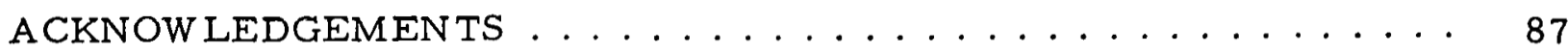

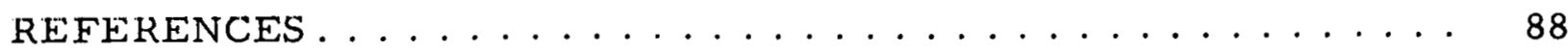




\section{LIST OF FIGURES}

No.

Title

$\underline{\text { Page }}$

1. Major Components of the G-3 Capsule............. 11

2. Schematic of Typical F-1 Fuel Pin .............. 11

3. Relative Fuel-pin Positions . . . . . . . . . . . . . . 13

4. Axial Temperature Distribution for the Core Region of Fuel

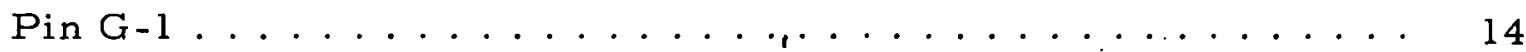

5. Axial Temperature Distribution for the Core Region of Fuel

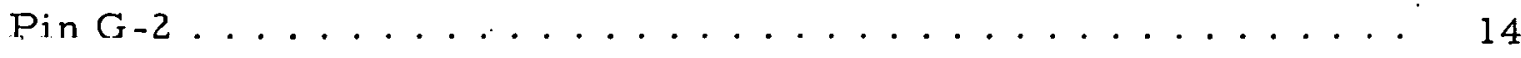

6. Axial Temperature Distribution for the Core Region of Fuel

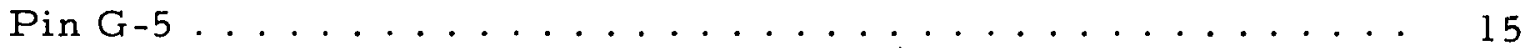

7. Axial Temperature Distribution for the Core Region of Fuel

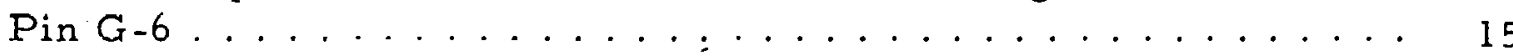

8. Axial 'l'emperature Distribution for the Core Region of Fuel

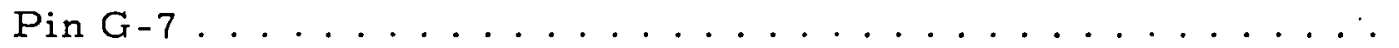

9. Overall View of Fuel Pin G-1, with the Zero Point on the Ruler Placed Even with the Bottom of the Capsule . . . . . . . . .

10. Region at the Top of the Fuel Column of $G-1$ that Exhibited a.

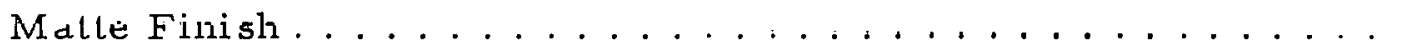

11. Gamma Scans Showing the Relative Activity for ${ }^{137} \mathrm{Cs}$ and ${ }^{95} \mathrm{Nb}$ in the Fuel Column of $\mathrm{G}-1 \ldots \ldots \ldots \ldots$

12. Gamma Scans Showing the Relative Aclivily for ${ }^{137} \mathrm{Cs}$ and ${ }^{95} \mathrm{Nb}$ in the Fuel Column of $\mathrm{G}-2 \ldots \ldots \ldots \ldots$

13. Gamma Scans Showing the Relative Activity for ${ }^{137} \mathrm{Cs}$ and ${ }^{95} \mathrm{Nb}$ in the Fuel Column of $\mathrm{G}-5 \ldots \ldots \ldots \ldots$

14. Gamma Scans Showing the Relative Activity for ${ }^{137} \mathrm{Cs}$ and ${ }^{45} \mathrm{Nb}$ in the Fuel Column of $G-6 \ldots \ldots \ldots \ldots \ldots$

15. Gamma Scans Showing the Relative Activity for ${ }^{137} \mathrm{Cs}$ and ${ }^{95} \mathrm{Nb}$ in the Fuel. Column of $\mathrm{G}-7 \ldots \ldots \ldots 24$

16. Postirradiation Diametral Profile of Fuel Pin G-1....... 25

17. Postirradiation Diametral Profile of Fuel Pin G-2 . . . . . 26

18. Postirradiation Diametral Profile of Fuel Pin G-5. . . . . . 27

19. Postirradiation Diametral Profile of Fuel Pin G-'6. . . . . . . 28

20. Postirradiation Diametral Profile of Fuel Pin G-7........ 28

21. Response of the Eddy-current Tester for Fuel Pins G-1, G-6,

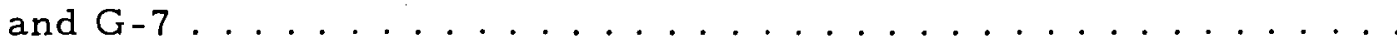




\section{LIST OF FIGURES}

No.

Title

Page

22. Flow -testing Apparatus Used to Determine Helium Flow Rates through Several Axial Regions of Fuel Pins G-1, G-6, and G-7...

23. Compression Seal Used in Higher Pressure Flow Tests on Element G-7 at the Upper Fuel-Blanket Interface . . . . . . . .

24. Low-pressure Test Results for G-7 Upper Interface at Ambient Temperature with the Rebuilt Flow-testing Apparatus . . . . . 32

25. High-pressure Test Results for G-7 Upper Interface . . . . . . . 33

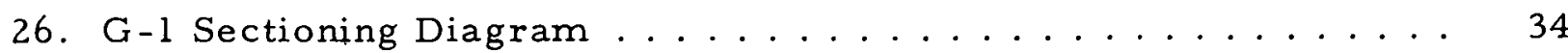

27. G-2, G-6, and G-7 Sectioning Diagram. .......... 34

28. Montage Showing Metallographic Sections from G-1 Referenced as to Their Positions in the Fuel Pin. . . . . . . . . . . . .

29. Montage Showing Metallographic Sections from G-2 Referenced as to Their Positions in the Fuel Pin. . . . . . . . . . .

30. Montage Showing the Metallographic Samples from G-6 Referenced as to Their Positions in the Fuel Pin . . . . . . . .

31. Montage Showing the Metallographic Sections from G-7

Referenced as to Their Positions in the Fuel Pin. . . . . . . . .

32. Midplane Section from Fuel Pin G-1 Showing Uneven Edge on the Central Hole and Ring of Porosity at the Outer Edge of the Columnar-grain Zone . . . . . . . . . . . . . .

33. Bottom of Fuel Column from Fuel Pin G-1 Showing Dendritic Structure in the Fuel near the Centerline and a Spherical, Metallic Fission-product Ingot. . . . . . . . . . . . . . .

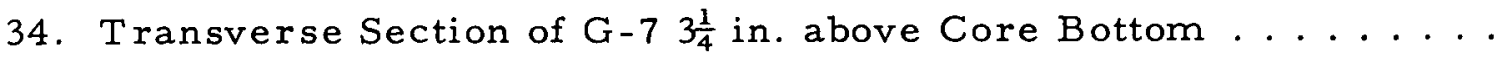

35. Transverse Section of G-7 Shown in Fig. 34 after Regrinding and Polishing ....................

36. Microstructure of Radial Strips of Fuel from Pin G-1 after Chemical Etching in a Solution of $10 \% \mathrm{H}_{2} \mathrm{SO}_{4}$ and $90 \% \mathrm{H}_{2} \mathrm{O}_{2} \ldots \ldots$

37. Microstructure of Radial Strips of Fuel from Pin $G_{x}-$ ? a fter Chemical Etching in a Solution of $10 \% \mathrm{H}_{2} \mathrm{SO}_{4}$ and $90 \% \mathrm{H}_{2} \mathrm{O}_{2} \ldots \ldots$.

38. Microstructure of Radial Strips of Fuel from Pin G-6 after Chemical Etching in a Solution of $10 \% \mathrm{H}_{2} \mathrm{SO}_{4}$ and $90 \% \mathrm{H}_{2} \mathrm{O}_{2} \ldots \ldots$

39. Microstructure of Radial Strips of Fuel from Pin G-7 after Chemical Etching in a Solution of $10 \% \mathrm{H}_{2} \mathrm{SO}_{4}$ and $90 \% \mathrm{H}_{2} \mathrm{O}_{2} \ldots \ldots$ 


\section{LIST OF FIGURES}

No $\underline{\text { Title }}$

40. Bubble Tracks in the Fuel from Pins $G-1$ and $G-6$, Indicating that the Bubbles Are Moving in Opposite Directions . . . . . . . 46

41. Radial Plutonium Distribution at the Core Midplane of G-1 . . . 47

42. Radial Plutonium Distribution at the Core Midplane of G-6 . . . 47

43. Radial Plutonium Distribution 13 in. above Core Bottom of G-6 . 47

44. Radial Mo and Nd Distribution in the Oxide Phase of the Fuel at

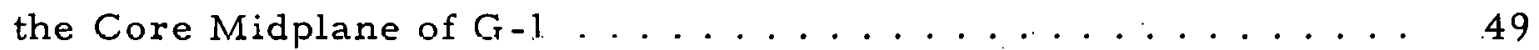

45. Fuel Microstructure near the Bottom of the Fuel Column of G-1. 50

46. Areds Cuintaining IIigh $\mathrm{Cs}$ Concentrationo in tho Blanket Pollet Adjacent to the Bottom of the G-1 Fuel Column......... 51

47. Part of a Deposit of CsI in the Upper Blanket Region of G-7 . . . 52

48. Typical Fuel-Cladding Chemical Interaction in the Metallographic Sample from Fuel Pin G-1 . . . . . . . . . . .

49. Typical Fuel-Cladding Chemical Interaction in the Metallographic Sections from Fuel Pin $G-2 \ldots \ldots \ldots$

50. Typical Fuel-Cladding Chemical Interaction in the Metallographic Sections from Fuel Pin $G-6 \ldots \ldots$

51. Typical Fuel-Cladding Chemical Interaction in the Transverse Metallographic Sections from Fuel Pin G-7 ...........

52. Electron-microprobe Scanning Images of GA Fuel Pin G-1 at Core Midplane. . . . . . . . . . . . . . . . . . .

53. Electron-microprobe Scanning Images of GA Fuel Pin G-1 from a Sccond Location on the Sample.

54. Electron-microprobe Scanning Images of Typical FCCI at Core

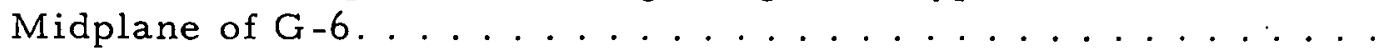

55. Line Scans of FCCI at Core Midplane of G-6. . . . . . . . . 61

156. Cladding Microstructure 3.3 in. above the Bottom of Core in G-1 .

57. Cladding Microstructure 6.75 in. above the Bottom of Fuel Column $\mathrm{G}-1 \ldots \ldots \ldots \ldots \ldots$

58. Cladding Microstructure 11.3 in. above the Bottom of Fuel Column $\mathrm{G}-1 \ldots \ldots \ldots \ldots$

59. Cladding Microstructure 3.25 in. above the Bottom of Core in

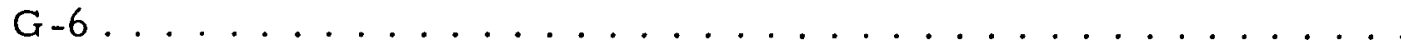




\section{LIST OF FIGURES}

No.

Title

Page

60. Cladding Microstructure 6.75 in. above the Bottom of Core in

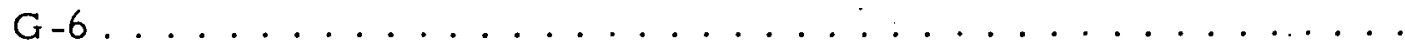

61. Cladding Microstructure 11.15 in. above the Bottom of Core

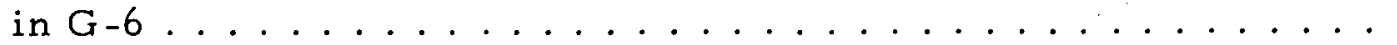

62. Relative Axial ${ }^{137} \mathrm{Cs}$ Gamma Activity and the Axial Diametral Profile of Pin G-1 Showing a Local Cladding Diametral Increase at the Same Axial Location as the Peak in the ${ }^{137} \mathrm{Cs}$ Activity near the Bottom Fuel-Blanket Interface . . . . . . . . . . .

63. Relative Axial ${ }^{137} \mathrm{Cs}$ Gamma Activity and the Axial Diametral Profile for Pin G-2 Showing a Local Cladding Diametral Increase at the Same Axial Location as the Peak in the ${ }^{137} \mathrm{Cs}$ Activity near the Top Fuel-Blanket Interface. . . . . . . . . . . .

64. Beta-Gamma Autoradiographs of the Midplane Cross Section from Fuel Pins $G-1, G-2, G-6$, and $G-7 \ldots \ldots 73$

65. Amount of Central Hole Closing at the Top of the Fuel Columns.. 77

66. Maximum FCCI Depth for the F -1 Series Fuel Pins at $\sim 5$ at. $\%$

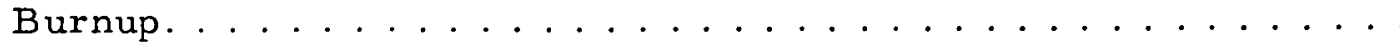

67. SEM Photographs of G-1 Cladding Microstructures at the Reactor-core Midplane . . . . . . . . . . . . . . . .

68. SEM Photographs of Unirradiated Archive Cladding Annealed $1000 \mathrm{~h}$ at Temperatures from 700 to $800^{\circ} \mathrm{C} \ldots \ldots \ldots \ldots$

69. Depletion of Cr Adjacent to the FCCI in the Cladding from the

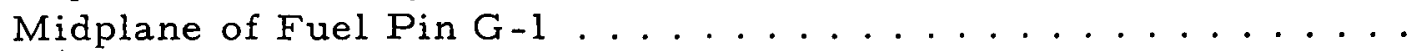

70. Diametral Fuel-density Distribution for Top and Bottom of G-6 Fuel Column. . . . . . . . . . . . . . . . . .

71. Radial Fuel-density Distribution for the Transverse Sections from $\mathrm{G}-6 \ldots \ldots \ldots \ldots \ldots \ldots \ldots$

72. Diametral Fuel-density Distribution for Top (a) and Bottom (b) of G-1 Fuel Column....................

73. Radial Fuel-density Distribution for Sections from $r_{x}-1 \ldots \ldots$

74. Radial Fuel-density Distribution for Sections from G-1 11.3 in. above Core Bottom. 


\section{LIST OF TABLES}

No.

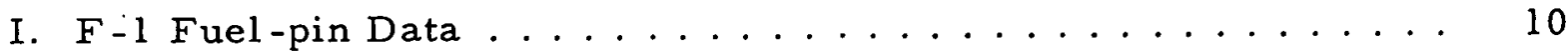

II. Thermal-barrier Dimensions ................. 12

III. Run-by-run Peak Power Ratings . . . . . . . . . . . . . . 13

IV. Time-averaged Peak Cladding Temperatures for the F-l GCFR

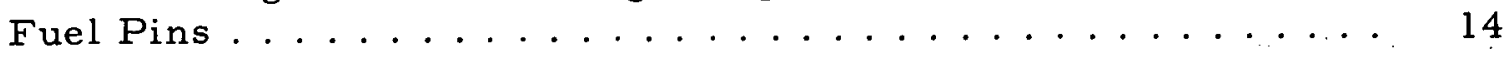

V. F-1 Series Fuel-column-length Measurements . . . . . . . 17

VT. Diameter. Čhanges för F -1 Fuel Piris. . . . . . . . . . . 29

VII. Results of Gas Sampling and Analysis ............. . . 30

VIII. Flow-testing kesults with Low-pressure Tesl Apparatus. . . . 31

IX. Burnup Determinations for $G-1, G-2$, and $G-6 \ldots \ldots 35$

$X$. Elemental Composition of the Metallic Inclusiuns in $G-1$ al llie Core Midplane . . . . . . . . . . . . . . . . 48

XI. Fuel-Cladding Chemical Interaction Data for GCFR F-1 Series

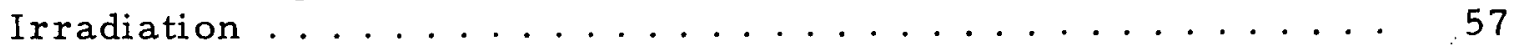

XII. Cladding-density Measurements . . . . . . . . . . . 68

XIII. Peak Fuel Inner Surface Temperatures for G-1 Calculated Using Three Thermal Performance Codes ...........

XIV. Measured and Calculated Burnups for F-1 Pins G-1, G-2, and $\mathrm{G}-6 \ldots \ldots \ldots \ldots \ldots \ldots$

XV. Oxygen Potential Data for G-1 at the Core Midplane....... 78 
POSTIRRADIA TION EXAMINATIONS OF FUEL PINS

FROM THE GCFR F-1 SERIES

OF MIXED-OXIDE FUEL PINS

AT $\sim 5.5$ at. \% BURNUP

by

R. V. Strain and C. E. Johnson

\begin{abstract}
Postirradiation examinations were performed on five fuel pins from the Gas-Cooled Fast-Breeder Reactor F-1 experiment irradiated in EBR-II to a peak burnup of $\sim 5.5$ at. \%. These encapsulated fuel pins were irradiated at peak-power linear ratings from $\sim 13$ to $15 \mathrm{~kW} / \mathrm{ft}$ and peak cladding inside diameter temperatures from $\sim 625$ to $760^{\circ} \mathrm{C}$. The maximum diametral change that occurred during irradiation was $0.2 \% \Delta \mathrm{D} / \mathrm{D}_{0}$. The maximum fuel-cladding chemical interaction depth was 2.6 mils in fuel pin G-1 and $1 \mathrm{mil}$ or less in the other three pins examined destructively. Significant migration of the volatile fission products occurred axially to the fuel-blanket interfaces. The postirradiation examination data indicate that fuel melted at the inner surface of the annular fuel pellets in the two highest power rating fuel pins, but little axial movement of fuel occurred.
\end{abstract}

\title{
I. INTRODUCTION
}

The F-1 series experiment ${ }^{1}$ is being irradiated in the Experimental Breeder Reactor-II (EBR-II) as part of the fuel-pin development program for the Gas-Cooled Fast-Breeder Reactor (GCFR). The general objective of the F-1 experiment is to study fuel-element behavior at cladding temperatures typical of normal and hot-spot conditions in the GCFR, i.e., in the range of $600-800^{\circ} \mathrm{C}$. The fuel pins were designed with features typical of future GCFR designs, within the limitations imposed by performing the experiment in EBR-II in flowing sodium and without venting the fission gases from the pins. Charcoal traps were placed in some of the elements to obtain data on the behavior of activated charcoal under conditions that may be encountered in the pressure-equalization and gas-purification systems of GCFR plants. The fuel pins also were designed with large plenums to maintain low internal pres sures. The GCFR fuel pins will be vented and will not be subject to cladding stresses that result from internal pressurization under normal operating conditions. 
The F-1 encapsulated fuel pins are being irradiated in a Mark B-7B subassembly, a seven-capsule array, with planned interim examinations at burnups of approximately 25,000,50,000, 100,000 and 125,000 MWd/Te. The $\mathrm{G}-3$ capsule was removed from the subassembly after 25,000 $\mathrm{MWd} / \mathrm{Te}$ and given an extensive postirradiation examination. ${ }^{2}$ Five capsules we re removed from the subassembly after 53,000 MWd/Te. One original capsule and six replacement capsules are continuing to the higher burnups. The present report encompasses the detailed destructive examination given the five encapsulated fuel pins (G-1, G-2, G-5, G-6, and G-7) terminated at 53,000 MWd/Te. Initial nondestructive examinations of the capsules were performed at the Hot Fuel and Examination Facility (HFEF) of Argonne National Laboratory (ANL) at the EBR-II site in Idaho. Disassembly of the capsules and destructive examination of the fuel pins were performed in the Alpha-Gamma Hot-Cell Facility (AGHCF) of the Materials Science Division in Illinois.

A. Capsule and Fuel-pin Descriptions

Each of the capsules was composed of three major components: the outer capsule, the thermal barrier, and the fuel pin, as shown in Fig. 1. The fuel pin (Fig. 2) consisted of a 13.5-in. -long fuel column composed of 0.2595-in. outside diameter (OD) by 0:250-in.-long annular fuel pellets with a 0.058 -in.diam central hole. The fuel pellets had dished ends with a dish depth of $0.006 \mathrm{in}$. The composition of the mixed-oxide pellets was $85 \mathrm{wt} \% \mathrm{UO}_{2}(93 \%$ ${ }^{235} \mathrm{U}$ ) and 15 wt $\% \mathrm{PuO}_{2}$. The fuel weight, smeared density, and oxygen-tometal $(O / M)$ ratio are given in Table $I$ for each fuel pin. A 3 -in.-long axial blanket composed of 0.2595 -in. OD by 0.250 -in.-long solid pellets of natural $\mathrm{UO}_{2}$ was located at each end of the fuel column. An Inconel* spring was located above the upper blanket to maintain the pellet-stack geometry. A sealed capsule containing activated coconut charcoal was located near the bottom of both the upper and lower gas plenums. Fuel pins $G-6$ and $G-7$ contained charcoal beds (active traps) in the plenum regions that were open to the gas in the fuel pins. The cladding was a $20 \%$ cold-worked Type 316 tube with a 0.0185 -in. wall and a $0.300-$ in. OD.

TABLE I. F-1 Fuel-pin Data

\begin{tabular}{lcccc}
\hline $\begin{array}{c}\text { Fuel } \\
\text { Pinc }\end{array}$ & $\begin{array}{c}\text { Oxide Fuel } \\
\text { Woight, } \mathrm{g}\end{array}$ & $\begin{array}{c}\text { O/M } \\
\text { Ratio }\end{array}$ & $\begin{array}{c}\text { Smeared } \\
\text { Density, } \\
\% \text { TD }\end{array}$ & $\begin{array}{c}\text { Fuel to } \\
\text { Cladding Gap, } \\
\text { mils }\end{array}$ \\
\hline G-1 & 109.50 & 1.992 & 82.64 & $3.8-4.9$ \\
G-2 & 111.08 & 1.971 & 84.12 & $3.0-3.8$ \\
G-5 & 110.21 & 1.990 & 83.51 & $4.1-4.5$ \\
G-6 & 107.72 & 1.972 & 82.65 & $4.0-4.6$ \\
G-7 & 107.90 & 1.984 & 82.54 & $3.7-4.5$ \\
\hline
\end{tabular}

*Trade name for a nickel-base alloy with $70 \% \mathrm{Ni}$ (min.) and $14-17 \% \mathrm{Cr}, 5-9 \% \mathrm{Fe}$, and $2-1 / 4$ to $2-3 / 4 \% \mathrm{Ti}$ as the other miajor constituents. 


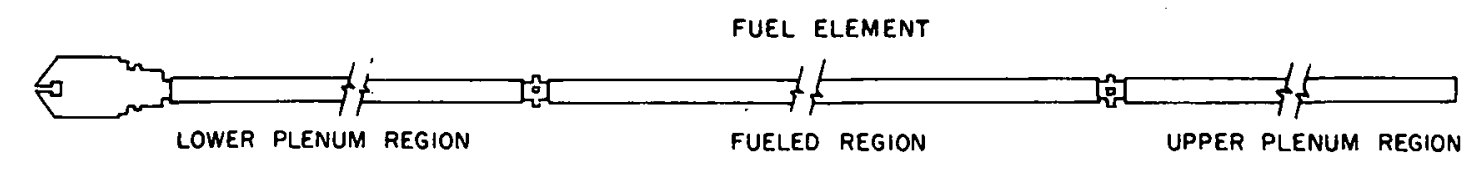

0.300 in. OD $\times 18.5-\mathrm{mi}$ WALL $20 \%$ COLD-WORKED TYPE 316 STAINLESS STEEL

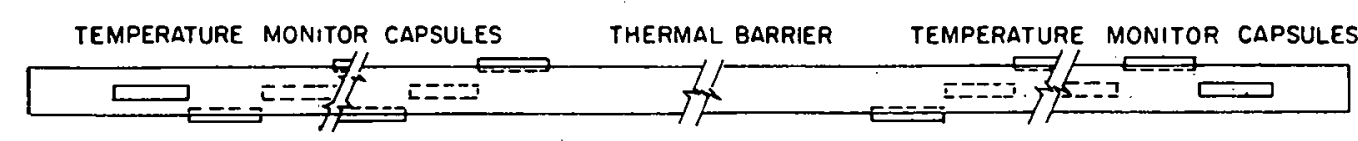

0.625 in. $00 \times 0.435$ in. 10 SOLUTION-TREATED TYPE 304 STAINLESS STEEL

CAPSULE TUBE

$0.778 \mathrm{in.} \mathrm{OD} \times 0.725 \mathrm{in.} 10$ SOLUTION-TREATED TYPE 304 STAINLESS STEEL

Fig. 1. Major Components of the G-3 Capsule. MSD Neg. No. 166497.
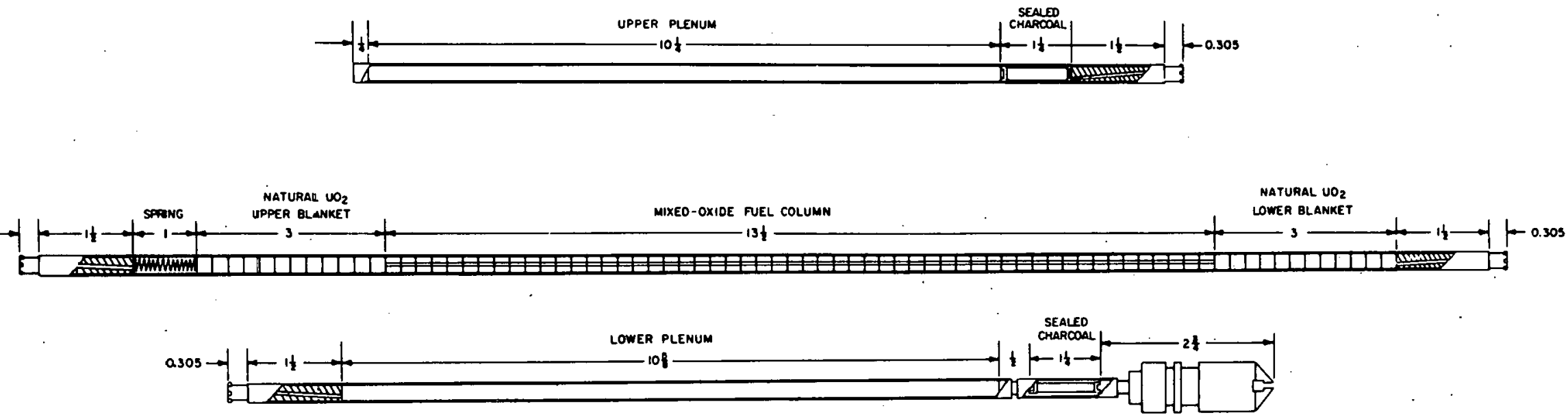

Fig. 2. Schematic of Typical F-1 Fuel Pin. Fuel pins $G-6$ and $G-7$ have charcoal in the upper and lower plenum regions. All dimensions are in inches. MSD Neg. No. 63999. 
Each thermal barrier consisted of a heavy-walled, solution-treated Type 304 stainless steel tube. The barriers were sized to provide the desired cladding temperature for specific pins. The inside diameter (ID) and OD of each thermal barrier are given in Table II. Twenty-four slots, 0.167 in. wide by $0.934 \mathrm{in}$. long, we re cut through the tube to accommodate capsules containing silicon-carbide temperature monitors. Twelve of the monitors were located between $3 / 4$ and 18 in. from the bottom of the barrier, and the other twelve were located between 1 and 19 in. from the top of the barrier. A slot $\sim 85 \mathrm{mils}$ wide and $60 \mathrm{mils}$ deep was machined the full length of the barrier to accommodate a dosimeter assembly. The dosimeter assembly consisted of a small capsule ( 0.042 in. diam) containing $15-$ mil wires of vanadium, aluminum, copper, and small particles of fissile material. Five of these capsules were placed at various axial locations in a 0.065 -in. OD by 0.056 -in. ID tube running the full length of the thermal barrier.

TABLE II. Thermal-barrier Dimensions

\begin{tabular}{|c|c|c|c|c|c|}
\hline \multirow[b]{2}{*}{ Paramotore } & \multicolumn{5}{|c|}{ Fuel Pins } \\
\hline & $G-1$ & $C_{-T}=?$ & $r-5$ & $r-6$ & $G-7$ \\
\hline UU, in. & 0.678 & 0.647 & 0.632 & 0.596 & 0.575 \\
\hline ID, in. & 0.375 & 0.375 & 0.375 & 0.435 & 0.481 \\
\hline
\end{tabular}

The outer capsules consisted of 0.778 -in. OD by 0.725 -in. ID solutiontreated Type 304 stainless steel tube. Heat transfer from the fuel pin to the thermal barrier and from the the rmal barrier to the capsule was provided by sodium in the annuli. The capsule was wrapped with a 0.020 -in.-diam wire to space the capsules and provide for mixing of the coolant in the subassembly.

\section{B. Irradiation Conditions}

The five capsules were irradiated in subassembly X094 and then X094A for Runs 47 through 54 and 56 through 61 , respectively. The relative positlons of the capsules in the subassemblies are shown in Fig. 3. The capsules were irradiated in row 7 of the reactor, which is the outer row of the expanded EBR-II core (the inner blanket region of the original 76 subasserribly core). A steep flux gradient occurs across this row in EBR-II; therefore, the peak power of the fuel pins varied from $15.0 \mathrm{~kW} / \mathrm{ft}$ for $\mathrm{G}-1$ to $12.75 \mathrm{~kW} / \mathrm{ft}$ for $\mathrm{G}-7$. (for Run 51), although the fuel composition was the same in all fuel pins. The fission rate for each position in EBR-II is a function of the reactor loading for each run. Because of the relatively high ratio of experiments-to-driverfuel subassemblies in EBR-II, the loading of the reactor changes quite fre quently. As a result, the fission rate, and therefore the power rating of the fuel elements, is also subject to change for almost every run. The peak power for each fuel pin on a run-by-run basis is given in Table III. These 


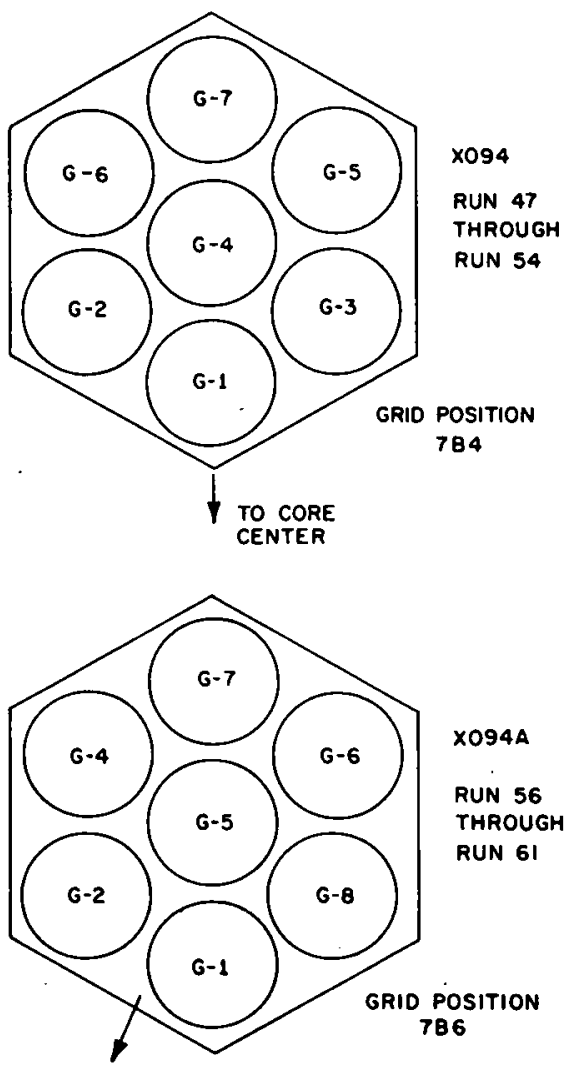

Fig. 3. Relative Fuel-pin Positions. MSD Neg. No. 63997. powers were calculated from fission-rate data calculated by the EBR-II Project using the DOT code. ${ }^{3}$ The fission rates were reduced by $9 \%$ to correct for the EBR-II power deficit and were also corrected after each run to account for burnup. A value of $196 \mathrm{MeV}$ per fission was used to calculate the power.

Fuel-pin temperatures were calculated based on the run-by-run power data using the HECTIC III code (a modification of HECTIC II by the EBR-II Project). The thermal barrier was simulated when the cladding temperatures were calculated using an artificially thick capsule wall. The capsule-wall thickness was determined by an iterative calculation that was used to compare the HECTIC temperature drop from the capsule OD to cladding $O D$ with detailed hand calculations of the temperature drop using the real capsule geometry at the core midplane. The fuel temperatures are less accurate than the cladding temperatures because the HECTIC code does not calculate the gap conductance. A gap conductance of $1000 \mathrm{Btu} / \mathrm{h}-\mathrm{ft}^{2}-{ }^{\circ} \mathrm{F}$ was used in the calculations. The General Electric fuel conductivity model ${ }^{5}$ is used in the HECTIC subroutine OXIDE to calcu-

late the fuel centerline temperature. The estimated accuracy of the calculated cladding temperatures is $\pm 20^{\circ} \mathrm{C}$ and that of the fuel temperatures $\pm 100^{\circ} \mathrm{C}$.

TA BLE III. Run-by-run Peak Power Ratings

\begin{tabular}{lcccccccccccccc}
\hline & \multicolumn{11}{c}{ Peak Power Ratings, $\mathrm{kW} / \mathrm{ft}$} \\
\cline { 2 - 14 } $\begin{array}{l}\text { Fuel } \\
\text { Pins }\end{array}$ & 47 & 48 & 49 & 50 & 51 & 52 & 53 & 54 & 56 & 57 & 58 & 59 & 60 & 61 \\
\hline G-1 & 14.6 & 13.6 & 14.8 & 14.5 & 15.0 & 13.9 & 13.9 & 13.3 & 14.2 & 13.6 & 14.2 & 14.0 & 14.0 & 13.9 \\
G-2 & 14.1 & 13.2 & 14.3 & 13.9 & 14.4 & 13.4 & 13.4 & 12.8 & 14.4 & 13.7 & 14.4 & 14.1 & 14.2 & 14.0 \\
G-5 & 13.0 & 12.1 & 13.2 & 12.7 & 13.3 & 12.4 & 12.4 & 11.8 & 13.9 & 13.3 & 13.9 & 13.7 & 13.7 & 13.6 \\
G-6 & 13.0 & 12.1 & 13.2 & 12.6 & 13.3 & 12.4 & 12.4 & 11.8 & 13.2 & 12.6 & 13.2 & 13.0 & 13.0 & 12.9 \\
G-7 & 12.5 & 11.6 & 12.6 & 12.1 & 12.8 & 11.8 & 11.9 & 11.3 & 12.9 & 12.4 & 12.9 & 12.7 & 12.7 & 12.6 \\
\hline
\end{tabular}

The peak cladding temperature (inner surface just above the reactor midplane) of the fuel pins for each run is shown in Table IV. The approximate length of each of the runs (total length of the run, although most of the runs consist of two or more parts) in hours is also listed in the table. These times at temperature were used to calculate the time-averaged peak cladding temperature for the fuel pins. Axial temperature distributions for the cladding and fuel are shown in Figs. 4 through 8 , using the power conditions in Run 51 . 
These results show that the temperature profile as well as the peak temperature are influenced by the power (location with respect to the reactor-core center) and the thickness of the thermal barrier. The thermal barriers have tended to cause relatively large axial thermal gradients in the lower half of the core region and quite flat profiles in the top half. The axial temperature distribution in most unencapsulated fuel elements in EBR -II is nearly linear over the core region because EBR-II has a nearly flat axial power profile (particularly after the stainless steel reflector was placed in the reactor beginning with Run 56).

TABLE IV. Time-averaged Peak Cladding Temperatures for the F-1 GCFR Fuel Pins

\begin{tabular}{|c|c|c|c|c|c|c|c|c|c|c|c|c|c|c|c|}
\hline \multirow[b]{2}{*}{$\begin{array}{l}\text { Fuel } \\
\text { Pins }\end{array}$} & \multicolumn{14}{|c|}{ Peak Cladding Inner-surface Temperature. ${ }^{\circ} F^{a}$} & \multirow{2}{*}{$\begin{array}{c}\text { Time- } \\
\text { averaged } \\
\text { Temp., } \\
{ }^{\circ} \mathrm{F}\end{array}$} \\
\hline & $\begin{array}{r}47 \\
194\end{array}$ & $\begin{array}{l}48 \\
79\end{array}$ & $\begin{array}{r}49 \\
356\end{array}$ & $\begin{array}{r}50 \\
535\end{array}$ & $\begin{array}{r}51 \\
597\end{array}$ & $\begin{array}{r}52 \\
593\end{array}$ & $\begin{array}{r}53 \\
596\end{array}$ & $\begin{array}{r}54 \\
584\end{array}$ & $\begin{array}{r}56 \\
595\end{array}$ & $\begin{array}{r}57 \\
548\end{array}$ & $\begin{array}{r}58 \\
595\end{array}$ & $\begin{array}{r}59 \\
596\end{array}$ & $\begin{array}{r}60 \\
595\end{array}$ & $\begin{array}{r}61 \\
595\end{array}$ & \\
\hline$G-1$ & 1381 & - & 1391 & 1376 & 1396 & 1350 & 1351 & 1323 & 1368 & 1339 & 1367 & 1358 & 1358 & 1353 & 1361. \\
\hline$G-2$ & 1344 & - & 1354 & 1339 & 1359 & 1315 & 1315 & 1289 & 1357 & 1329 & 1356 & 1347 & 1347 & 1343 & 1338 \\
\hline$G-3$ & 1280 & - & 1289 & 1275 & 1293 & 1253 & 1253 & 1229 & - & - & - & $=$ & - & - & 1266 \\
\hline$G-5$ & 1291 & - & 1300 & 1286 & 1305 & 1264 & 1265 & 1240 & 1321 & 1296 & 1322 & 1313 & 1313 & 1309 & 1295 \\
\hline $0-0$ & 1225 & - & 1232 & 1220 & 1237 & 1200 & 1200 & 1178 & 1234 & 1211 & 1234 & 1226 & 1225 & 1222 & 1219 \\
\hline$G-7$ & 1159 & - & 1166 & 1153 & 1170 & 1137 & 1137 & 1118 & 1175 & 1154 & 1175 & 1168 & 1168 & 1165 & 1158 \\
\hline
\end{tabular}

$a_{\text {The }}$ run is indicated by the top row of numbers, and the time in hours is given in the second row. The total time for all runs was $6979 \mathrm{~h}$.

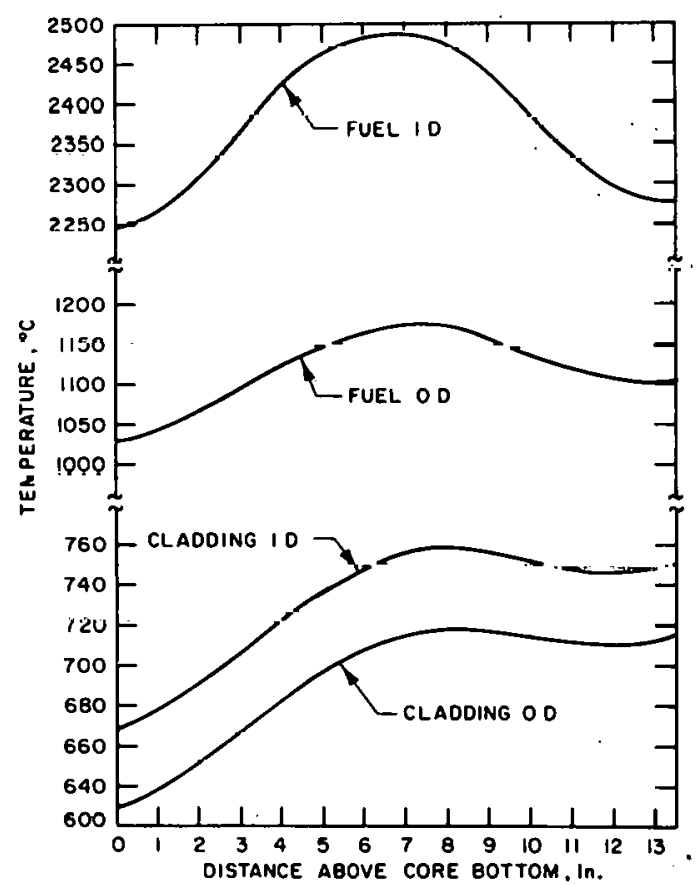

Fig. 4. Axial Temperature Distribution for the Core Region of Fuel Pin G-1. MSD Neg. No, 63955.

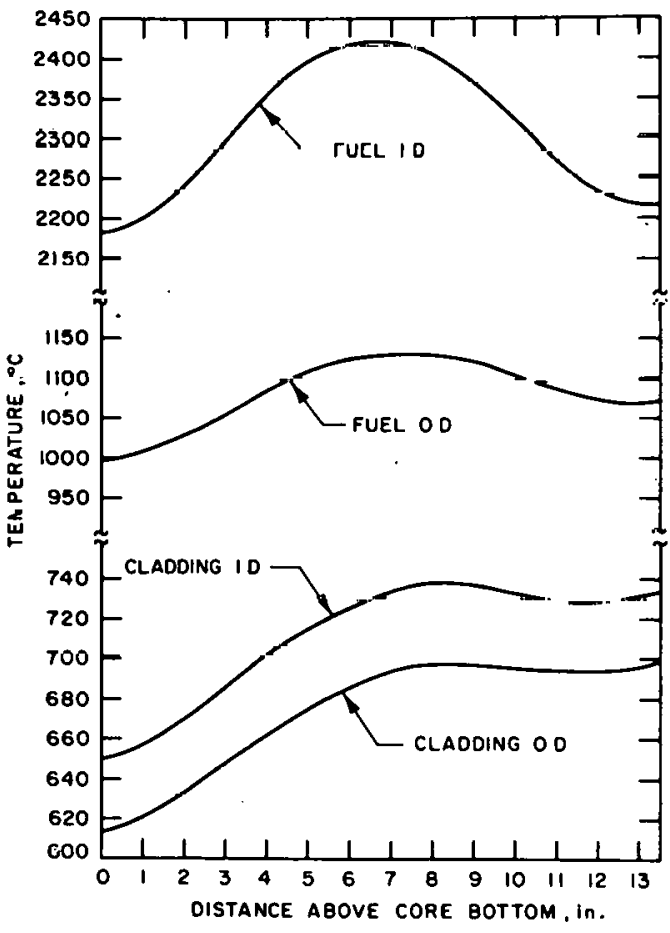

Fig. 5. Axial Temperature Distribution for the Core Region of Fuel Pin G-2. MSD Neg. No. 63956. 


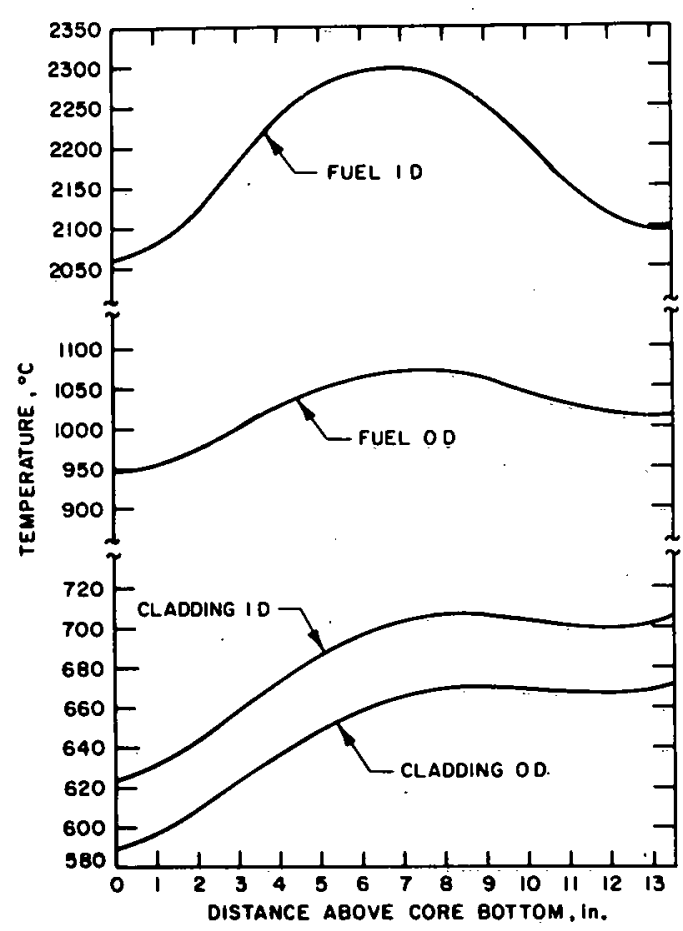

Fig. 6. Axial Temperature Distribution for the Core Region of Fuel Pin G-5. MSD Neg. No. 63957.

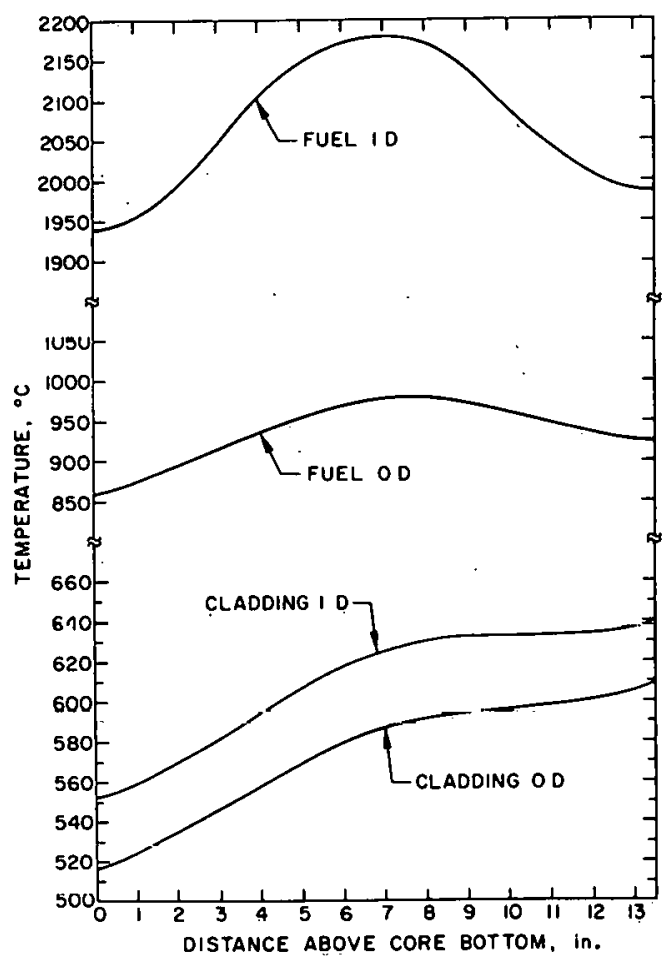

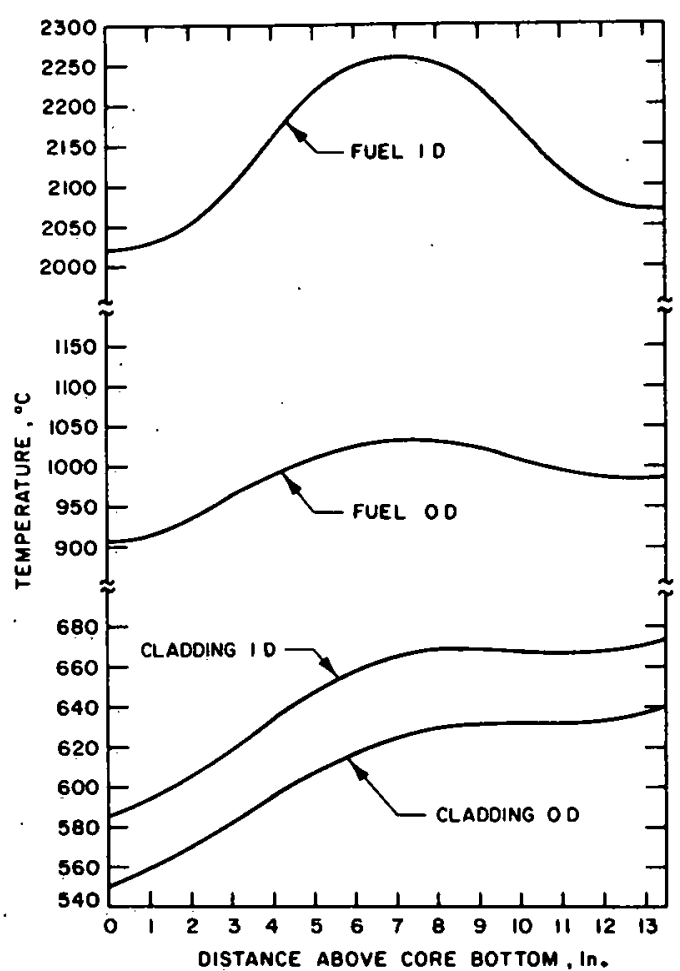

Fig. 7. Axial Temperature Distribution for the Core Region of Fuel Pin G-6. MSD Neg. No. 63958.

Fig. 8

Axial Temperature Distribution for the Core Region of Fuel Pin G-7. MSD Neg. No. 63960 . 
These five capsules were irradiated in two segments, Runs $47 \mathrm{~B}$ through 54 and Runs 56 through 61. During the interim examination of the subassembly between Runs 54 and 56, the configuration of the EBR-II was changed to include four rows of stainless steel reflector subassemblies (rows 8-11). One effect of the stainless steel reflector subassemblies was to raise the neutron flux and fission rate in the outer rows of the core (row 7 is considered to be the outer most row of the core region in this case). To compensate for the increased fission rate, the subassembly was moved further from the core center, from grid position 7B4 to 7B6, and placed in a "tailored position." The "tailored position" consisted of placing a row of depleted uranium blanket subassemblies in row 8 adjacent to the subassembly to maintain a radial flux gradient similar to the one in position 7B4. In addition to the subassembly being moved at the interim examination, each capsule was rotated $180^{\circ}$ with respect to the center of the core before they were loaded into subassembly X094A and placed in position $7 \mathrm{~B} 6$.

C. Disassembly and Examination of the Capsule

After receipt at the AGHCF, the capsules were visually examined through the hot-cell windows and photographed at a magnification of $1 X$. The capsules were photographed next to a ruler so that the maximum bow in the capsules would be apparent. Measurement of the maximum bow in the capsules using this technique showed that the only capsule exhibiting significant bow $(>0.05$ in.) was $G-1$, which had a maximum bow of $0.12 \pm 0.02$ in. The bow near the midlength of $\mathrm{G}-1$ was toward its $180^{\circ}$ azimuthal orientation, which was also toward the reactor-core center when the subassembly was in position $7 \mathrm{~B} 6$.

Capsule bows of the magnitude observed in these capsules were not detrimental to the performance of the capsules and caused no difficulties in dismantling the subas sembly.

The visual examination and photographs of the capsules revealed no unusual or abnormal features. The lower 25 in. of the capsules were discolored and had a blue-gray cast. However, this is generally the condition of the cooler region of capsules irradiated in EBR-II.

The disassembly of the earlier G-3 capsule was fully described previously, ${ }^{2}$ and the five capsules were disassembled using similar techniques. No serious difficulties were experienced during the disassembly of the capsules. In each case, the capsule tube was removed from the thermal barrier in three sections, as was done for G-3. Apparently, even the minor bowing of these capsules was sufficient to cause binding of the capsule tube against the temperature monitor capsules that protruded from the thermal barrier.

The only other difficulty encountered was the removal of a few of the dosimeter capsules from the 0.0625 -in.-diam tube. In three or four cases, the dosimeter capsule tube acted as if it were quite brittle and shattered during the stripping of the 0.0625 -in. tube. In the se cases the dosimeter material was also damaged and was discarded. Forty-three dosimeter capsules were successfully removed and shipped to General Atomic (GA) for analyses. 
D. Nondestructive Examination of the Fuel Pins

Nondestructive examination of the fuel pins consisted of neutron radiography, visual examination, gamma scanning, profilometry, and eddy-current scanning.

1. Neutron Radiography

Neutron radiography of all encapsulated fuel pins was performed at TREAT using both dysprosium and indium foils. The results of measurements of the fuel-column lengths are shown in Table V. These data show that no significant changes occurred in the fuel-column lengths of the F-1 fuel pins. The neutron radiographs also showed that no significant relocation of fuel nor gross failures had occurred in the fuel pins.

TABLE V. F-l Series Fuel-column-length Measurements

\begin{tabular}{ccccc}
\hline $\begin{array}{c}\text { Fuel } \\
\text { Pins }\end{array}$ & $\begin{array}{c}\text { Measured } \\
\text { Length, in. }\end{array}$ & $\begin{array}{c}\text { Initial } \\
\text { Length, in. }\end{array}$ & $\begin{array}{c}\text { Adjusted } \\
\text { Length, in. }\end{array}$ & $\begin{array}{c}\text { Increase, } \\
\%\end{array}$ \\
\hline G-1 & 13.75 & 13.63 & 13.67 & 0.29 \\
G-2 & 13.8125 & 13.654 & 13.73 & 0.58 \\
G-4 & 13.5625 & 13.48 & 13.48 & 0.0 \\
G-5 & 13.6875 & 13.60 & 13.60 & 0.0 \\
G-6 & 13.5625 & 13.46 & 13.48 & 0.15 \\
G-7 & 13.5000 & 13.50 & 13.42 & -0.60 \\
G-8 & 13.5625 & - & 13.48 & -0.60 \\
\hline
\end{tabular}

2. Visual and Photographic Examinations

Visual and photographic examinations of the fuel pins showed that their surfaces were in good condition, as illustrated by the photographs of G-1 shown in Fig. 9. Minor discolorations that fit the pattern of the temperature monitors in the thermal barrier were found between 3 and $17 \mathrm{in}$. above the bottom end-fitting weld. These marks were also found previously on fuel pin G-3 but apparently had no effect on the performance of the fuel pin since they did not extend into the fueled region. A significant change in the appearance of the surfaces of $G-1$ and $G-2$ was observed just above the fuel-blanket interface ( 35 in. above the bottom of the capsule). This region of $\mathrm{G}-1$ is shown at higher magnification in Fig. 10. At the interface, the surface changes from the usual shiny condition to a matte or dull finish that extends $\sim 3 / 4$ in. upward from the interface. One explanation for the condition is that it is a result of plate-out of impurities in the bond sodium. A large temperature gradient in the sodium occurs in this region of the fuel pin, and other studies 


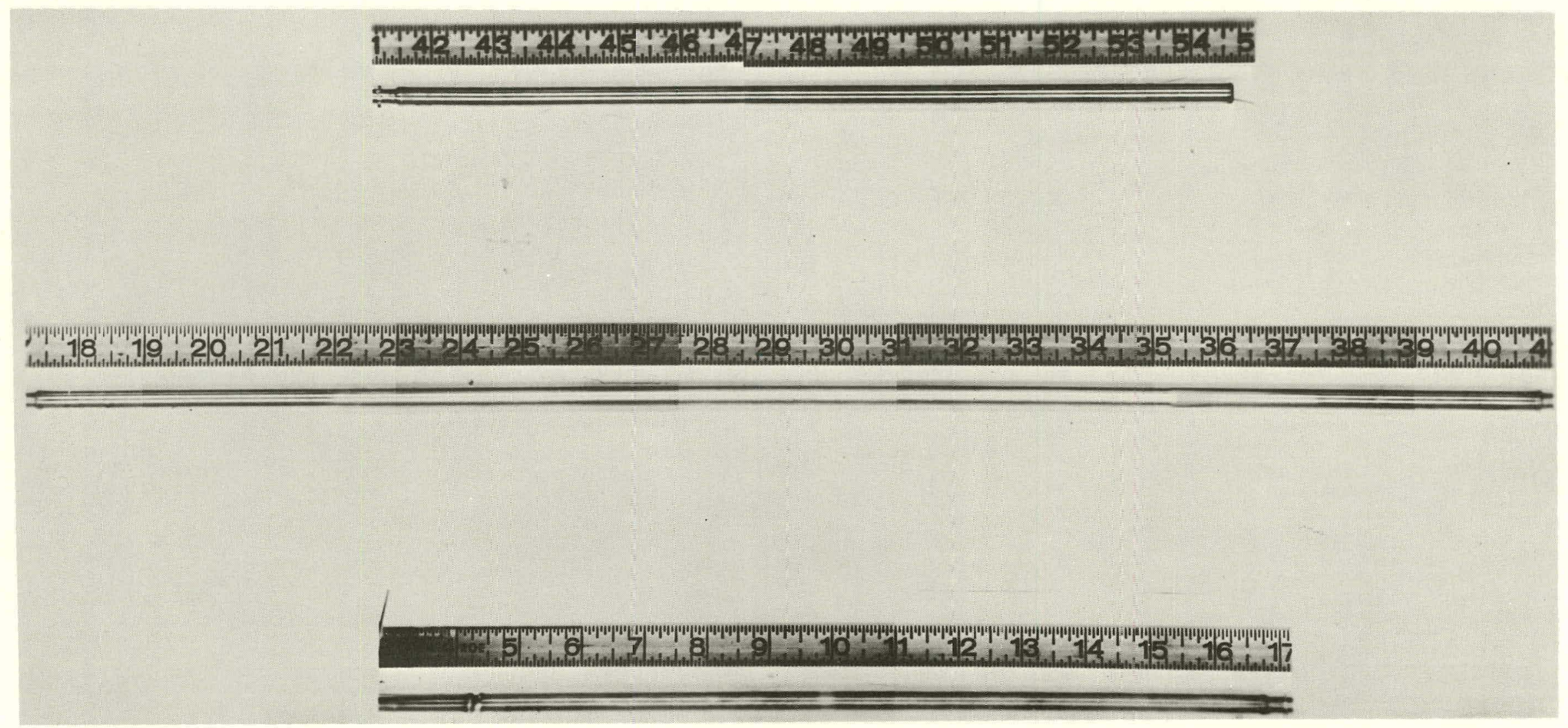

Fig. 9. Overall View of Fuel Pin G-1, with the Zero Point on the Ruler Placed Even with the Bottom of the Capsule. MSD Neg. No. 182696. 


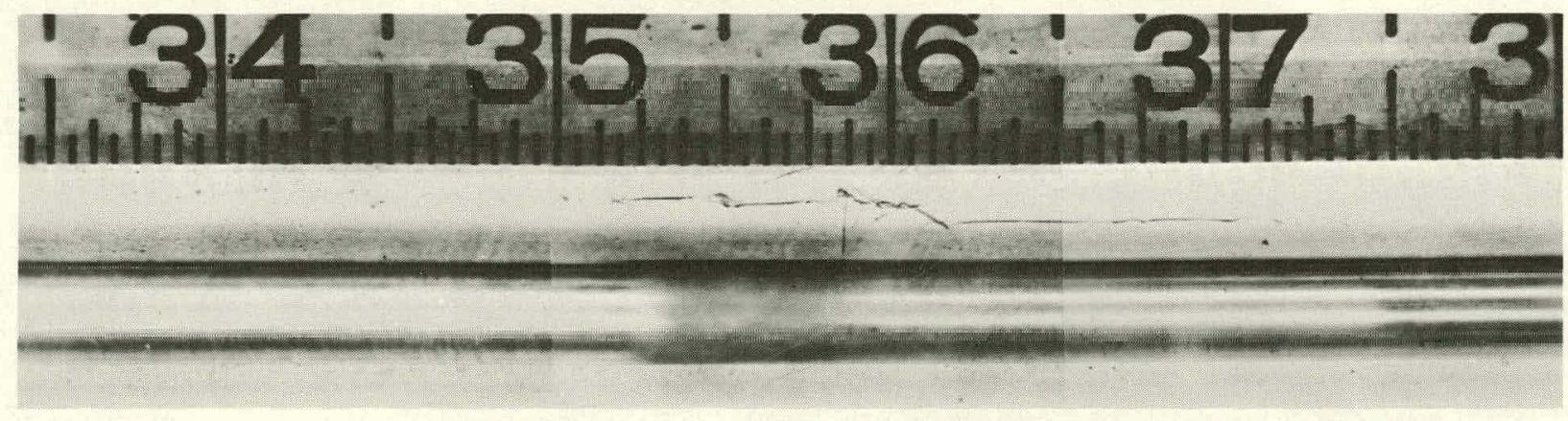

Fig. 10. Region at the Top of the Fuel Column of G-1 that Exhibited a Matte Finish. MSD Neg. No. 182697.

have shown that, in systems containing sodium, impurities from the sodium tended to be deposited in regions where a large temperature gradient existed.

\section{Gamma Spectroscopy}

Gamma spectroscopy was performed on the fuel pins using a lithium-drifted germanium $\mathrm{Ge}(\mathrm{Li})$ crystal scintillation detector. Continuous axial scanning for a given isotope was the most frequently used method of gamma scanning on these $F-1$ series fuel pins. This type of spectroscopy is useful for making qualitative comparisons of the relative axial concentrations of gamma-active materials. When this technique is used, no corrections are made for the background activity and therefore care must be taken in interpreting apparent peaks in the gamma activity for any isotope. For cases in which the results from continuous scanning were ambiguous, point counting was performed so that the background activity corrections could be made and the relative activity of an isotope could be determined more realistically.

The results of the continuous scans are shown in Figs. 11 through 15. The striking feature on these scans is the axial migration of ${ }^{137} \mathrm{Cs}$ to the ends of the fuel column. The gamma scans indicate that the concentration of $\mathrm{Cs}$ is greatest just below the fuel-blanket interface at the bottom of the fuel column. Cesium in significant quantities has also migrated into the upper blanket just above the top fuel-blanket interface and, in some cases, has migrated axially a distance of two or three pellets into the blanket. Apparently the higher cladding temperature at the top of the fuel column causes greater axial migration of $\mathrm{Cs}$. As shown in Fig. 11, a concentration of Cs was also located at the bottom of the lower blanket against a stainles steel plug. Point counting showed that none of the less volatile fission products were concentrated in this region. Therefore, Cs appears to have been transported down to the end plug rather than being generated from fuel particles that might have dropped into this region from the fuel column.

The continuous axial gamma scans for ${ }^{103} \mathrm{Ru},{ }^{106} \mathrm{Rh},{ }^{95} \mathrm{Nb}$, and ${ }^{95} \mathrm{Zr}$ from fuel pins $G-2, G-5, G-6$, and $G-7$ showed no unusual features. However, the long elapsed time between the last irradiation and the scanning of tuel pins $G-2$ and $G-5$ reduced the counting rate for these isotopes to levels of 


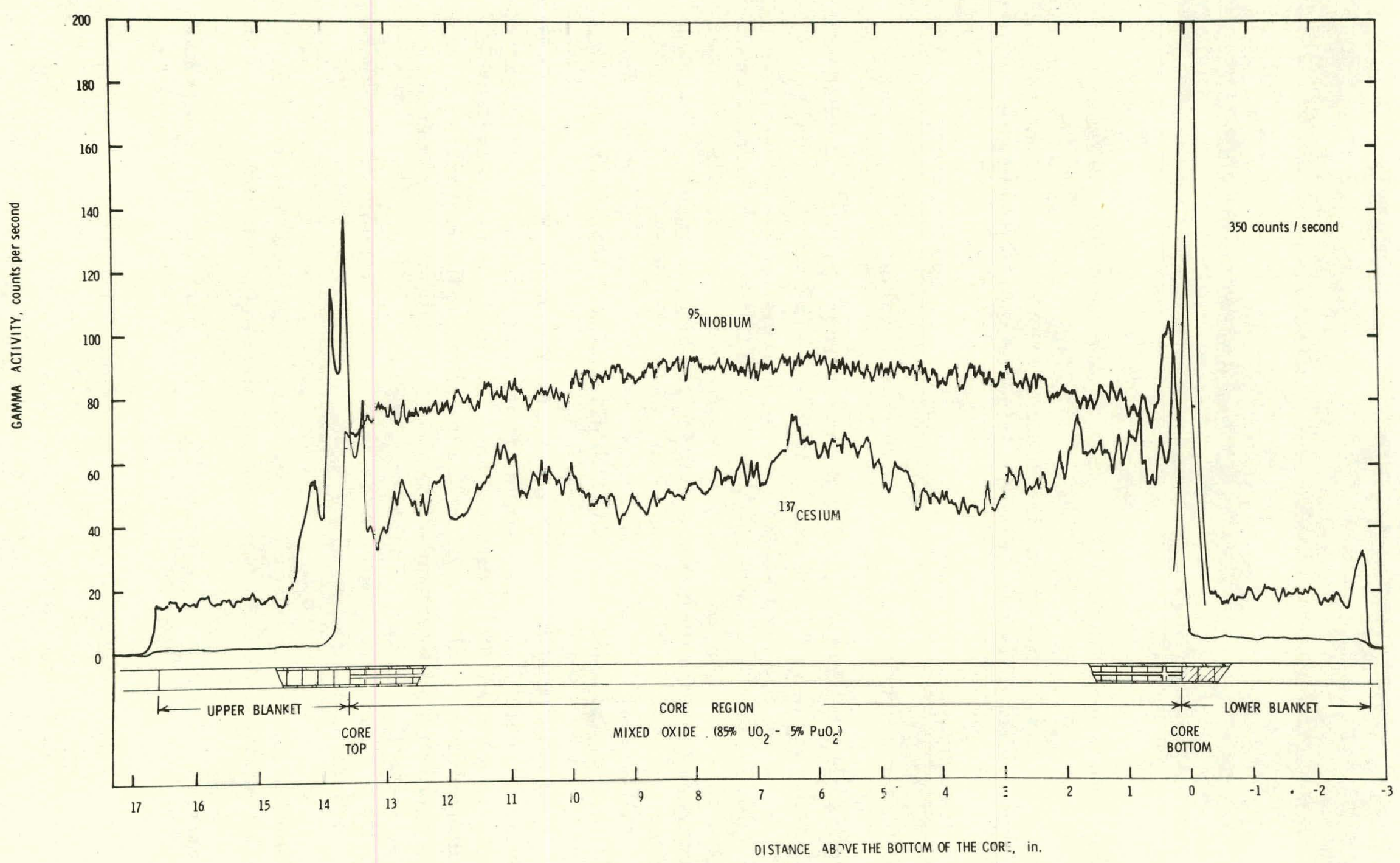

Fig. 11. Gamma Scans Showirg the Relative Activi:y for ${ }^{137} \mathrm{Cs}$ and ${ }^{95} \mathrm{Nb}$ in the Fuel Columr of G-1. MSD Neg. No. 168790. 


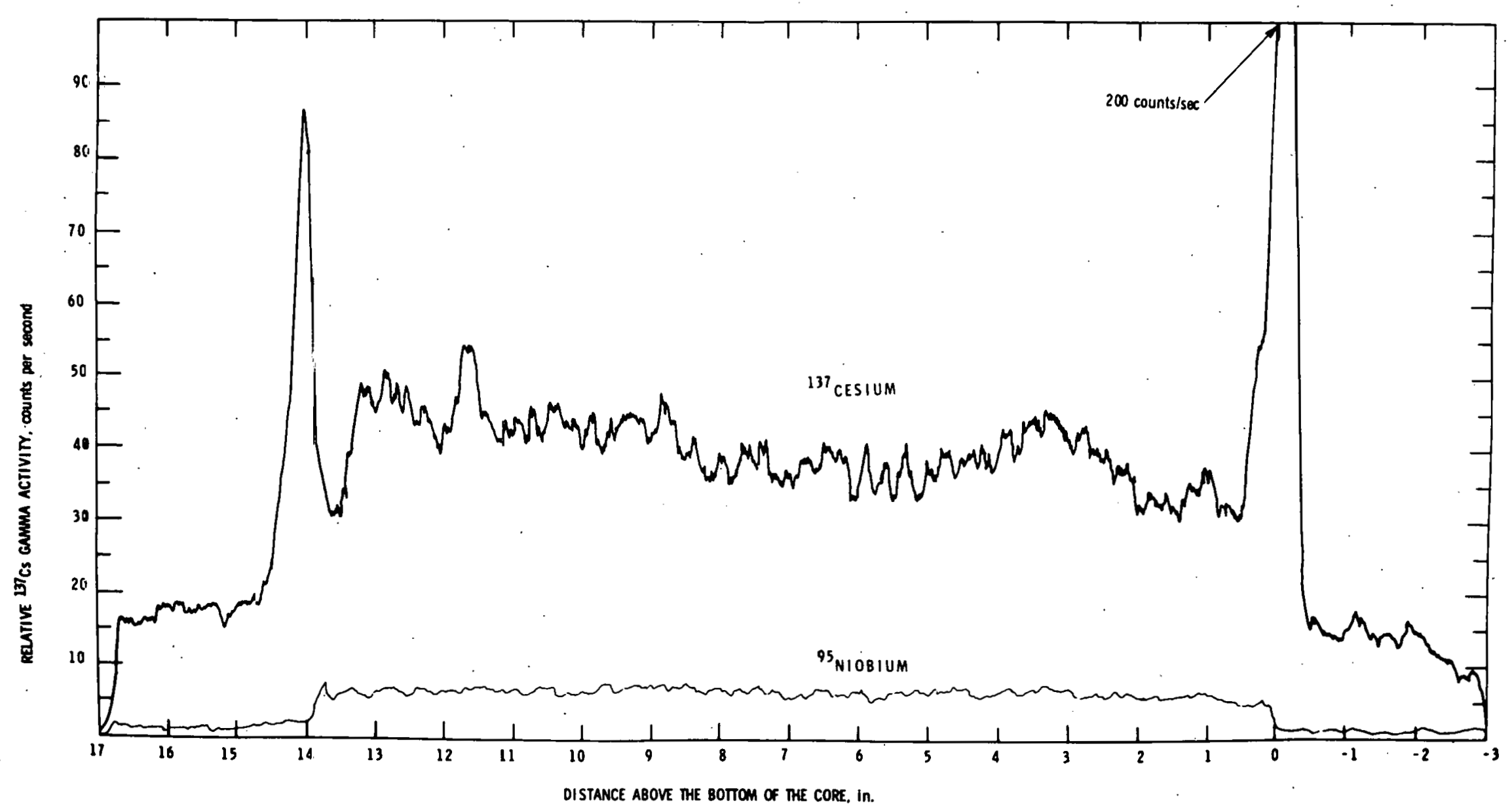

Fig. 12. Gamma Scans Showing the Relative Activity for ${ }^{13} \overline{7} \mathrm{Cs}$ and $95 \mathrm{Nb}$ in the Fuel Column of G-2. MSD Neg. No. 182698. 


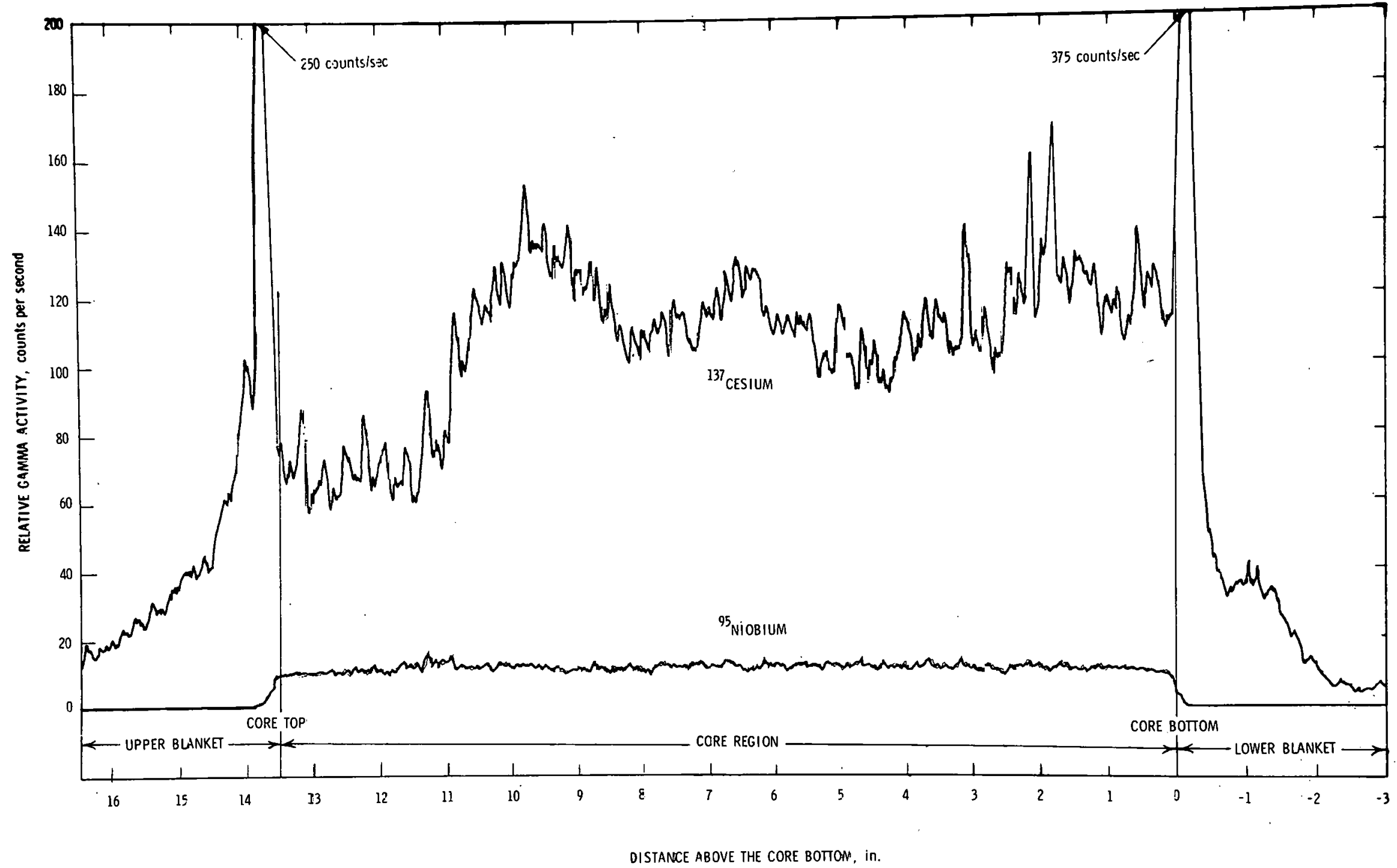

Fig. 13. Gamma Scans Showing the Relative R.ctivity for ${ }^{137} \mathrm{Cs}$ and ${ }^{95} \mathrm{~N}$ in the Fuel Column of G-5. MSD Neg. No. 182237. 


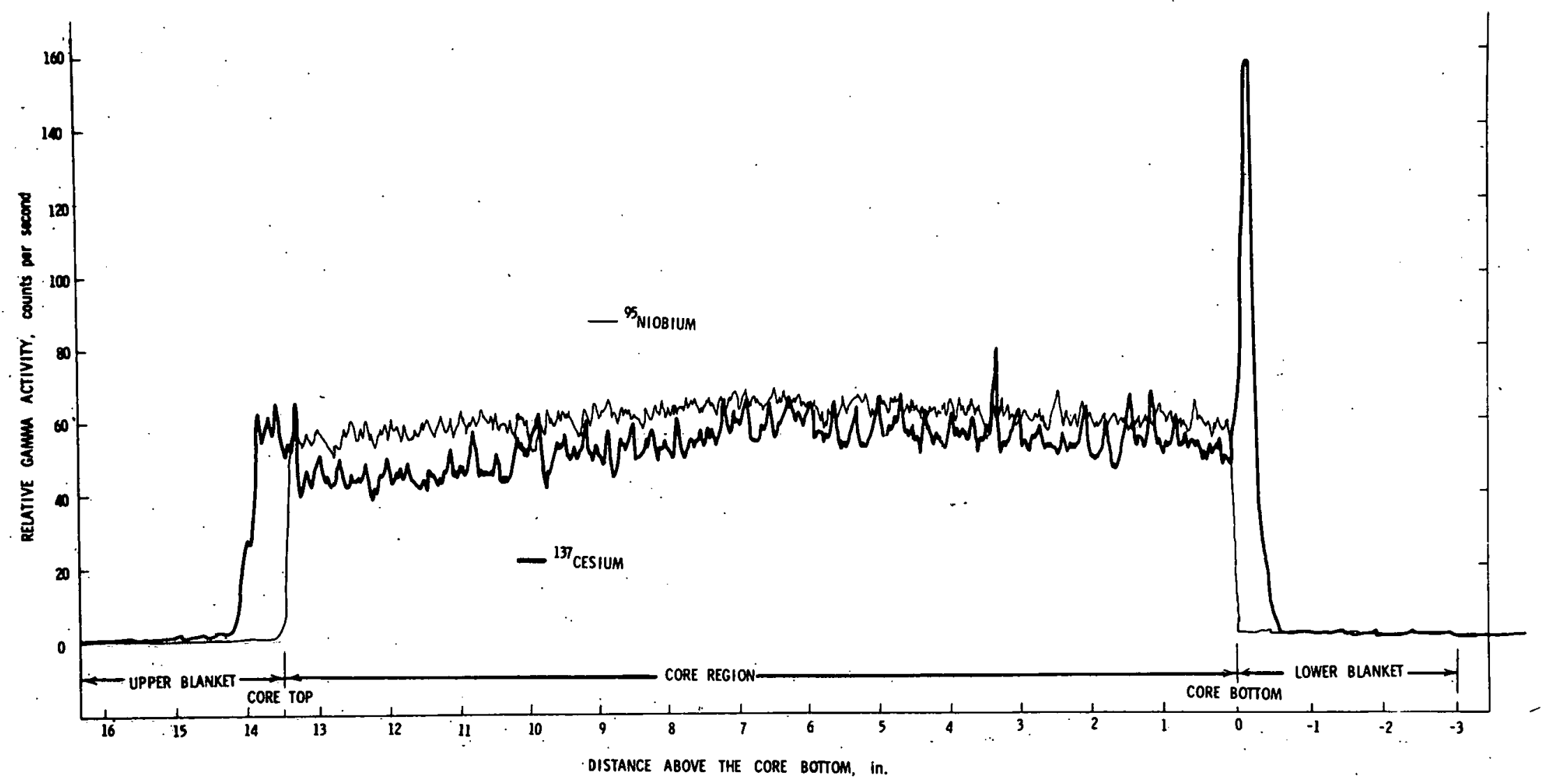

Fig. 14. Gamma Scans Showing the Relative Activity for ${ }^{137} \mathrm{Cs}$ and ${ }^{95} \mathrm{Nb}$ in the Fuel Column of G-6. MSD Neg. No. 169259. 


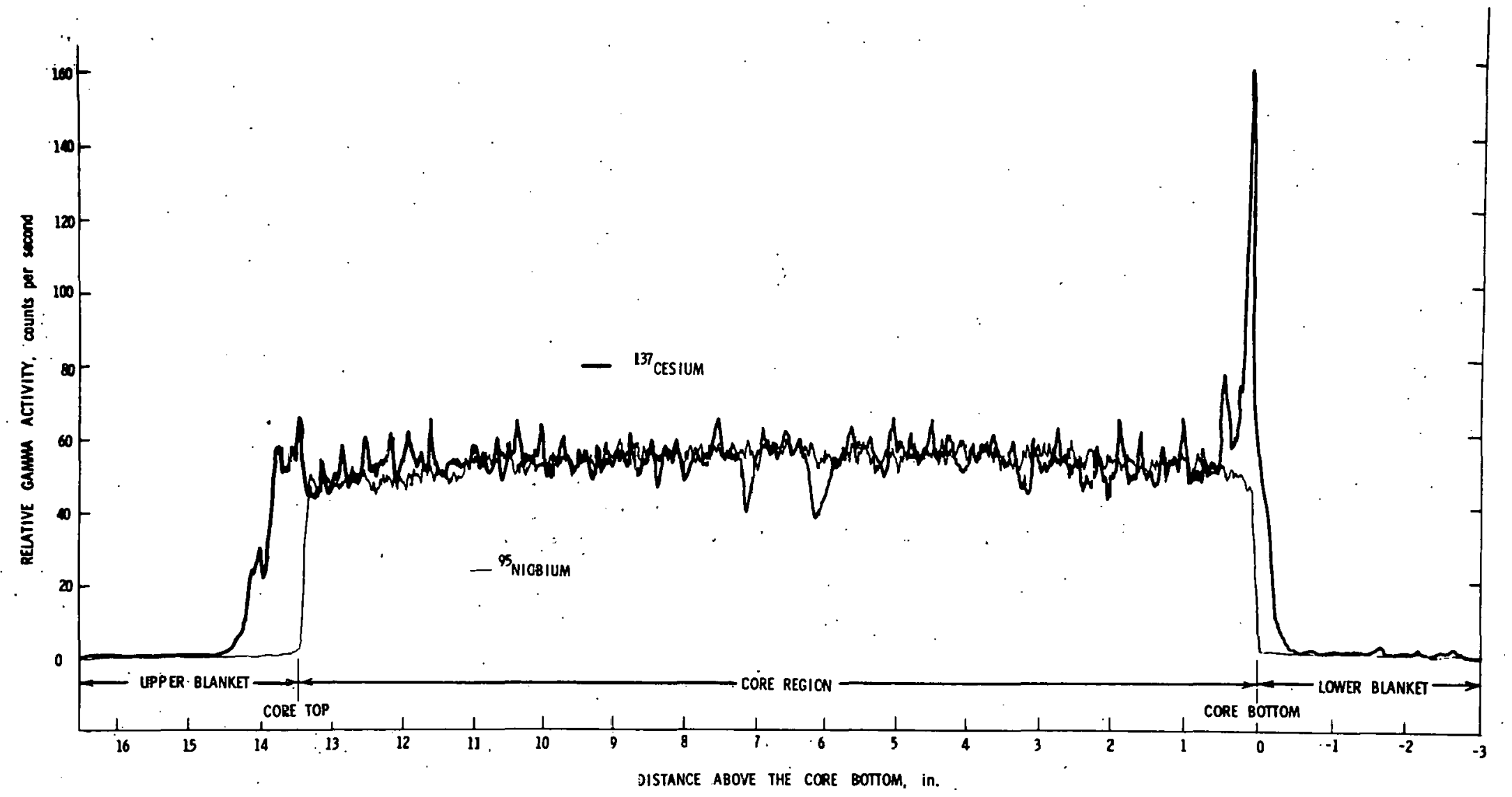

Fig.. 15. Gamma Scans Showing the Relative Activity for ${ }^{137} \mathrm{Cs}$ and ${ }^{95} \mathrm{Nb}$ in the Fuel Column of G-7. MSD Neg. No. 162960. 
little statistical significance. The scan for the less volatile isotopes in fuel pin G-l shows a concentration of fission products in the lowe $r$ $1 / 2$ in. of the fuel column, as shown by the ${ }^{95} \mathrm{Nb}$ scan in Fig. 11 . Point counting confirmed an increased level of gamma activity from these isotopes in this region. The subsequent destructive examination showed that the fission-product concentration was high at the bottom of the fuel column because of a large metallic fission-product ingot and a greater concentration of fuel which resulted from relocation of fuel due to centerline melting in the fuel column. Another examination also showed the fuel pin G-2 had also undergone fuel melting. The lack of a peak in the fission-product gamma activity at the bottom of the $G-2$ fuel column has been attributed to the poor statistics obtained from the very low count rate. The relative gamma activity profiles of ${ }^{137} \mathrm{Cs}$ and ${ }^{95} \mathrm{Nb}$ reflect the time span, approximately ten months, over which the gamma scanning was performed and the decay of ${ }^{95} \mathrm{Nb}$ and the buildup of ${ }^{137} \mathrm{Cs}$. No corrections were made for this decay/buildup, and therefore no quantitative comparisons between fuel pins are possible. Also, no corrections were made for background radiation or specimen. geometric considerations,

\section{Profilometry}

Diametral measurements were made on the pins using a contacttype profilometer with an accuracy of \pm 0.0002 in. Measurements were made at orientations of $0,45,90$, and $135^{\circ}$, and the measurements at each orientation were checked by running the element $180^{\circ}$ to these orientations. Results of the profilometry measurements are shown in Figs. 16 through 20. The results of the maximum diameters and diameter changes are summarized in Table VI. These values show that the relative maximum diameter change (maximum diameter less the diameter at the ends of the fueled region of the element) range from $0.2 \%$ for element $G-1$ to $0.07 \%$ for elements $G-6$ and $G-7$. The profile of elements $G-1$ and $G-2$ show waviness at $\sim 1 / 4-i n$. intervals, indicating fuel-cladding mechanical interaction.

\section{Eddy-current Inspection}

The cladding of the fuel pins was inspected using a pulsed eddycurrent tester capable of detecting defects in the cladding ID and OD surfaces.

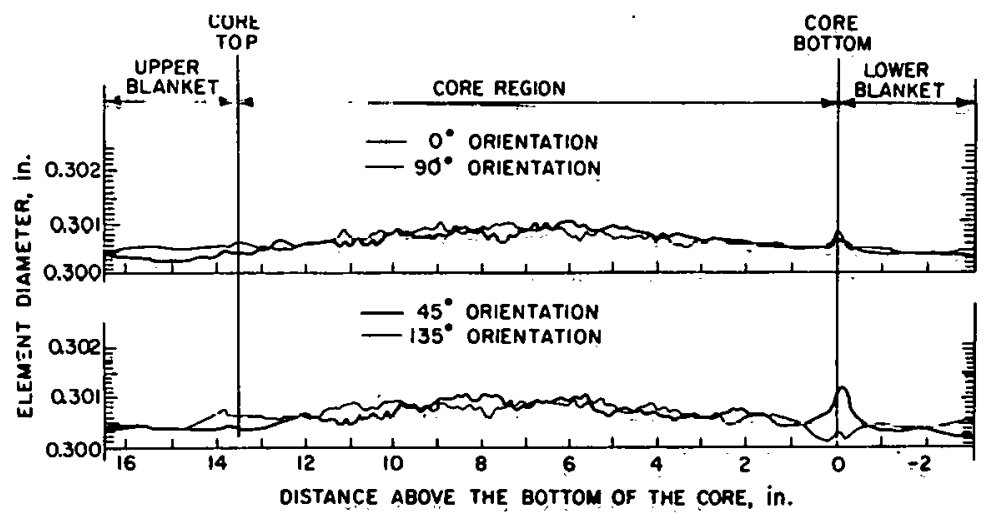

Fig. 16

Postirradiation Diametral Profile of Fuel Pin G-1. MSD Neg. No. 168570. 


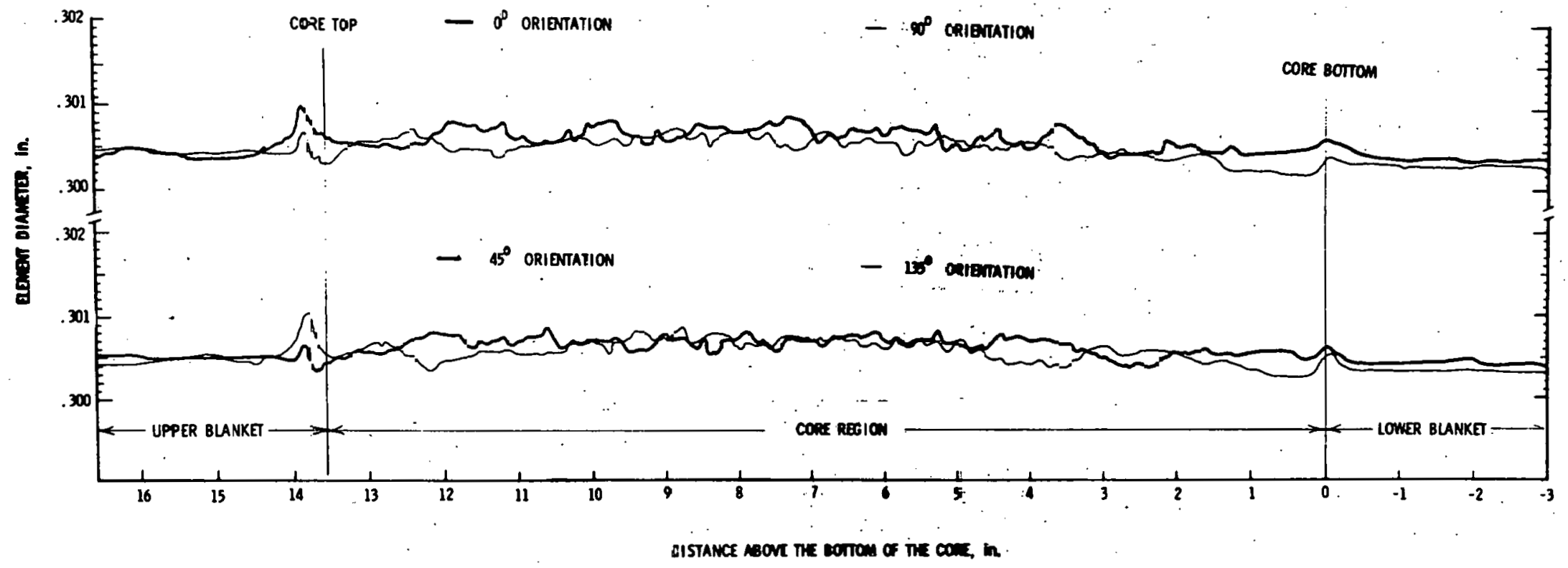

§ig. 17. Postirradiation Diametral Profile of Fuel Pin G-2. MSD Neg. No. 181301. 


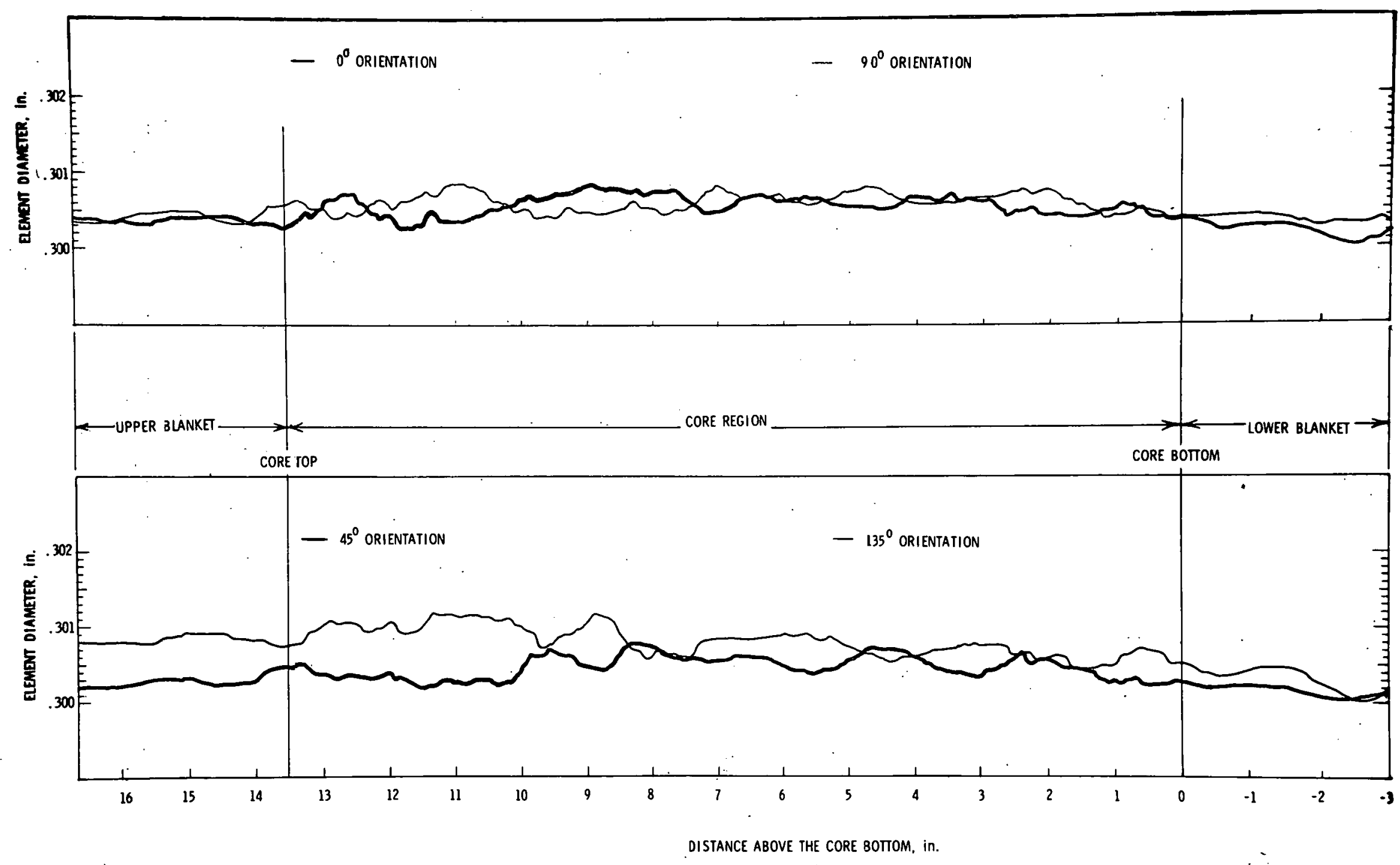

Fig. 18. Postirradiation Diametral Profile of Fuel Pin G-5. MSD Neg. No. 182236. 


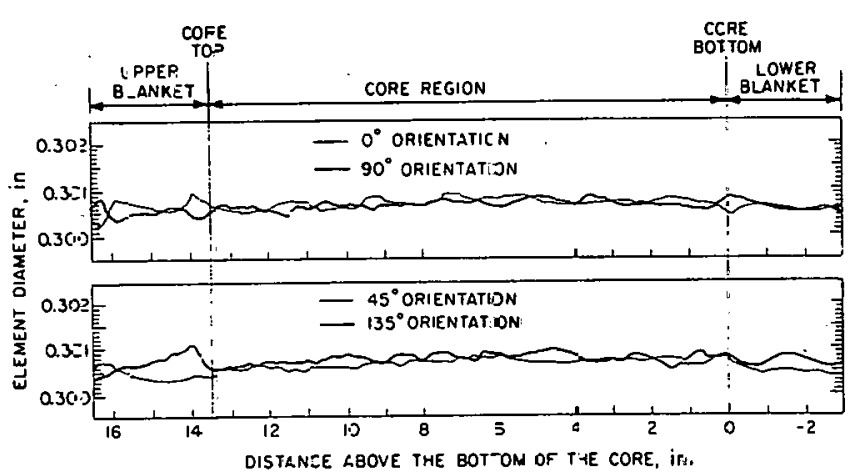

Fig. 19

Posti:radiation. Diametral Profile of

Fuel Pin G-6. MSD Neg. Nc. 169261.
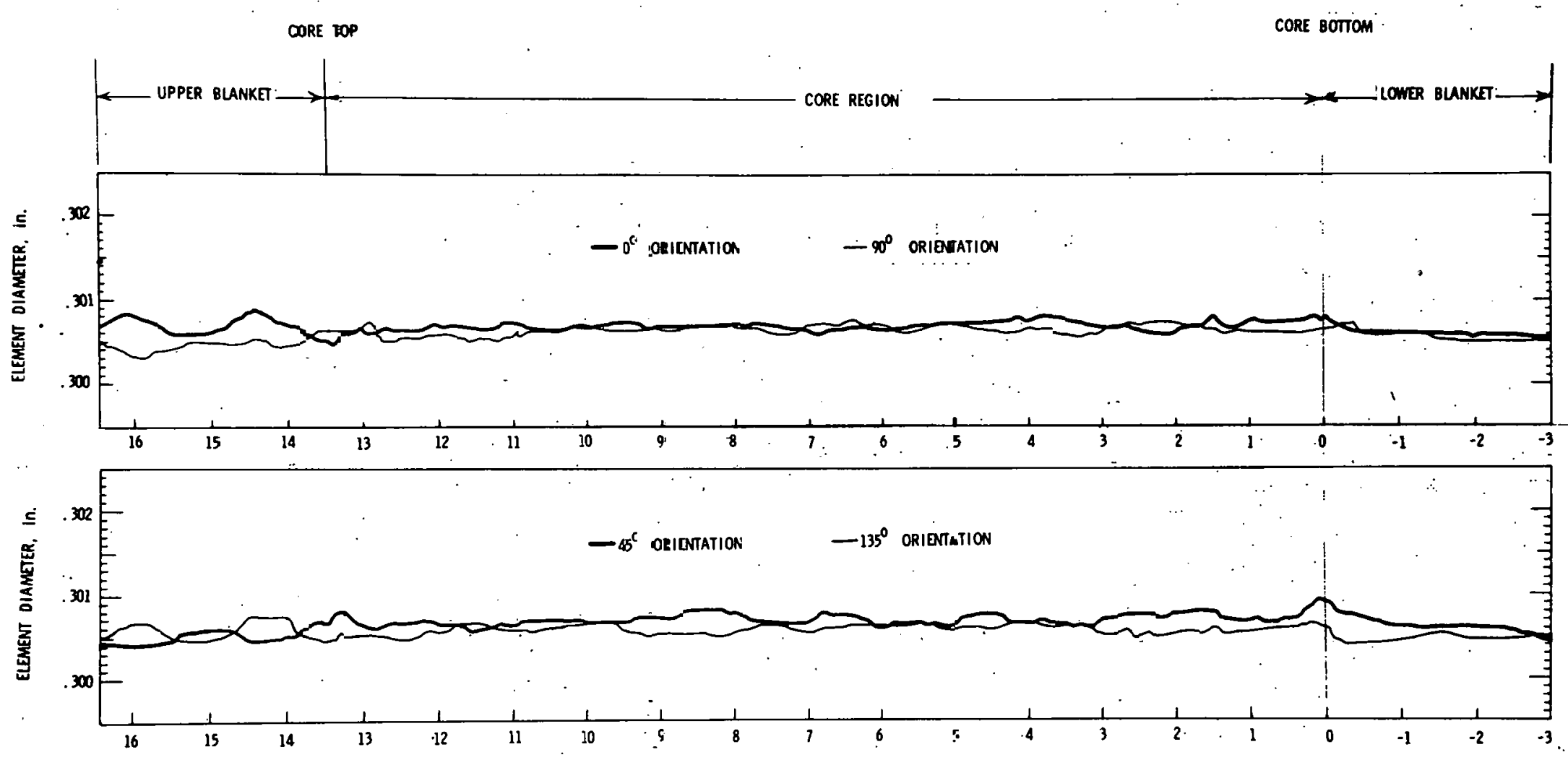

DISTANCE ABOVE THE CORE BOTTOM, ir.

Fig. 20. ?ostirradiation Diarterral P:ofile of Fuel Pin G-7. MSD Meg. N5. 169262. 
TABLE VI. Diameter Changes for F-I fuel Pins

\begin{tabular}{|c|c|c|c|c|c|c|c|c|c|c|c|c|c|c|c|c|}
\hline \multirow{2}{*}{$\begin{array}{l}\text { Fuel } \\
\text { Pins }\end{array}$} & \multicolumn{4}{|c|}{ Maximum Diameter. in. } & \multicolumn{4}{|c|}{$\begin{array}{c}\text { Distance from } \\
\text { Reference Point, in. }\end{array}$} & \multirow{2}{*}{$\begin{array}{c}\text { Average } \\
\text { Maximum } \\
\text { Diameter. } \\
\text { in. }\end{array}$} & \multicolumn{2}{|c|}{ Average Minimun } & \multicolumn{2}{|c|}{ n Diameter, in. } & \multirow{2}{*}{$\begin{array}{c}\text { Average } \\
\text { Minimum } \\
\text { Diameter. } \\
\text { in. }\end{array}$} & \multirow{2}{*}{$\begin{array}{c}\text { Maximum } \\
\Delta D . \\
\text { in. }\end{array}$} & \multirow{2}{*}{$\begin{array}{c}\text { Maximum } \\
\Delta \mathrm{D} / \mathrm{D}_{0} \\
\%\end{array}$} \\
\hline & $\mathbf{0}$ & 45 & 90 & 135 & 0 & 45 & 90 & 135 & & 0 & 45 & 90 & 135 & & & \\
\hline$G-1$ & 0.3011 & 0.3010 & 0.3010 & 0.3009 & $10-1 / 2$ & $10-1 / 2$ & $11-1 / 2$ & 11 & 0.3010 & 0.3004 & 0.3003 & 0.3004 & 0.3004 & 0.3004 & 0.0006 & 0.20 \\
\hline$G-2$ & 0.3009 & 0.3008 & 0.3007 & 0.3008 & $11-3 / 4$ & $12-1 / 2$ & $11-1 / 2$ & $11-3 / 4$ & 0.3008 & 0.3004 & 0.3004 & 0.3003 & 0.3004 & 0.3004 & 0.0003 & 0.10 \\
\hline$G-5$ & 0.3008 & 0.3011 & 0.3008 & 0.3007 & $15-1 / 2$ & $15-1 / 2$ & $13-1 / 2$ & $12-3 / 4$ & 0.30085 & 0.3004 & 0.3004 & 0.3003 & 0.3002 & 0.3003 & 0.0004 & 0.13 \\
\hline$G-6$ & 0.3008 & 0.3008 & 0.3007 & 0.3008 & $11-1 / 2$ & $11-1 / 2$ & $11-1 / 2$ & $11-1 / 2$ & 0.3008 & 0.3006 & 0.3005 & 0.3006 & 0.3006 & 0.3006 & 0.0002 & 0.07 \\
\hline & & & 0.3009 & & & & 11 & $11 \cdot 1 / 2$ & & & & & & & & \\
\hline G-7 & 0.3007 & 0.3008 & 0.3007 & 0.3007 & $11-1 / 2$ & $11-1 / 2$ & $11-1 / 2$ & $11-1 / 2$ & 0.3007 & 0.3006 & 0.3006 & 0.3005 & 0.3005 & 0.3005 & 0.0002 & 0.07 \\
\hline
\end{tabular}

The system utilizes a point probe that covers $\sim 18^{\circ}$ of the circumference of the fuel pin. The entire surface is covered by scanning at $15^{\circ}$ azimuthal intervals. The results of this method are qualitative in that the response to fissionproduct attack (many small defects) is cumulative and much greater than the response to large single flaws. Since the device is presently calibrated against small discrete flaws machined into tubing, the amplitude of the response is not a good measure of the depth or extent of cladding attack. The results of typical scans $\left(0^{\circ}\right.$ orientation) for fuel pins $G-1, G-6$, and $G-7$ are shown in Fig. 21 . Subsequent metallography on sections from the three pins shows that the amplitude of the response from the eddy-current tester did not correspond to the depth of cladding attack. The attack in $G-1$ was more than twice as severe as the attack in G-6 and G-7. The attack in G-6 and G-7 was similar, although the eddy-current traces show similar responses for $G-1$ and $G-6$ and a less response for G-7. For the F-1 series of fuel pins, the eddy-current inspection method was quite sensitive to any alteration of the inner cladding surface, but the method was less than successful in indicating the severity of the alteration.

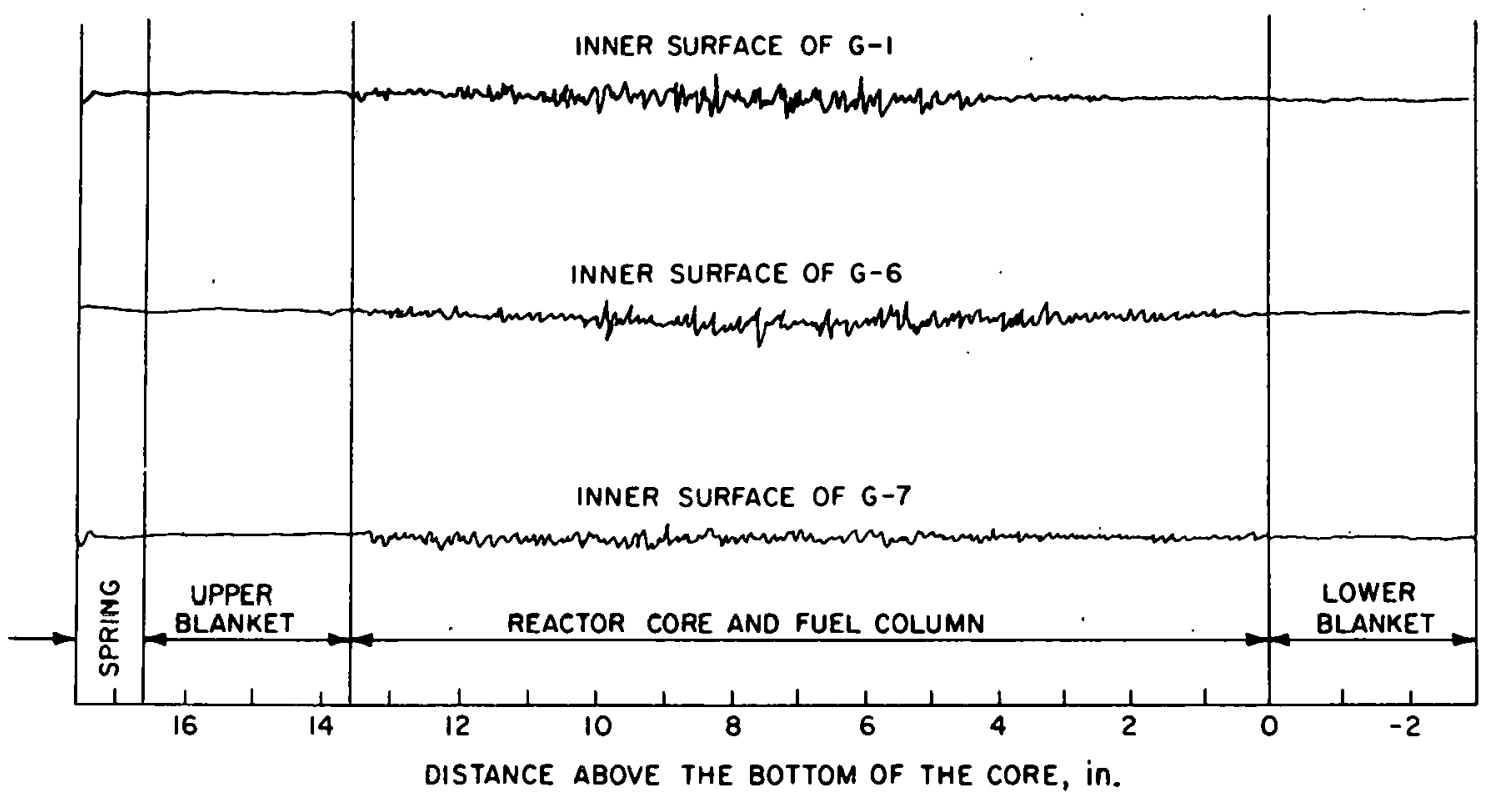

Fig. 21. Response of the Eddy-current Tester for Fuel Pins G-1, G-6, and G-7. MSD Neg. No. 182925. 
E. Destructive Examinations

Destructive examinations were performed on four of the five fuel pins, i.e., G-1, G-2, G-6, and G-7. The results of these examinations are described herein.

\section{Gas Sampling and Analysis}

The gas was extracted from fuel pins G-1, G-2, and G-6 by drilling into the plenum region and transferring the gas to an evacuated measuring and sampling apparatus. After the volume of the gas was determined, samples of the gas were analyzed using a gas mass spectrometer. The results of the determinations are shown in 'T'able VII. The low fission-gas release shown for fuel pin G-6 may have resulted from significant amounts of fission gas being absorbed on the active (open) charcoal traps. A relatively long time was required to extract the gas from the G-6 plenum, which also indicates that gas was absorbed on the charcoal in the traps. The measured gas volumes and measured plenum volumes indicate that the internal pressure at the end of life was low for these fuel pins. The maximum pressure calculated for G-1 was $\sim 240$ psi at operating temperature.

TABLE VII. Results of Gas Sampling and Analysis

\begin{tabular}{|c|c|c|c|c|}
\hline \multirow[b]{2}{*}{ Gas } & & \multicolumn{3}{|c|}{$\begin{array}{c}\text { Volume of Gases Extracted, } \\
\text { cc (STP) }\end{array}$} \\
\hline & & $G-1$ & $G-2$ & $G-6$ \\
\hline $\mathrm{H}_{2}$ & & $<0.14$ & $<0.13$ & $<0.08$ \\
\hline $\mathrm{He}$ & & 22.6 & 22.5 & 19.2 \\
\hline $\mathrm{H}_{2} \mathrm{O}$ & $’$ & $<0.14$ & - & - \\
\hline $\mathrm{N}_{2}$ & & 0.3 & 0.4 & 0.25 \\
\hline $\mathrm{O}_{2}$ & & $<0.03$ & $<0.01$ & $<0.01$ \\
\hline Ar & & 0.08 & 0.11 & 0.08 \\
\hline $\mathrm{CO}_{2}$ & & $<0.14$ & - & 0.04 \\
\hline $\mathrm{Kr}$ & & 17.3 & 15.0 & 9.5 \\
\hline $\mathrm{Xe}$ & & 99.9 & 95.7 & 54.4 \\
\hline Total rias & & 139.3 & 131.1 & 83.4 \\
\hline $\begin{array}{l}\text { Calculated } \\
\text { Fission-gas }\end{array}$ & & & & \\
\hline Generation, cc & & .111 .84 & 110.25 & 96.29 \\
\hline $\begin{array}{l}\text { Fission Gas } \\
\text { Released to }\end{array}$ & & & & . \\
\hline Plenum, \% & & 104.8 & .100 .4 & 66.4 \\
\hline $\begin{array}{l}\text { Measured } \\
\text { Plenum }\end{array}$ & & & & \\
\hline Volume, cc & & 21.6 & 21.5 & 18.5 \\
\hline
\end{tabular}


2. Flow Testing

Internal helium flow tests were made on fuel pins $G-1, G-6$, and G-7 to determine whether significant flow restrictions existed in the fuelblanket interface regions. Similar flow tests made on fuel pin G-3 from the F-1 series and pin GB-9 from a sweep-gas experiment irradiated in the Oak Ridge Reactor had shown a flow restriction tendency at the fuel-blanket interfaces. Initially, the flow tests were run at relatively low pressures with $50 \mathrm{in.}$. water ( $\sim 2$ psi gauge) as the maximum pressure. The apparatus used to make these tests is shown in Fig. 22. The tests were performed by drilling 0.08 -in.-diam holes through the cladding $\sim 3 / 8$ in. above and below the initial (as-loaded) fuel-blanket interface. A saddle valve was clamped over one of the holes, and the flow of helium that had been forced into the pin on one side of the interface and out through the other hole was measured at several pressures. The results of measurements at 45 in. of water (1.6 psi) are given in Table VIII. These results are in general agreement with data obtained previously for pin G-3, which showed flow rates of $0.3 \mathrm{ml} / \mathrm{s}$ at 50 in. of water at both interfaces. The lack of measurable flow across the upper interface in pin G-7 was the exception to the general trend that indicated the severity of flow restriction increased as the powe $x$ and operating temperatures for the pins increased.

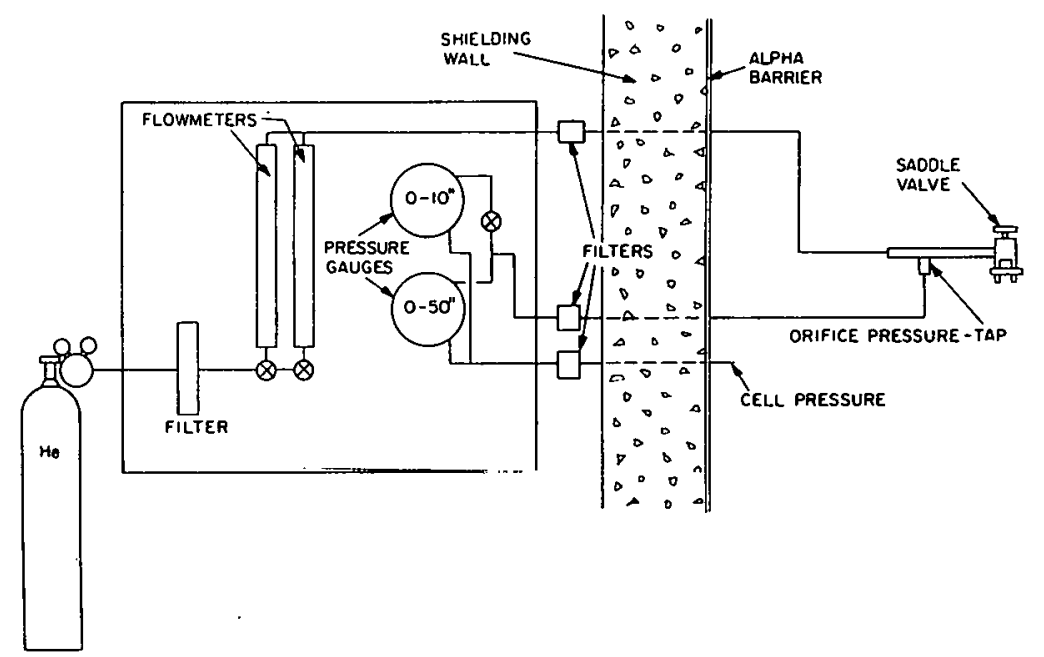

Fig. 22

Flow-testing Apparatus Used to Determine Helium Flow Rates through Several Axial Regions of Fuel Pins $G-1$, G-6, and G-7. MSD Neg. No. 63996 .

TABLE VIII. Flow-testing Results with Low-pressure Test Apparatus

\begin{tabular}{lccc}
\hline Fuel & $\begin{array}{c}\text { Nifferential } \\
\text { Pressure, } \\
\text { in. } \mathrm{H}_{2} \mathrm{O}\end{array}$ & $\begin{array}{c}\text { Flow Rate at Lower } \\
\text { Fuel-Blanket } \\
\text { Interface, } \\
\mathrm{ml} / \mathrm{s}\end{array}$ & $\begin{array}{c}\text { Flow Rate at Upper } \\
\text { Fuel-Blanket } \\
\text { Interface, } \\
\mathrm{ml} / \mathrm{s}\end{array}$ \\
\hline $\mathrm{G}-1$ & 15 & $\sim 0.02$ & $\sim 0.03$ \\
$\mathrm{G}-6$ & 45 & 0.23 & 0.55 \\
$\mathrm{G}-7$ & 45 & 0.73 & $\mathrm{ND}^{\mathrm{a}}$ \\
\hline
\end{tabular}

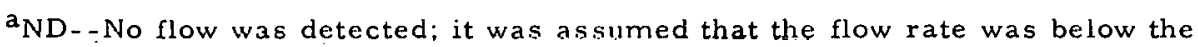
detectability limit of the low-pressure test apparatus. 
The flow-testing apparatus was rebuilt to extend its pressure capability to $50 \mathrm{psi}$ in an effort to determine if flow was completely blocked at the upper interface of G-7. The method of sealing the system on the fuel pin also was modified by replacing the saddle valve with an O-ring seal (Fig. 23). The results of a series of flow tests run at the upper interface of pin G-7 are shown in Figs. 24 and 25. The first test (Fig. 24) was a lowpressure test at room temperature that was expected to duplicate the earlier results with the low-pressure system. However, the flow rate at $\sim 45$ in. of water during this test was $1.1 \mathrm{ml} / \mathrm{s}$. The results showed that either the change in the method of sealing the system to the pin had changed the flow path because of lower clamping forces or a change had occurred at the interface as a result of storage and handling of the pin. The flow rate of $1.1 \mathrm{ml} / \mathrm{s}$ appears reasonable in light of the flow rate of $0.7 \mathrm{ml} / \mathrm{s}$ measured across the lower interface. Subsequent examinations revealed no significant $\mathrm{Cs}$ deposits in the region of the upper interface in $G-7$.

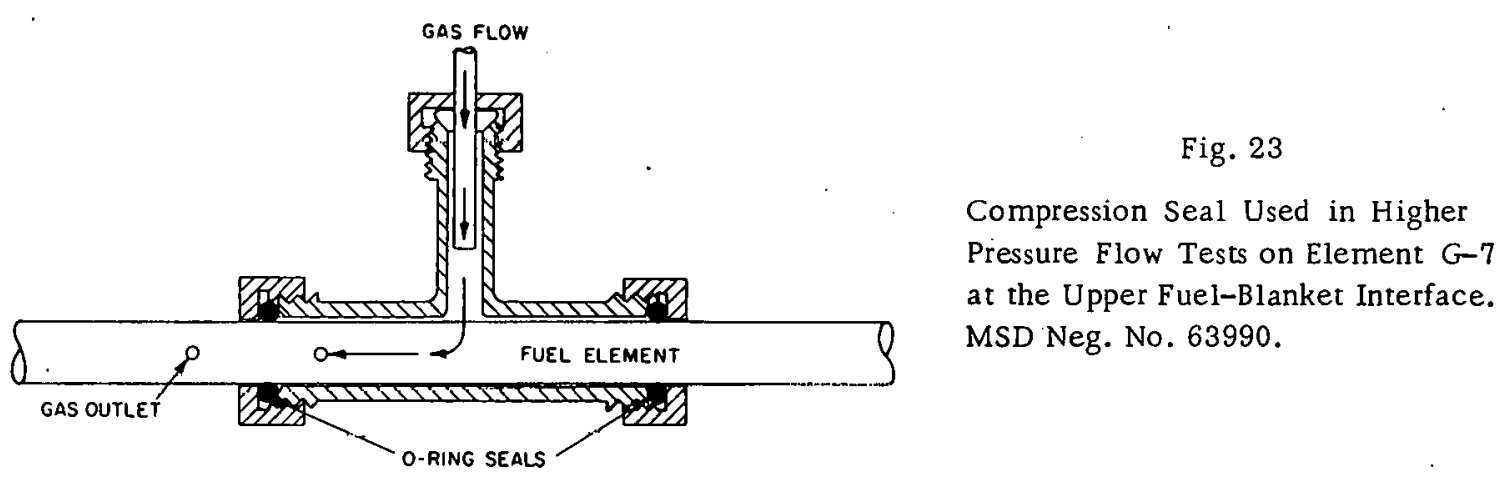

Fig. 24

Low-pressure Test Results for G-7 Upper Interface at Ambient Temperature with the Rebuilt Flow-testing Apparatus. MSD Neg. No.63998.

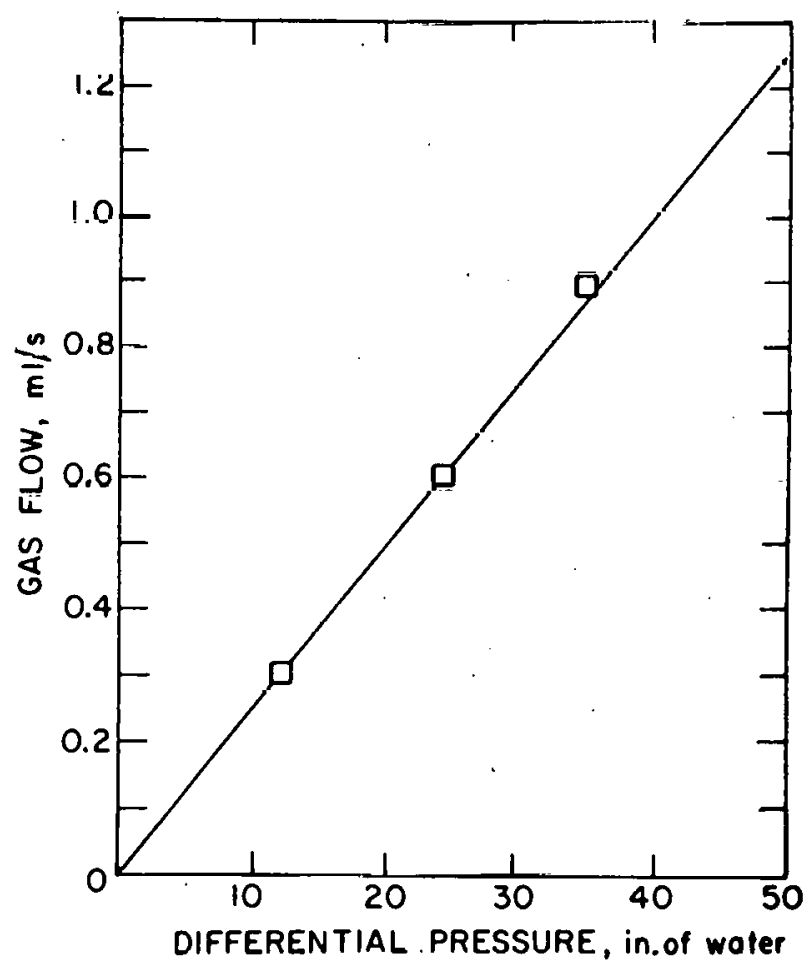




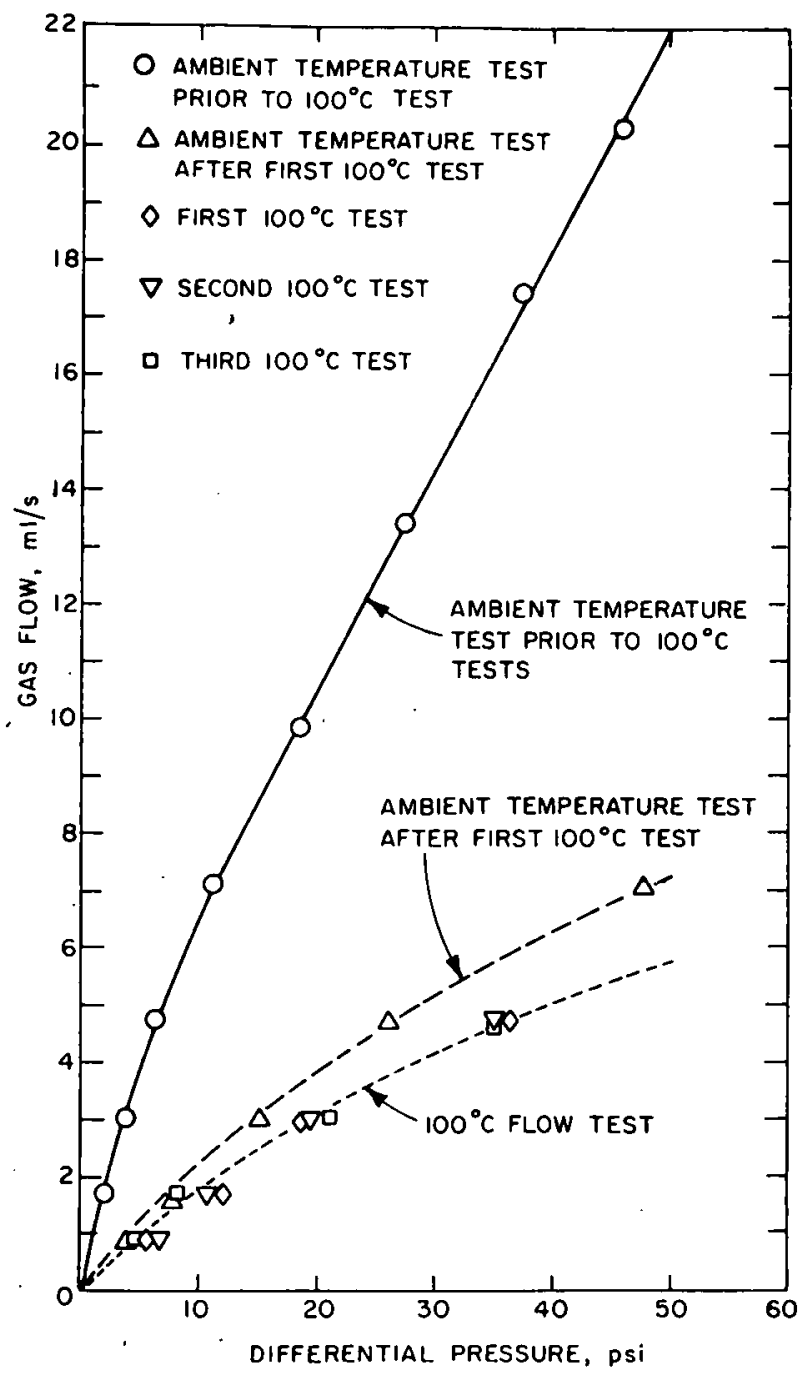

Fig. 25. High-pressure Test Results for G-7 Upper Interface. MSD Neg. No. 63995.
A series of "high"-pressure flow tests were then performed at the upper interface of G-7 at room temperature and with the fuel pin heated to $\sim 100^{\circ} \mathrm{C}$ by means of a lamp. The initial "high"-pressure test at ambient temperature showed a flow rate of $\sim 20 \mathrm{ml} / \mathrm{s}$ at $45 \mathrm{psi}$. The fuel pin was then heated to $\sim 100^{\circ} \mathrm{C}$ at the interface and flow tested with ambient temperature helium at pressures up to 35 psi. The flow rates at $100^{\circ} \mathrm{C}$ were significantly lower than the initial highpressure flow rates, as shown in Fig. 25. The fuel pin was allowed to cool overnight and was again flow tested at ambient temperature. The flow rates in this test were lower than in the initial ambient temperature test but slightly higher than in the $100^{\circ} \mathrm{C}$ tests. Subsequent tests at $100^{\circ} \mathrm{C}$ gave results similar to the first $100^{\circ} \mathrm{C}$ test.

The flow-test results show that, in general, the internal flow of helium is restricted at the fuel-blanket interfaces in the F-I series elements. The flow restriction is most severe in the fuel pin that operated at the highest power and temperature and is least severe in the fuel pin that operated at the lowest power and temperature.

In addition, the flow rates across the upper interface of G-7 were less at $100^{\circ} \mathrm{C}$ than at ambient temperature $\left(\sim 30^{\circ} \mathrm{C}\right)$. This result was unexpected because the heating was expected to cause expansion of the cladding that would open the flow channels inside the fuel pin adjacent to the cladding. This anomaly underlines the difficulty of extrapolating these flow tests to conditions that will exist in an operating GCFR fuel pin.

\section{Fuel-pin Sectioning}

The ceramographic and metallographic examinations of samples, including optical microscopy and electron-microprobe analysis of the fuel and cladding, constituted the major portion of the destructive examination. The fuel pins were cut into sections as shown in Figs. 26 and 27. The specimens for microscopy, three transverse and two longitudinal sections, were placed in electrically conducting mounts and prepared for optical microscopy and 
electron-microprobe analysis. The fuel was removed from the cladding of the burnup samples and analyzed for ${ }^{148} \mathrm{Nd},{ }^{139} \mathrm{La}, \mathrm{U}$, and $\mathrm{Pu}$ to determine the fuelpin burnup. The cladding pieces from the burnup samples taken near the core midplane from fuel pins G-1, G-2, and G-6 were used in density determinations to determine cladding swelling. Samples were sent to GA for experimental determination of cladding temperature based on the release of ${ }^{85} \mathrm{Kr}$ from the recoil layer of the cladding; those results are not included in the present report.

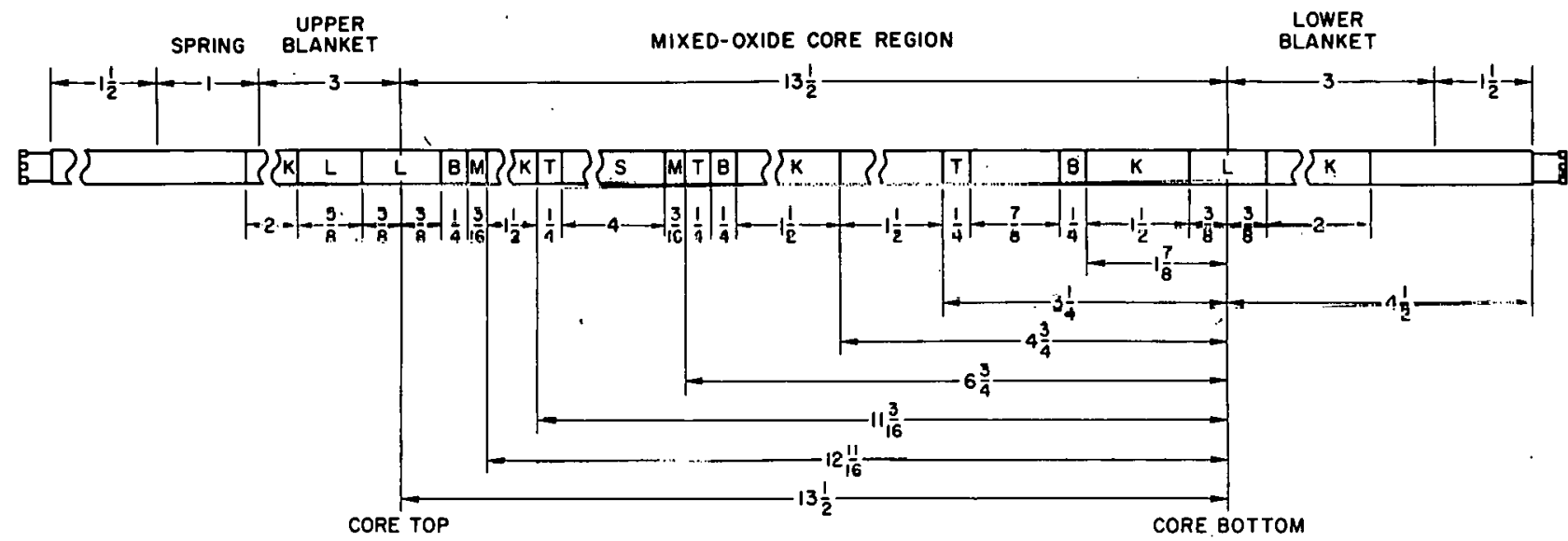

B - BURNUP SAMPLES

K - SAMPLES FOR TEMPERATURE DETERMINATION

L - LONGITUDINAL METALLOGRAPHIC SAMPLES

$M$ - SAMPLES FOR DETAILED MICROPROBE ANALYSIS

S - BIAXIAL STRESS-RUPTURE TEST SPECIMEN

T - TRANSVERSE METALLOGRAPHIC SAMPLES

Fig. 26. G-1 Sectioning Diagram. B, burnup samples; $K$, samples for temperature determination; L, longitudinal mctallographic samples; M. samples for detailed microprobe analyais; $S$, biaxial stress-rupture test specimen; and $T$, rransyerse merallngraphir samplex. $\Lambda 11$ dimensions are in inches. MSD Neg. No. 63947.

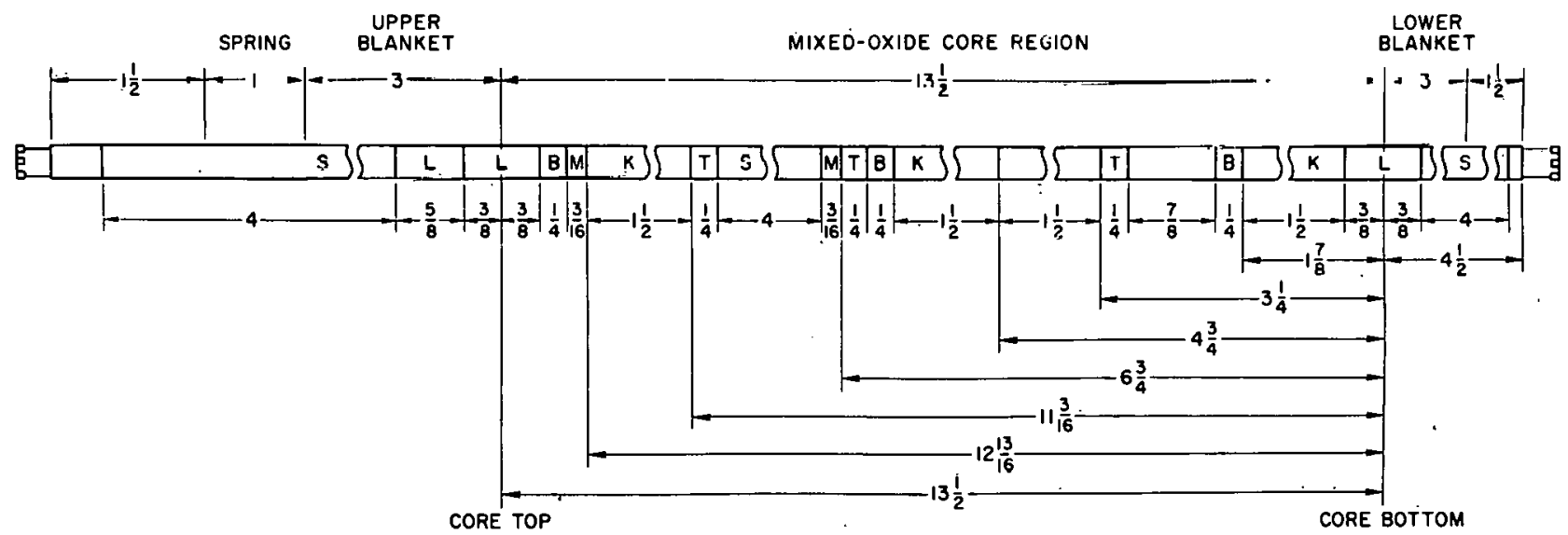

Fig. 27. G-2, G-6, and G-7 Sectioning Diagram. B, burnup samples; K, samples for temperature determination; I., lnngitudinal metallographic samples; $M$, samples for detalled microprobe analysis; S, biaxial stress-rupture test specimen; and $T$, transverse metallographic samples. $\Lambda 11$ dimensions are in inches. MSD Neg. No. 63948. 


\section{Burnup Analyses}

The burnups of fuel pins G-1, G-2, and G-6 were measured by chemical and mass-spectrographic analyses for ${ }^{148} \mathrm{Nd}$ and ${ }^{139} \mathrm{La}$. The results of analyses of samples from two or three axial locations on these pins are given in Table IX. The ${ }^{148} \mathrm{Nd}$ yields used in the analyses for ${ }^{235} \mathrm{U}$ and ${ }^{239} \mathrm{Pu}$ were 1.63 and 1.70 at. \%, respectively. The ${ }^{139} \mathrm{La}$ yields for ${ }^{235} \mathrm{U}$ and ${ }^{239} \mathrm{Pu}$ were 6.3 and 6.0 at. $\%$, respectively. The ${ }^{148} \mathrm{Nd}$ yield for a fast-neutron flux is more accurately known than the ${ }^{139} \mathrm{La}$ yield, and the burnups calculated from the ${ }^{148} \mathrm{Nd}$ analyses are considered the more accurate values for these pins.

TABLE IX. Burnup Determinations for G-1, G-2, and G-6

\begin{tabular}{lccc}
\hline $\begin{array}{c}\text { Fuel } \\
\text { Pins }\end{array}$ & $\begin{array}{c}\text { Distance above } \\
\text { Core Bottom, } \\
\text { in. }\end{array}$ & $\begin{array}{c}{ }^{148} \mathrm{Nd} \\
\text { Burnup } \\
\text { at. } \%\end{array}$ & $\begin{array}{c}{ }^{139} \mathrm{La} \\
\text { Burnup, } \\
\text { at. } \%\end{array}$ \\
\hline G-1 & $6 \frac{3}{8}$ & 5.35 & 5.58 \\
G-1 & $12 \frac{3}{4}$ & 4.35 & 4.34 \\
G-2 & 2 & 4.91 & 4.92 \\
G-2 & $6 \frac{3}{8}$ & 5.19 & 5.21 \\
G-2 & $12 \frac{3}{4}$ & 4.26 & 4.26 \\
G-6 & 2 & 4.44 & 4.46 \\
G-6 & $6 \frac{3}{8}$ & 4.68 & 4.74 \\
G-6 & $12 \frac{3}{4}$ & 3.95 & 3.97 \\
\hline
\end{tabular}

(a) Metallographic Examinations

The samples for microscopy were prepared in the AGHCF using slow-speed grinding and polishing machines. The samples were ground using 320- and 600-grit silicon carbide papers and were polished using 3then $1-\mu$ diamond paste. Hyprez* was used as the lubricant in the grinding and polishing steps. The samples were cleaned between preparation steps in ultrasonic baths containing ethanol. The cladding was etched electrolytically using $5 \% \mathrm{HCl}$ in methanol at $10 \mathrm{~V}$. The hot-cell atmosphere was nitrogen that contained $<.100 \mathrm{ppm}$ oxygen and $\sim 50 \mathrm{ppm}$ water.

The general features of fuel pins G-1, G-2, G-6, and G-7 are shown in the montages that comprise Figs. 28 through 31 . These figures show that the central hole (annular pellets) in the fuel was closed at the top and the bottom of the fuel column in the higher power pins (G-1 and G-2). In the lower power pins, the central holes were closed at the bottom of the fuel column and reduced in diameter at the top. Examination results from fuel pin G-3 at 


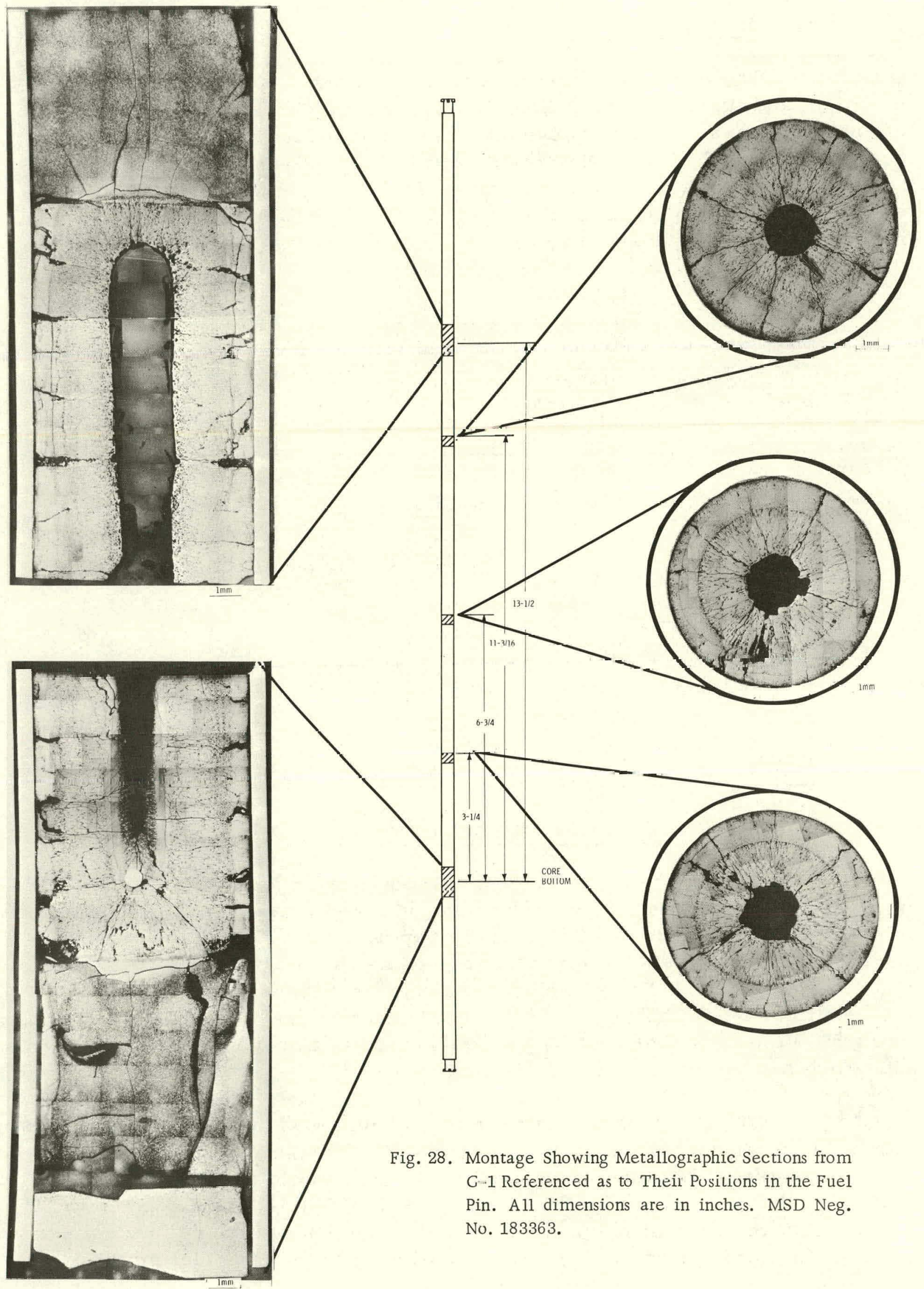



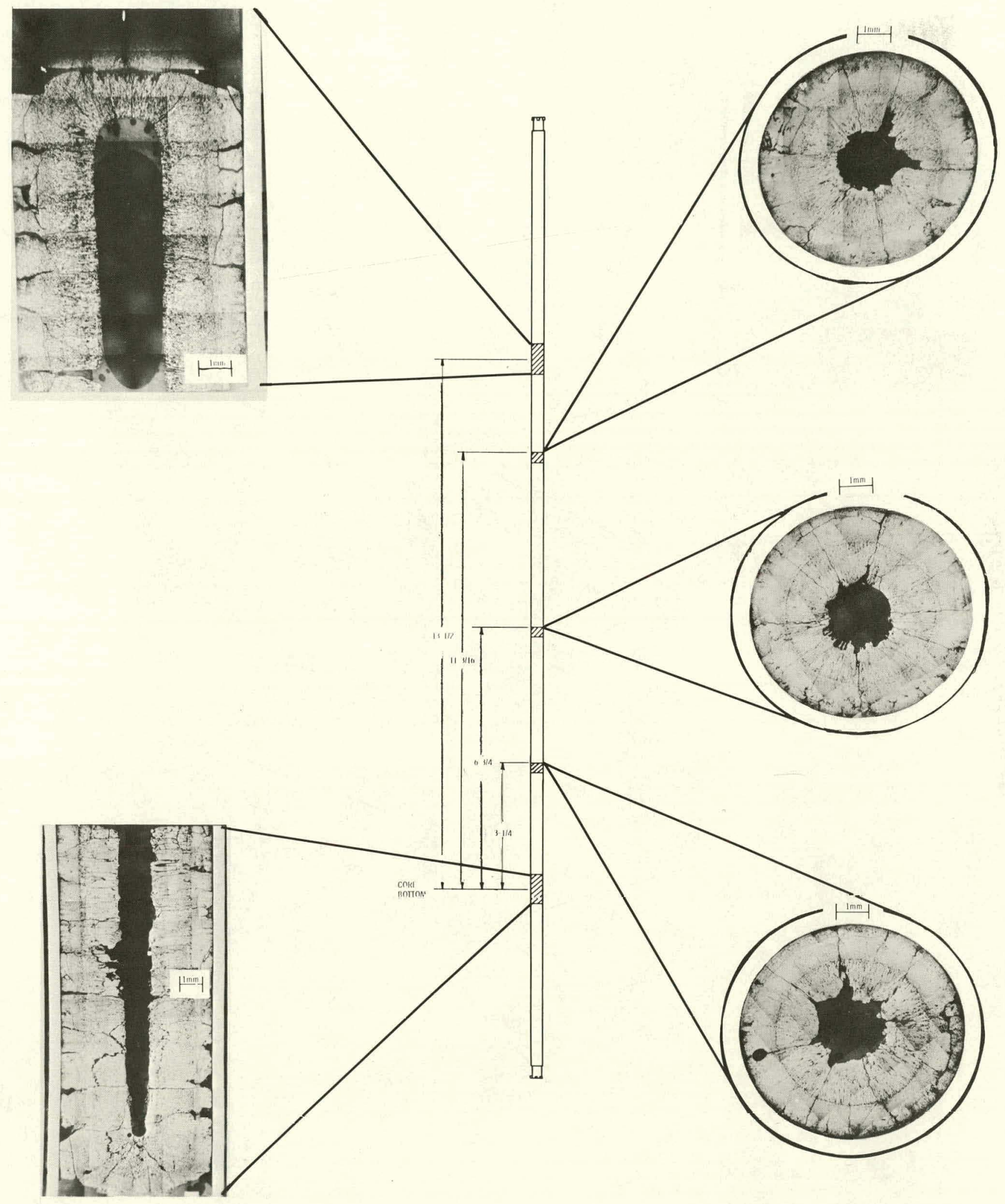

Fig. 29. Montage Showing Metallographic Sections from G-2 Referenced as to Their Positions in the Fuel Hin. All dimensions are in inches. MSD Neg. No. 183476. 


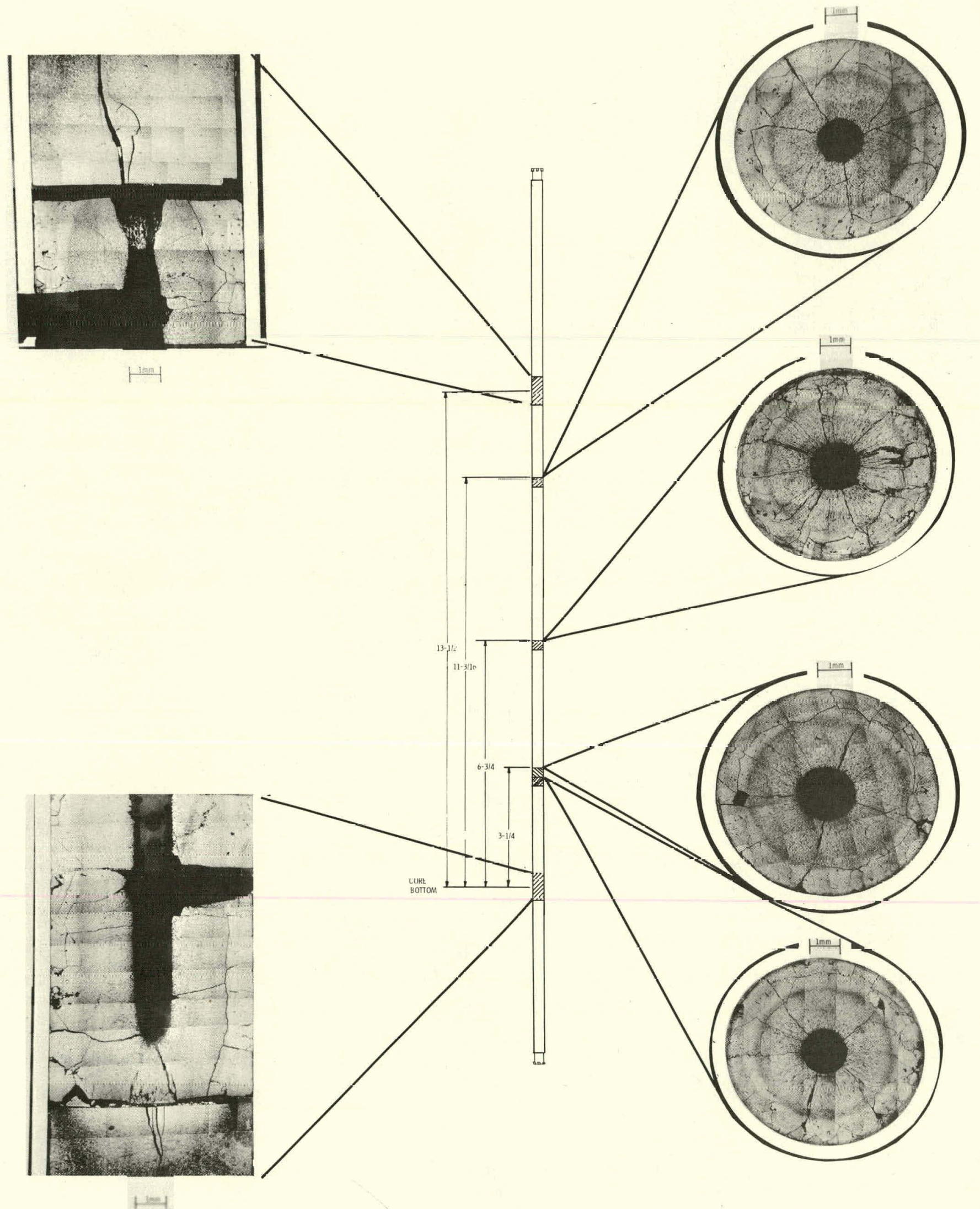

Fig. 30. Montage Showing the Metallographic Samples from G-6 Referenced as to Their Positions in the Fuel Pin. All dimensions are in inches. MSD Neg. No. 183475. 


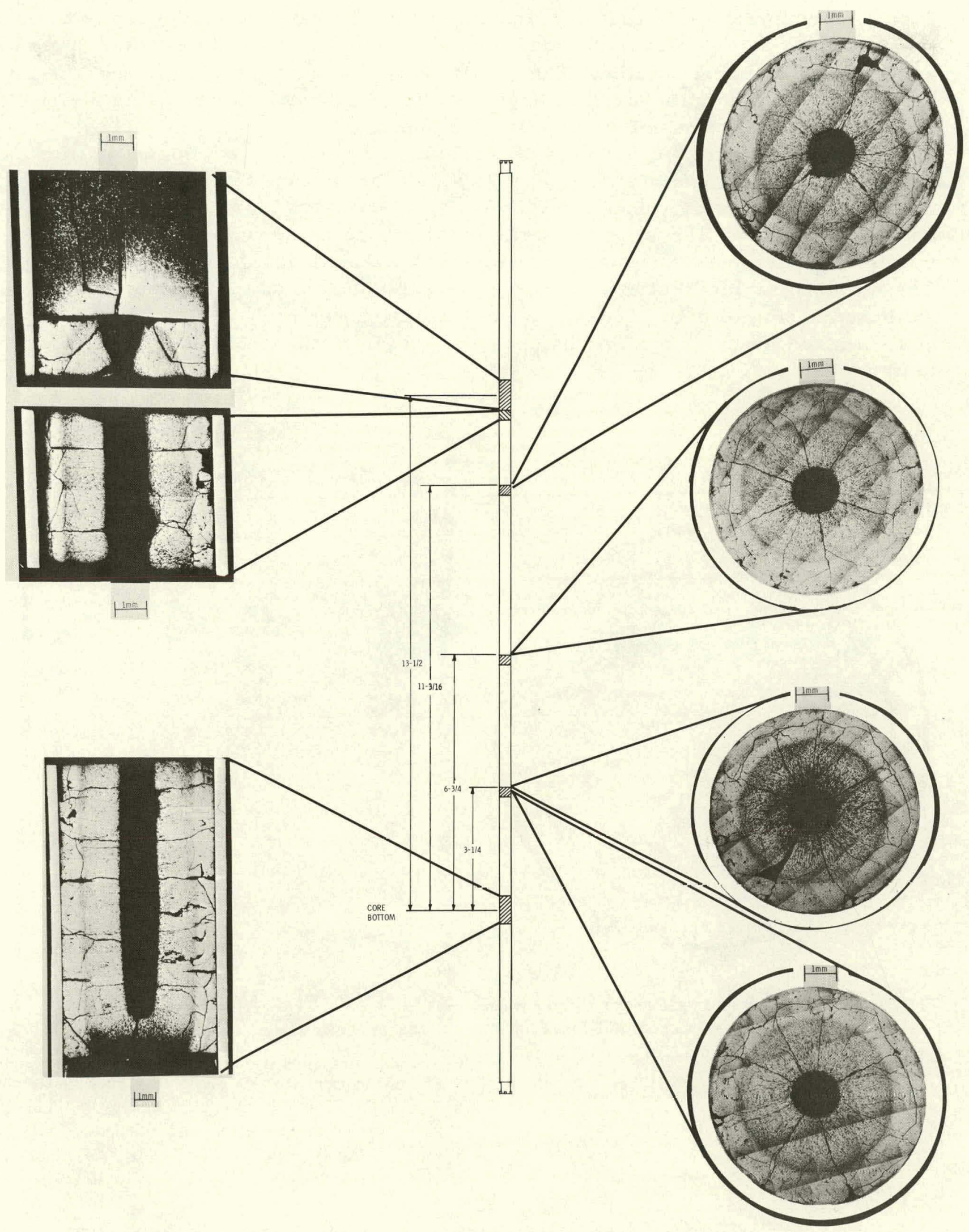

Fig. 31. Montage Showing the Metallographic Sections from G-7 Referenced as to Their Positions in the Fuel Pin. All dimensions are in inches. MSD Neg. No. 183465. 
3 at. \% burnup indicated that the closure of the central hole at the top of the fuel column was the result of condensation of fuel vapors in the cooler region at the end of the fuel column. The closing of the central hole at the bottom of the G-3 fuel column appeared to have resulted from fuel chips falling down the central hole and vapor transport. The sections of G-1 and G-2 show evidence of fuel melting in the form of irregular, but not jagged, edges on the central holes and dendritic fuel structures at the bottom of the fuel columns. These features, as they appeared in G-1, are shown in more detail in Figs. 32 and 33. The irregular-shape central voids are believed to be the result of molten-fuel drippage and not an artifact of the metallographic preparation. The metallographic sections that contained the uneven shape central voids also exhibited a ring of high porosity in the transition region between the columnar and equiaxed grain zones. Additional discussion of these features is deferred to Sec. II.B.

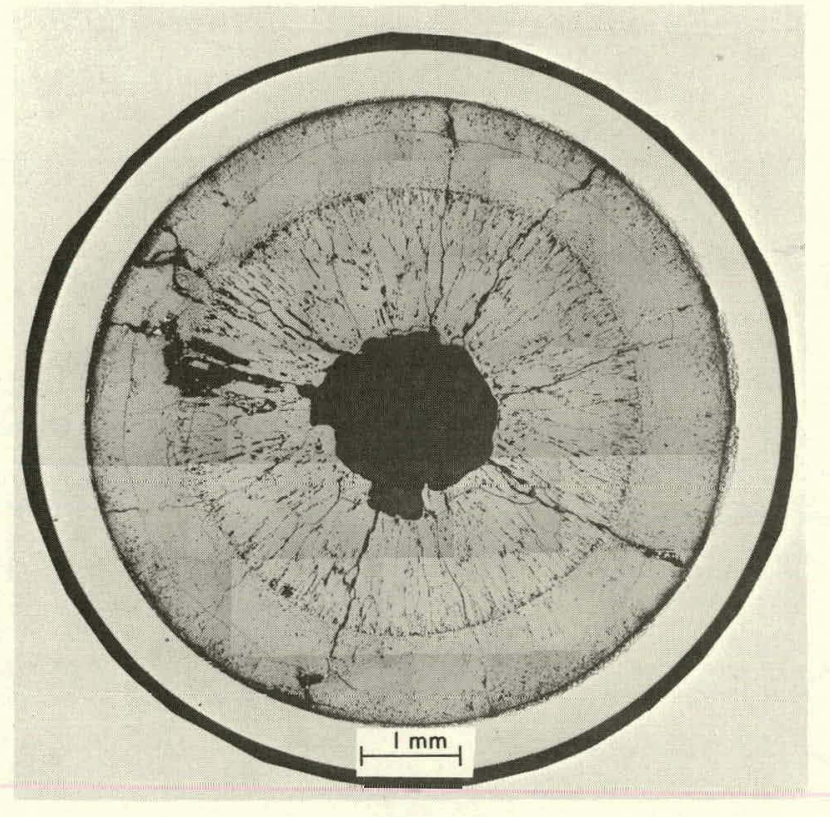

Fig. 32. Midplane Section from Fuel Pin $G-1$ Showing Uneven Edye on tlie Centidl Itrite and Ring of Porosity at the Outer Edge of the Columnargrain Zone. MSD Neg. No. 168568.

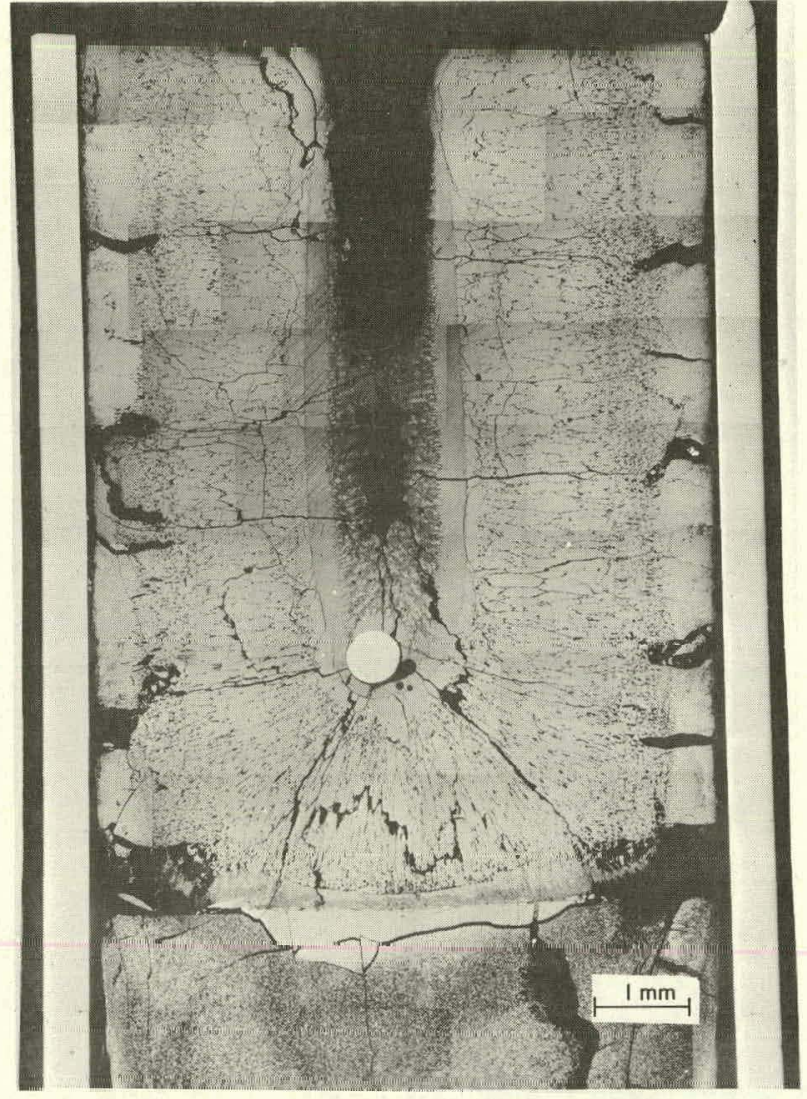

Fig. 33. Bottom of Fuel Column from Fuel Pin G-1 Showing Dendritic Structure in the Fuel near the Centerline and a Spherica1, Metallic Fission-product Ingot. MSD Neg. No. 168785 .

Figure 34 shows a transverse section through the G-7 pin 3.25 in. above the bottom of the fuel column. The columnar region of this section was generally more porous than that of other sections. Additional grinding, which removed $\sim 0.03$ in. of fuel, produced the structure in Fig. 35. The closeness of the two sections is attested by the almost identical cracking patterns. 
The abrupt change in the fuel structures is attributed to the first section being cut through the dished end of the pellet. The porous structure resulted from the dish volume that was incorporated into the fuel during the restructuring of the fuel in the reactor.

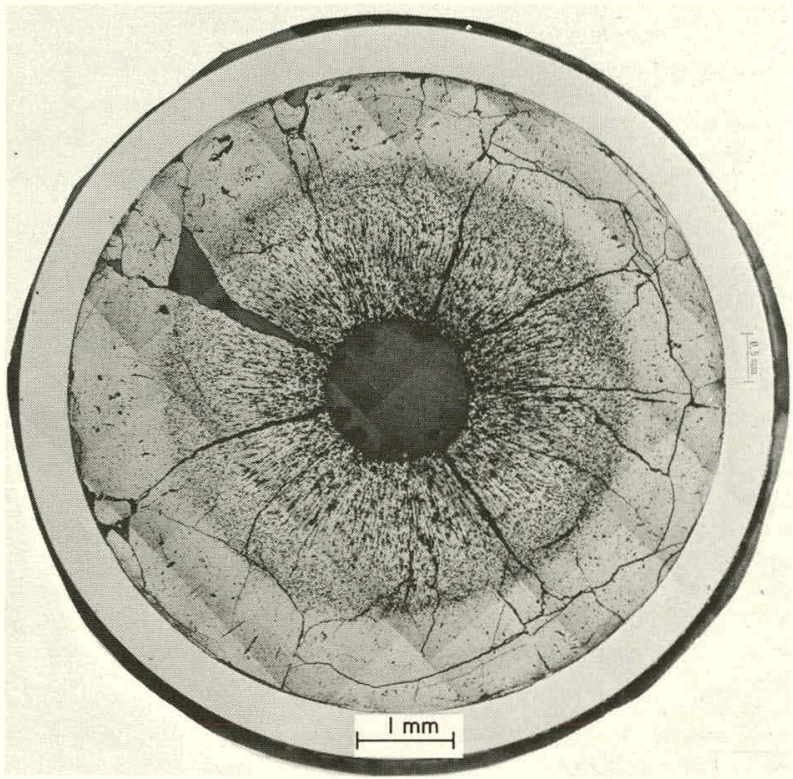

Fig. 34. Transverse Section of $\mathrm{G}-73 \frac{1}{4}$ in. above Core Bottom. The section was apparently cut quite close to a pellet interface. MSD Neg. No. 182653.

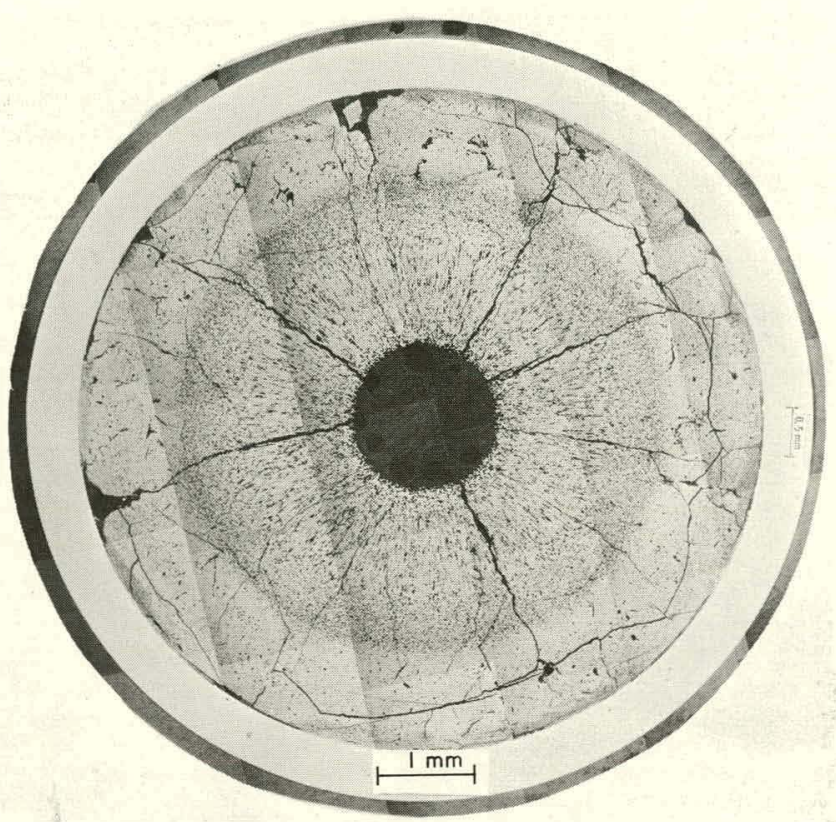

Fig. 35. Transverse Section of G-7 Shown in Fig. 34 after Regrinding and Polishing. MSD Neg. No. 182652.

The microstructures of the fuel at three axial locations in each pin are shown in Figs. 36 through 39. The etched structure in the fuel strips from G-1 and G-2 shows that grain growth has occurred in the fuel quite close to the cladding. In the lower power fuel pins $G-6$ and $G-7$, a wide (0.016 in.) unrestructured zone exists next to the cladding.

Etching of the fuel also revealed the trails left by gas bubbles in elements $\mathrm{G}-1$ and G-2, which indicated that the bubbles are migrating toward the cladding. In fuel pins G-6 and G-7, the bubbles appear to be migrating toward the centerline of the fuel pins. The bubble tracks are only slightly visible in Figs. 36 through 39 but are shown at higher magnification in Fig. 40.

\section{(b) Fuel-density Determinations}

The density of the fuel in the metallographic sections from fuel pins G-1 and G-6 was determined using computerized quantitative metallographic techniques. The results of these measurements, given in the Appendix, indicated that the fuel in the higher powered G-1 pin tended to have a higher density than in $G-6$. However, quantitative comparison of the results are tenuous because the measurement error is of the same order of magnitude as the measured differences. 


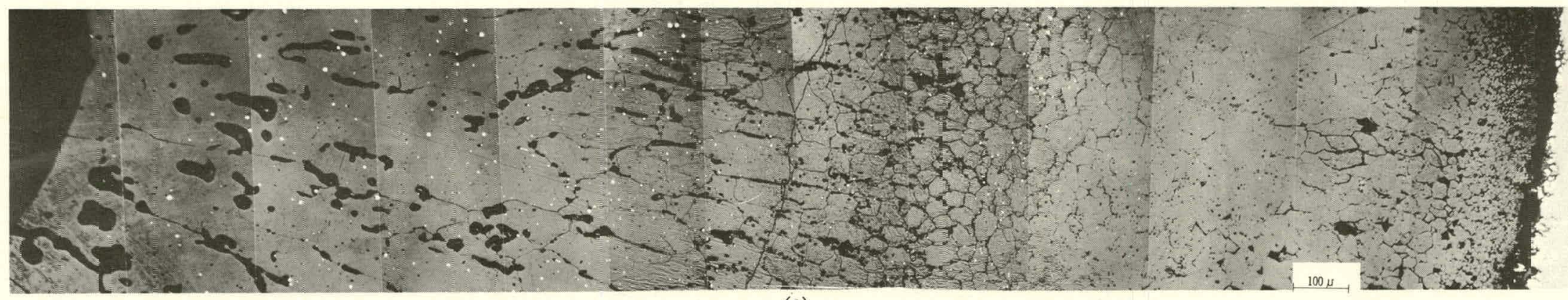

(a)

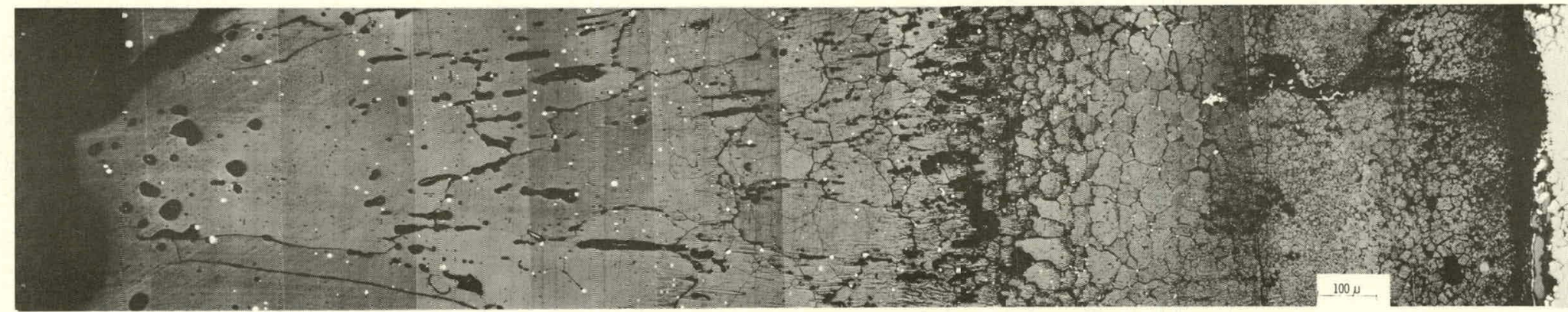

(b)

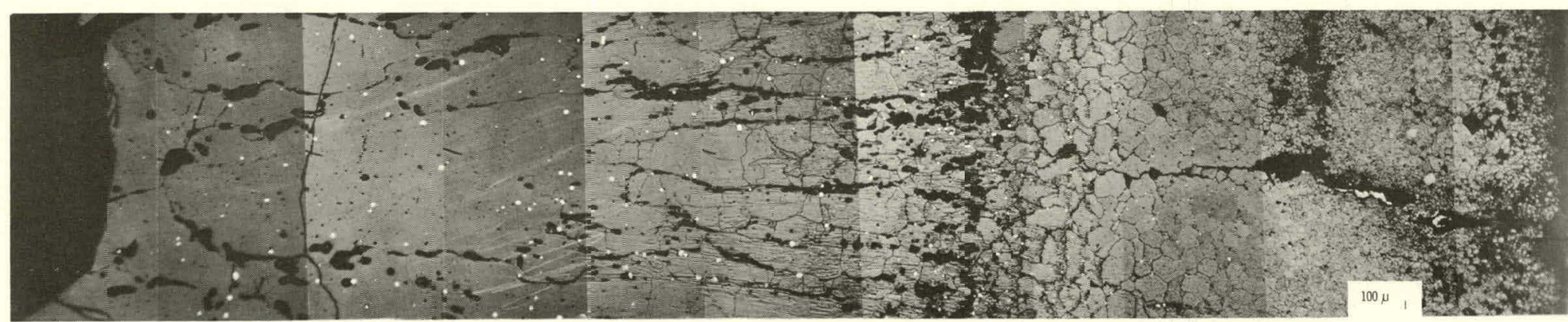

(c)

Fig. 36. Microstructure of Radial Strips of Fuel from Pin G-1 after Chemical Etching in a Solution of $10 \% \mathrm{H}_{2} \mathrm{SO}_{4}$ and $90 \% \mathrm{H}_{2} \mathrm{O}_{2}$. (a) Radial strip of fuel 11.3 in. above the bottom of the fuel column. (b) Radial strip of fuel 6.75 in. above the bottom of the fuel column. (c) Radial strip of fuel 3.25 in. above the bottom of the fuel column. MSD Neg. No. 169257 . 


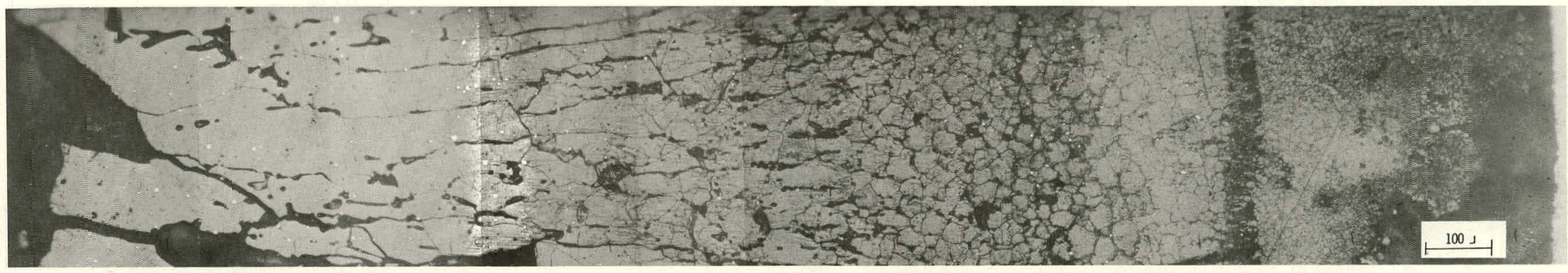

(a)

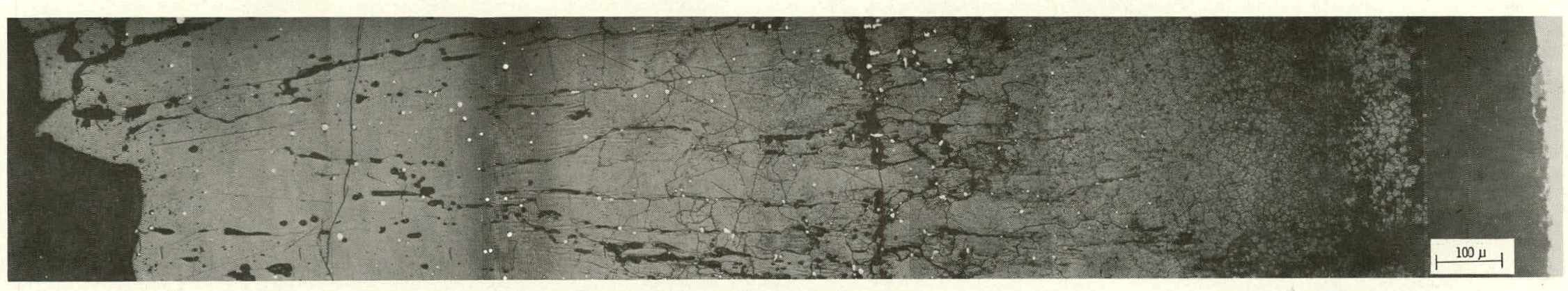

(b)

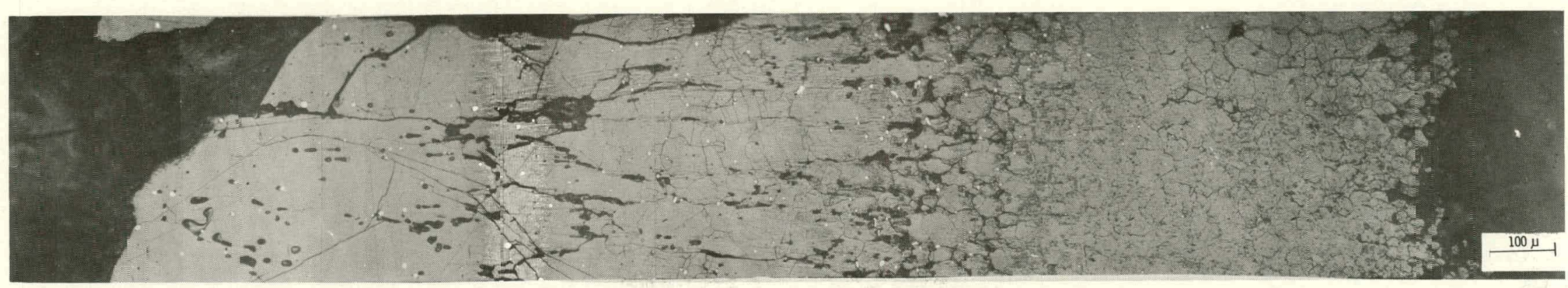

(c)

Fi६. 37. INicrostructure of Radial Strips of Fue- from Pin G-2 after Chemical Etching in a Solution of $10 \% \mathrm{H}_{2} \mathrm{SO}_{4}$ and $90 \% \mathrm{H}_{2} \mathrm{O}_{2}$. (a) Radial fuel strip $11 \frac{1}{4}$ in. above the core bottom. (b) Radial fuel strip at core midplane. (c) Radial fuel strip $3 \frac{1}{4}$ in. above the core bottom. MSD Neg. No. 181893. 


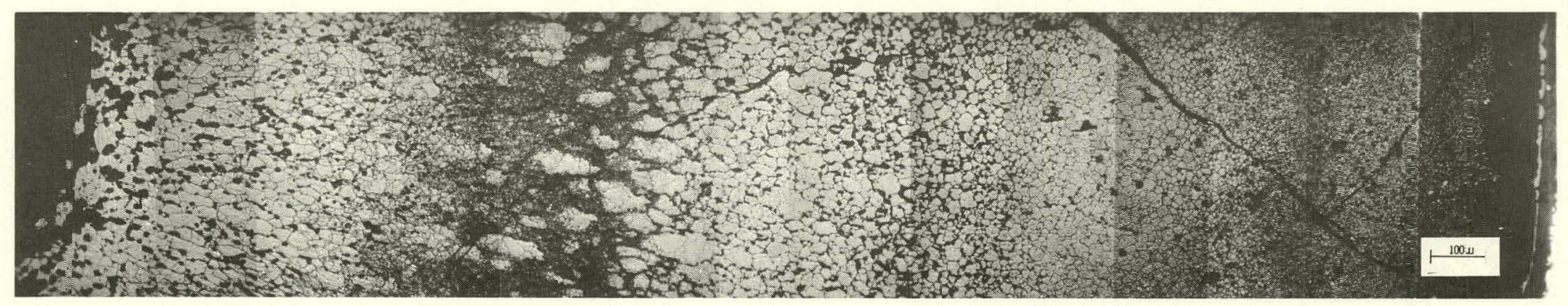

(a)

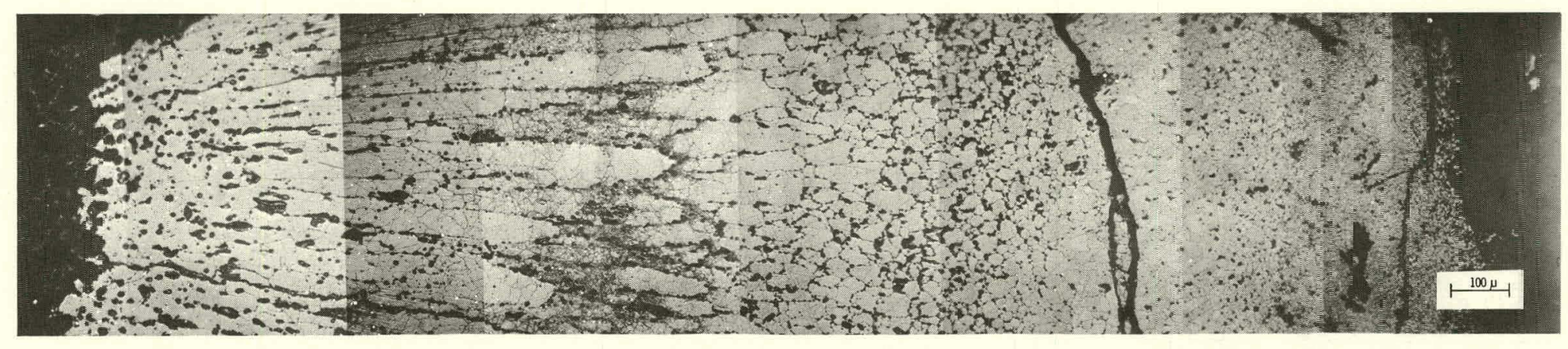

(b)

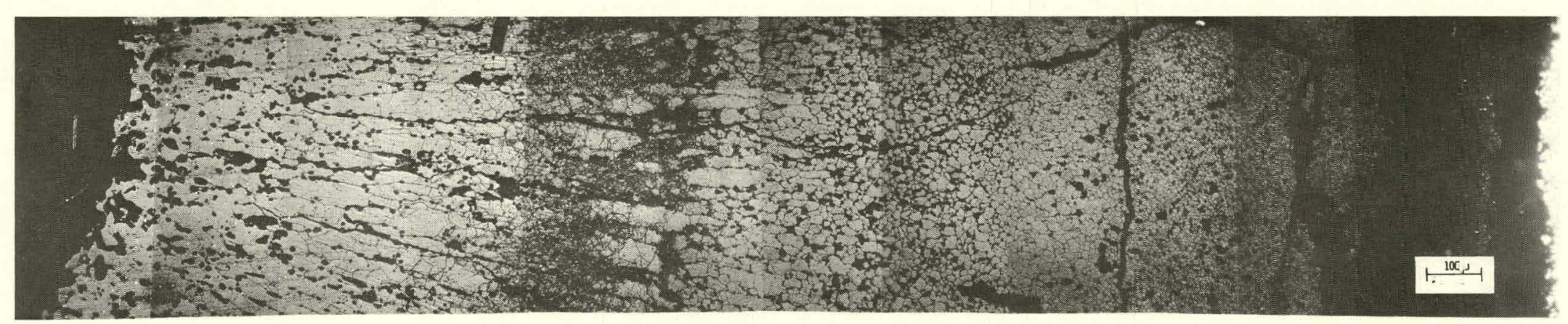

(c)

Fig. 38. Microstructure of Radial Strips of Fuel from Pin G-6 after Chemical Etching in a Solution of $10 \% \mathrm{H}_{2} \mathrm{SO}_{4}$ and $90 \% \mathrm{H}_{2} \mathrm{O}_{2}$ (a) Radial strip of fuel $11.15 \mathrm{in}$. above the bottom of the fuel column. (b) Radial strip of fuel 6.75 in. above the bottom of the fuel column. (c) Radial strip of fuel 3.25 in. above the bottom of the fuel column. MSD Nez. No. $1 \in 9959$. 

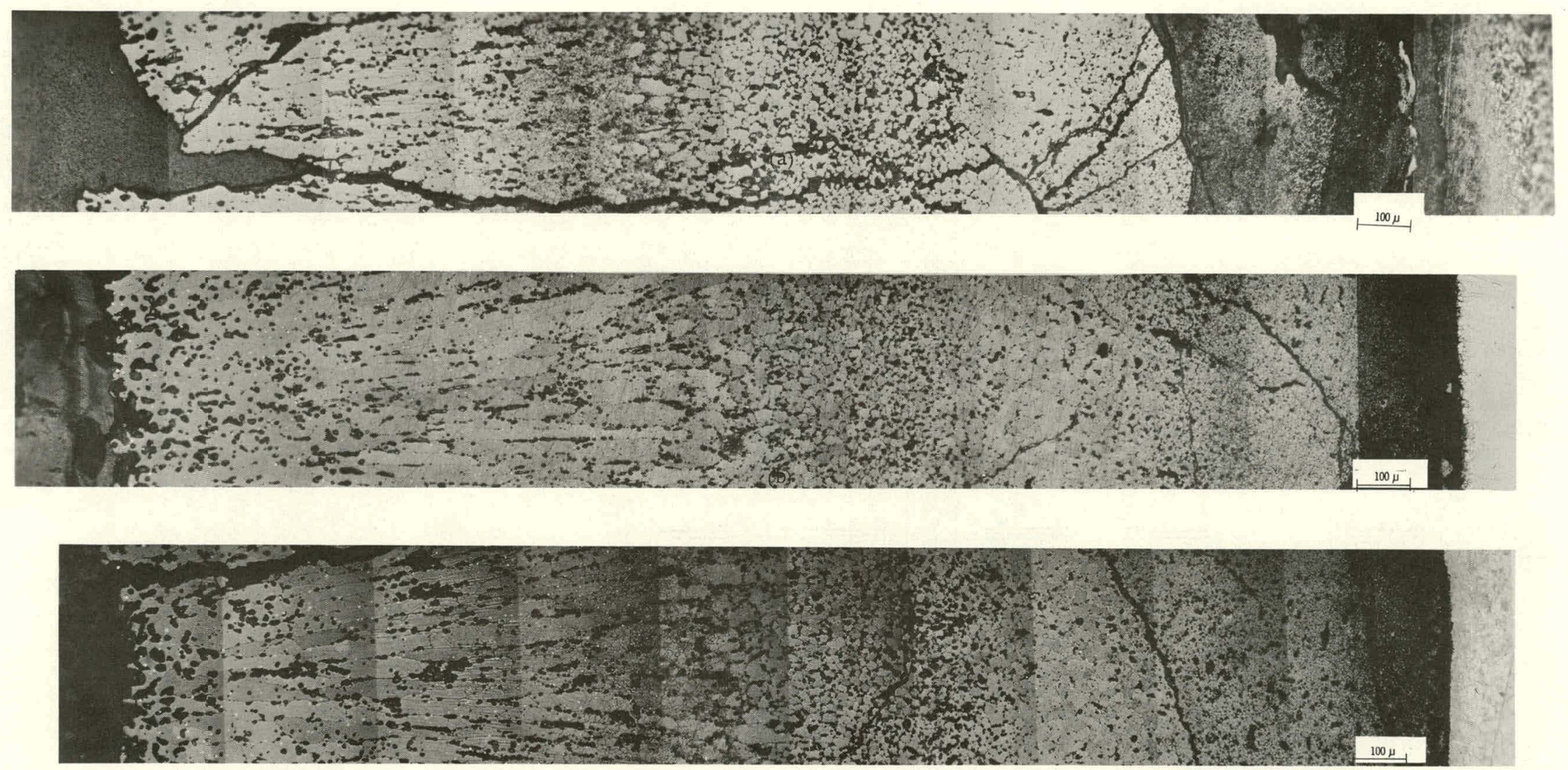

(c)

Fig. 39. Microstructure of Radial Strips of Fuel from Pin G-7 after Chemical Etching in a Solution of $10 \% \mathrm{H}_{2} \mathrm{SO}_{4}$ and $90 \%$ H $\mathrm{H}_{2} \mathrm{O}_{2}$. (a) Radial fuelstrip $11 \frac{1}{4}$ in. above the core bottom. (b) Radial fuel strip at core midplane. (c) Radial fuel strip $3 \frac{1}{4}$ in. above the core bottom. MSD Neg. No. 182655 . 


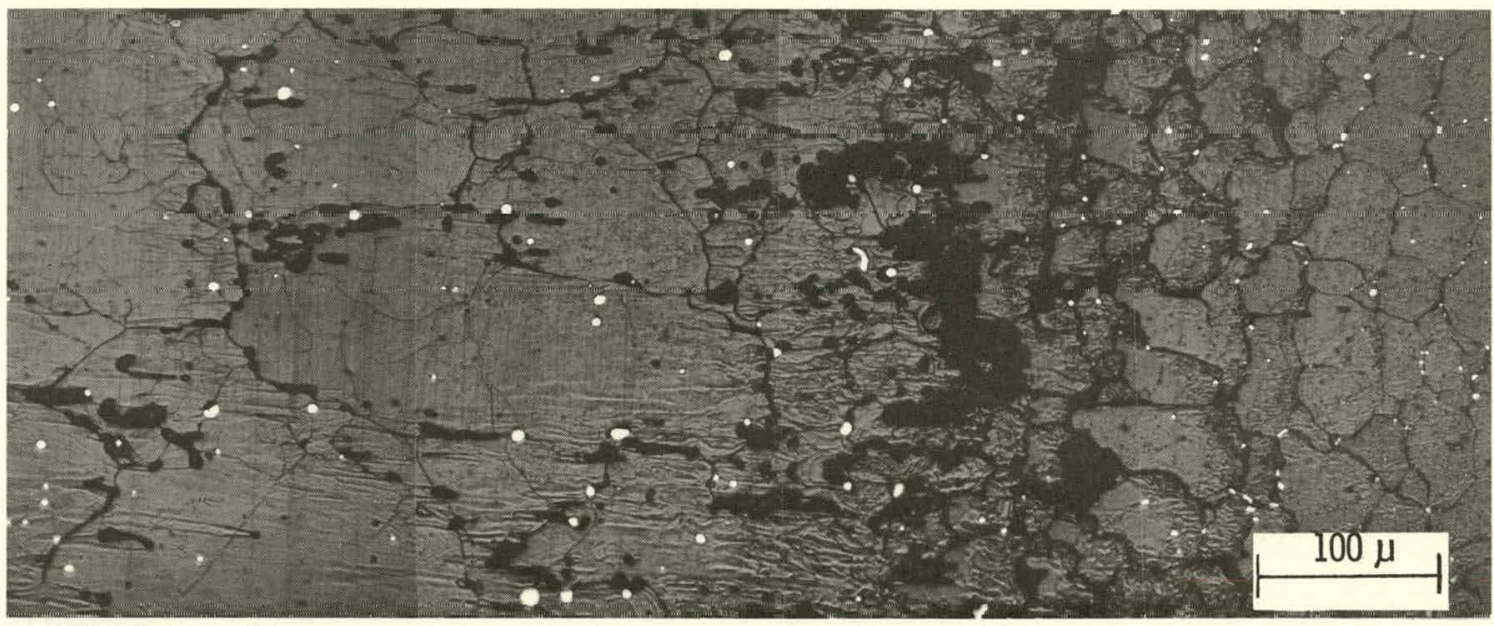

$G-1$

CENTLRLINL -

CLADDING

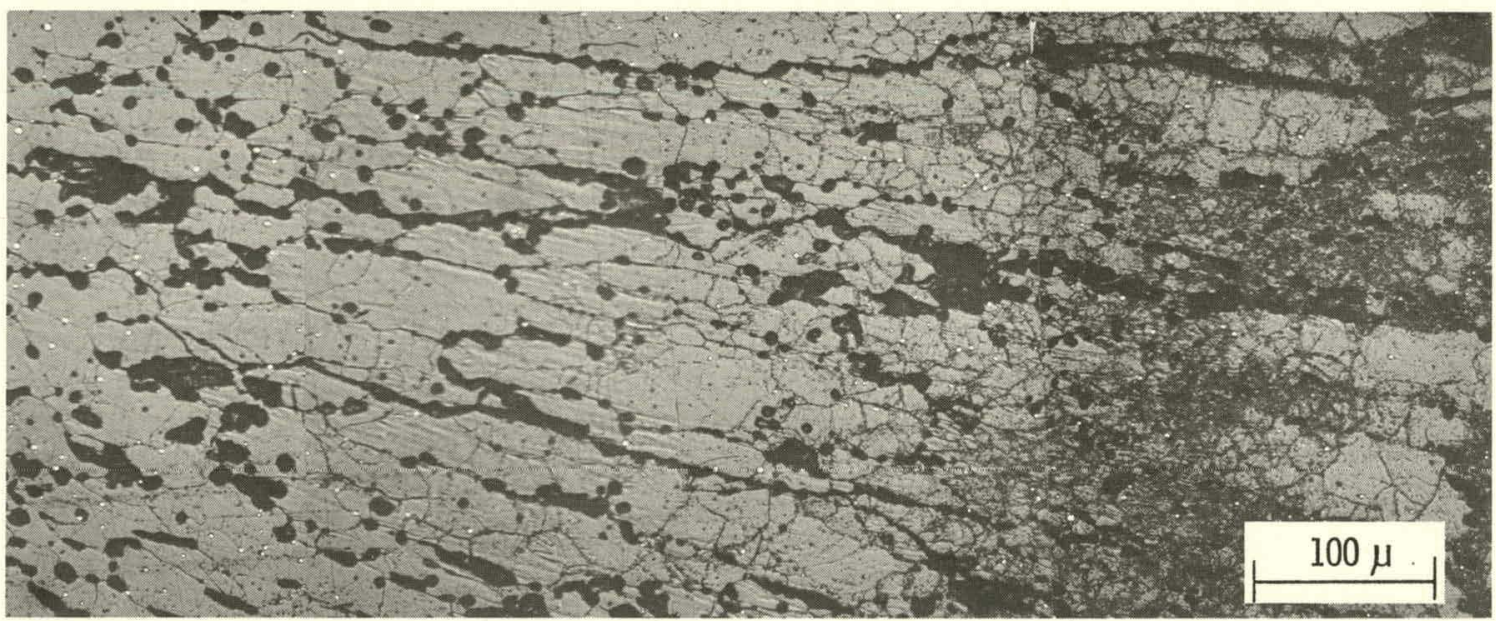

G-6

Fig. 40. Bubble Tracks in the Fuel from Pins $G-1$ and $G-6$, Indicating that the Bubblcs Arc Moving in Opposite Directions. MSD Neg. Nos. 169041-169044 (G-1); 169729-169732 (G-6).

(c) Electron-microprobe Examinations of the Fuel

Detailed electron-microprobe analyses were performed on the fuel in transverse sections from fuel pins G-1 and G-6. Specific areas of investigation were the radial distribution of $\mathrm{Pu}$, the radial variation in the composition of metallic fission-product inclusions, and the radial distribution of $\mathrm{Mo}$ and $\mathrm{Nd}$ in the oxide phase.

The radial distribution of $\mathrm{Pu}$ in the fuel cross section at the core midplane for fuel pin G-l is shown in Fig. 41. The distribution of Pu in this cross section is characterized by a linear gradient from the inner edge of the central void to $\sim 0.7$ of the fuel radius. At this point, the concentration changes suddenly to the approximate nominal composition of $15 \%$ Pu. Near the outer edge of the fuel the Pu composition also is higher than the nominal composition. The Pu content at the edge of the central void was $\sim 20 \%$, and 


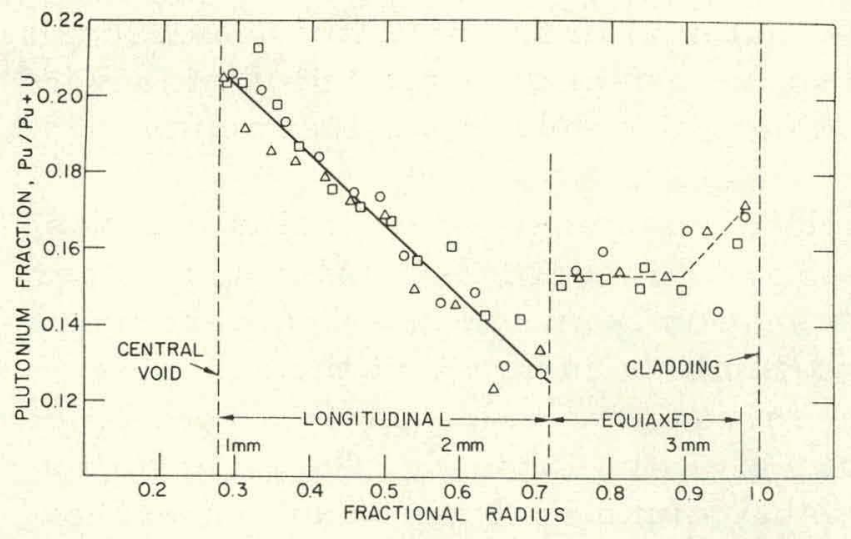

Fig. 41. Radial Plutonium Distribution at the Core Midplane of G-1. MSD Neg. No. 63962.

at the lower end of the linear gradient the fuel contained about $12.5 \% \mathrm{Pu}$.

These results indicate that fuel melting probably occurred out to $70 \%$ of the fuel radius sometime during the irradiation. The upturn of the Pu content of the fuel near the outer edge of the fuel has been observed in other fuel pins, generally at burnups $>10$ at. $\%$, but no explanation for this phenomenon is presently available.

The radial distribution of $\mathrm{Pu}$ for two sections from fuel pin G-6 is shown in Figs. 42 and 43 . The Pu distribution in the core midplane section (Fig. 42) was normal for a mixedoxide fuel with an $\mathrm{O} / \mathrm{M}$ of 1.97 . The hyperbolic gradient of the $\mathrm{Pu}$ is attributed to migration of $U$ and $O$ down the temperature gradient by vapor transport early in the fuel-restructuring process. The Pu distribution in the section 13 in. above the core bottom (Fig. 43) exhibited a downturn in Pu content at the edge of the central void and a "normal" distribution over the remainder of the fuel radius. The maximum $\mathrm{Pu}$ content and the short distance of $\mathrm{Pu}$ redistribution in this section reflect the lower power generation near the top of the fuel column, when compared with the power generated at the core midplane. Close examination of the radial distribution of $\mathrm{Pu}$ in this section of fuel shows that the downturn in $\mathrm{Pu}$ content occurs in fuel located inside the original radius

Fig. 42

Radial Plutonium Distribution at the Core Midplane of $\mathrm{G}-6$. The three traverses are designated by $O, \triangle$, and $\square$. MSD Neg. No. 63994.

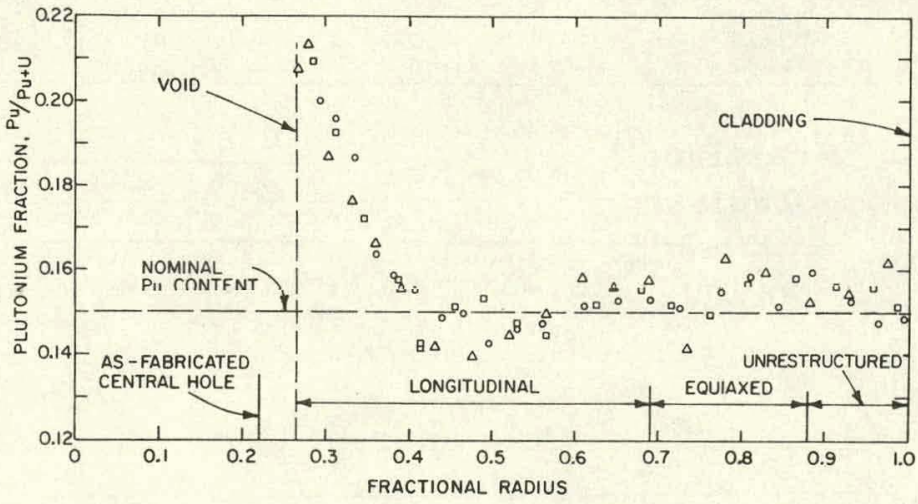

Fig. 43

Radial Plutonium Distribution 13 in. above Core Bottom of $\mathrm{G}-6$. The three traverses are designated by $\mathrm{O}, \Delta$, and $\square$. MSD Neg. No. 63993 . 
of the as-fabricated central hole. This material has apparently been deposited in this region as a result of axial relocation of fuel by evaporation of fuel in the hottest regions and its condensation near the ends of the fuel column.

The composition of metallic fission-product inclusions was determined in the core midplane section from fuel pin G-1. Attempts to perform similar analyses on the midplane section from fuel pin G-6 were unsuccessful because the inclusions were too small to assure that the analyses would not also include $x$-rays from the surrounding oxide phase. The composition of typical inclusions from G- 1 are given in Table X. The composition of the inclusions is fairly consistent in the columnar-grain zone except that the $\mathrm{Rh}$ concentration increases as a function of the distance from the element centerline. A step change in the composition of the inclusions occurs at the interface between the columnar- and equiaxed-grain zones (also a region of high porosity). The inclusions in the equiaxed-grain zone contain more Pd and less Tc and Ru than the inclusions in the columnar-grain zone. Inclusions that contained a high Mo concentration ( $91 \%$ ) were fuund in raclidl cıdcks in the fuel near the fuel outer diameter. These inclusions also contained a significant amount of $\mathrm{Cr}(\sim 4 \%)$. The radial distribution of $\mathrm{Mo}$ and $\mathrm{Nd}$ in the oxide phase of the fuel at the midplane of G-1 is shown in Fig. 44. The INd distribution would be expected to be uniform across the fuel radius because $\mathrm{Nd}$ is not a mobile fission product. The variations observed in the $\mathrm{Nd}$ distribution are attributed to the melting of the fuel. The radial distribution of Mo in the oxide phase is continuous and is used in Sec. II.D to calculate the radial oxygen potential for this cross section.

TABLE X. Elemental Composition of the Metallic Inclusions in $G-1$ at the Cinre Midplane

\begin{tabular}{|c|c|c|c|c|c|c|c|c|}
\hline \multirow{2}{*}{$\begin{array}{c}\text { Fractional } \\
\text { Radius }\end{array}$} & & \multicolumn{7}{|c|}{ Elements, wt \% } \\
\hline & & Mo & Tc & $\mathrm{Ru}$ & $\mathrm{Rh}$ & $\mathrm{Pd}$ & $\mathrm{Fe}$ & $\mathrm{Ni}$ \\
\hline 0.282 & $T$ & & & & & & & \\
\hline 0.354 & & 41.8 & 16.8 & 37.0 & 3.4 & 1.1 & - & - \\
\hline 0.441 & $\begin{array}{l}\text { Columnar- } \\
\text { grain Zone }\end{array}$ & 43.6 & 16.3 & 34.7 & 4.6 & 0.9 & - & - \\
\hline 0.538 & & 43.4 & 14.3 & 33.1 & 8.5 & 0.6 & - & - \\
\hline 0.646 & & 42.3 & 13.3 & 31.3 & 10.2 & 2.8 & 0.04 & 0.05 \\
\hline 0.708 & 4 & & & & & & & \\
\hline 0.723 & & 42.6 & 7.5 & 20.2 & 4.9 & 23.5 & 0.6 & 0.8 \\
\hline 0.733 & $\begin{array}{l}\text { Equiaxed- } \\
\text { grain Zone }\end{array}$ & 44.4 & 7.2 & 17.1 & 3.4 & 26.5 & 0.6 & 0.9 \\
\hline 0.815 & & 91 & 2.5 & 3.4 & $(\mathrm{Cr}$ & $=3.8)$ & - & - \\
\hline 0.974 & $\downarrow$ & & & & & & & \\
\hline
\end{tabular}




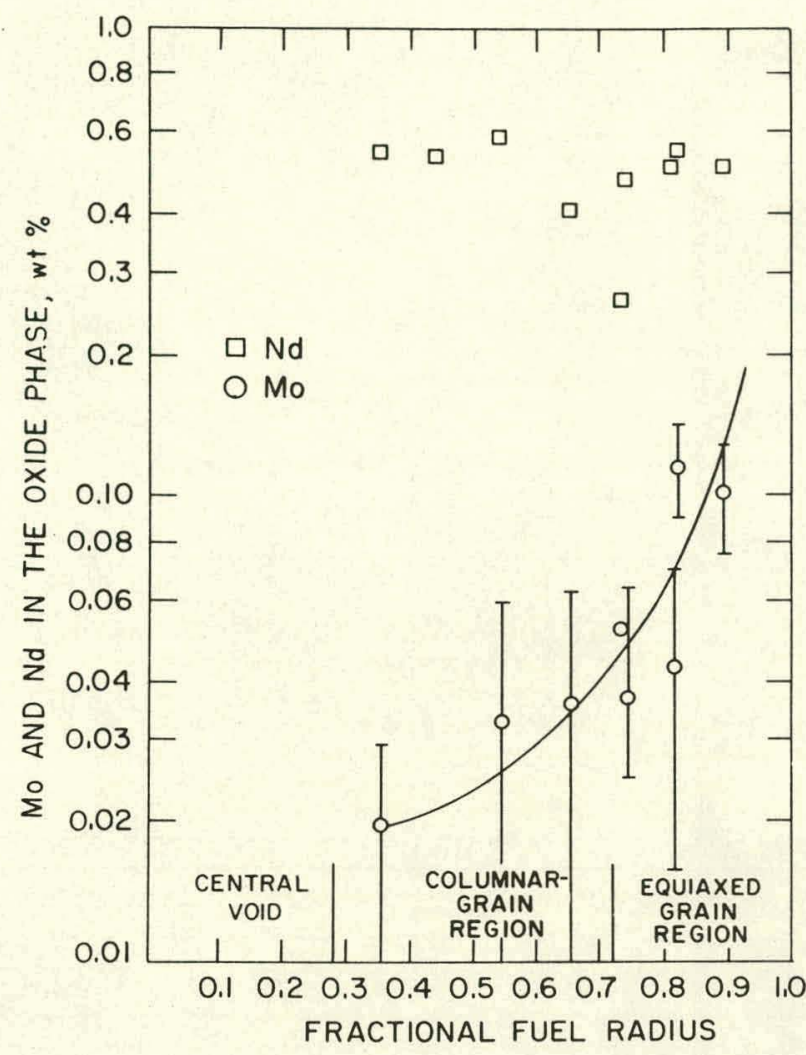

Fig. 44. Radial Mo and Nd Distribution in the Oxide Phase of the Fuel at the Core Midplane of G-1. MSD Neg. No. 63961.
An effort was made to determine the composition of the large metallic fission-product ingot in the bottom of pin G-1 (Fig. 33) and to determine the composition of the phases in the structure just above the ingot. Adequate standards were not available for quantitative analysis of the elements in any of these features; however, the qualitative determination of the composition of the features is quite informative.

The large fission-product ingot (Fig. 45) contained about equal parts of Mo, Tc, and Ru with small amounts of $\mathrm{Rh}$ and $\mathrm{Pd}$. This composition is similar to that of the metallic fissionproduct inclusions found in the columnar region of the fuel in the transverse section taken at the reactor-core midplane. This large ingot was apparently formed from smaller ingots that collect on the edges of the central void as a result of radial migration of inclusions up the temperature gradient.

A number of these small ingots either fell to the bottom of the central void or were carried to the bottom of the column by slumping fuel. The spherical shape of the ingot indicates that it was surrounded by molten material after movement to the bottom of the fuel column.

Examination of the dendritic structure near the bottom of $\mathrm{G}-1$

(Fig. 45) revealed that it was composed of $\mathrm{U}, \mathrm{Pu}$, and $\mathrm{Ba}$ (presumably as oxides) and only trace amounts of $\mathrm{Sr}$ and $\mathrm{Zr}$. The dark phase at the centerline was nearly pure $\mathrm{BaO}$. The light dendritic phase extending from the high density fuel contained very little $\mathrm{BaO}$ and had the same composition as the high density fuel. The other two phases contained significant amounts of $\mathrm{Ba}$; the phase with the dark appearance had the higher Ba content. The dendritic structure and $\mathrm{Ba}$ gradients indicate that eutectics were formed between the $\mathrm{UO}_{2}-\mathrm{PuO}_{2}$ fuel and $\mathrm{BaO}$ and the other two phases present may be mixed-oxide and bariumoxide compounds that correspond to $\mathrm{BaUO}_{3}$ and $\mathrm{Ba}_{3} \mathrm{UO}_{6}$ in the $\mathrm{Ba}-\mathrm{U}-\mathrm{O}$ system.

Extensive areas of the $\mathrm{UO}_{2}$ blanket pellet adjacent to the bottom of the G-1 fuel column contained Cs, as indicated in Fig. 46. No quantitative determination of the $\mathrm{Cs}$ content in these regions was made, but the $\mathrm{UO}_{2}$ contained significant amounts of $\mathrm{Cs}$ in the shaded regions. Similar examinations were performed in the region at the top of the fuel columns in fuel pins G- 6 and G-7. The Cs at the top of the fuel column and in the adjacent blanket 


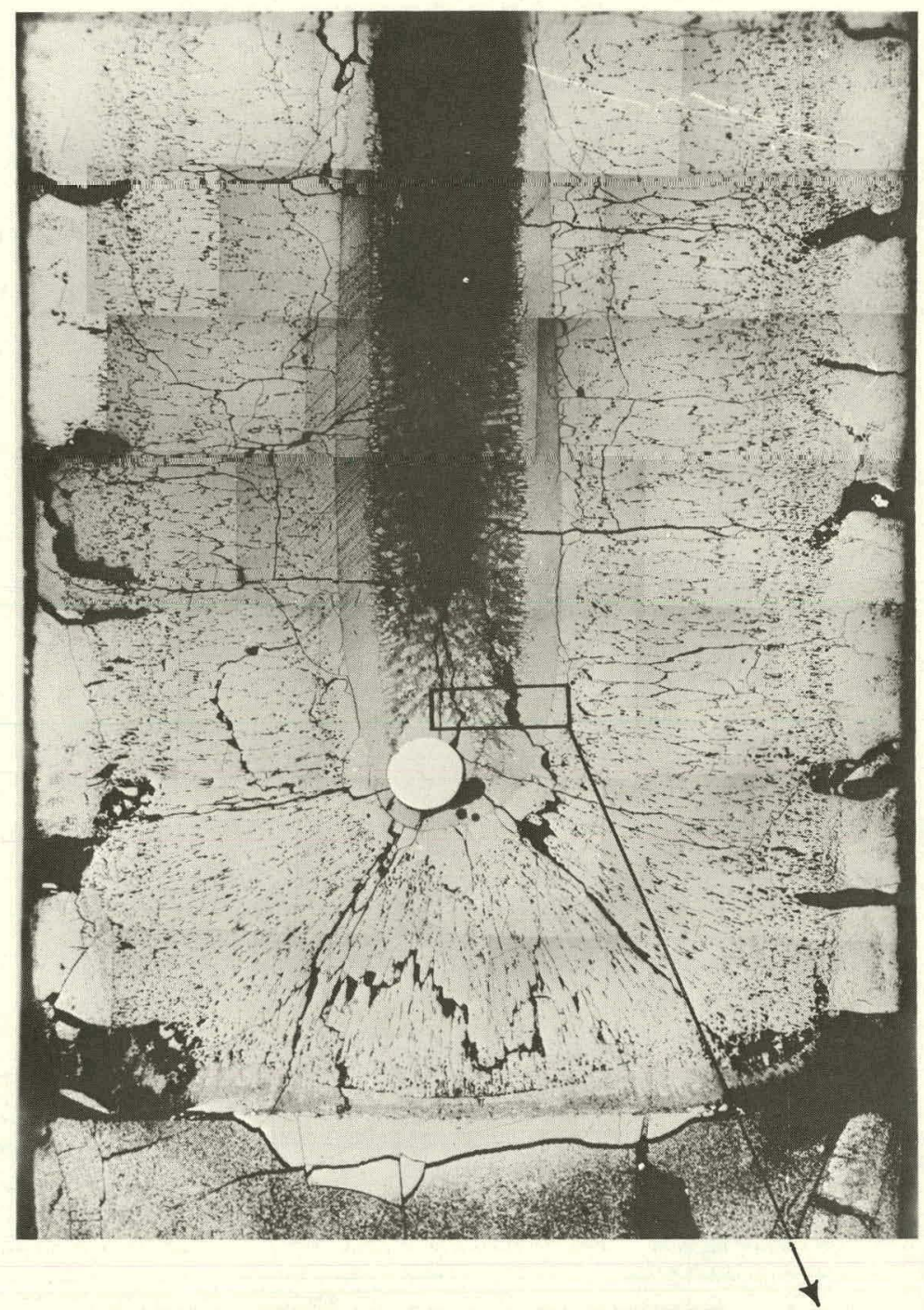

FUÉL MICROSTRUCTURE NEAR THE BOTTOM

OF THE FUEL COLUMN IN ELEMENT G-1

BOTTOM OF THE FUEL COLUMN

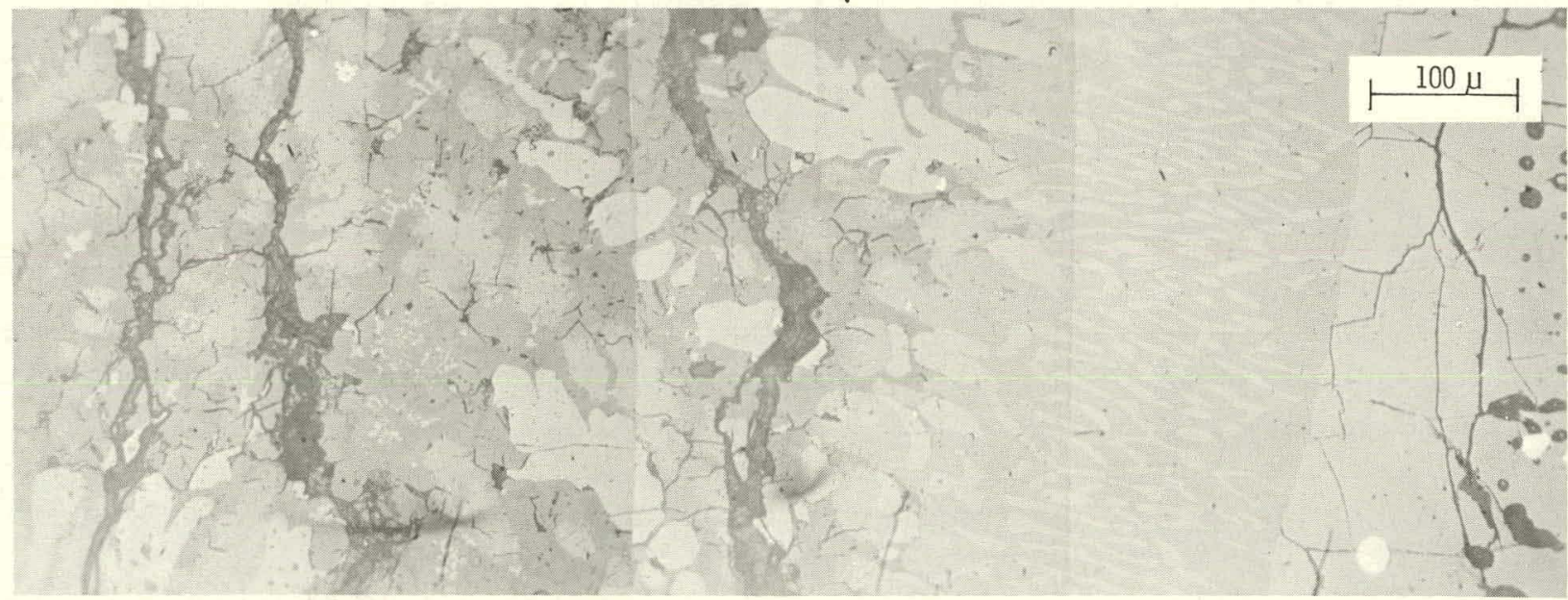

Fig. 45. Fuel Microstructure near the Bottom of the Fuel Column of G-1. MSD Neg. No. 181755. 


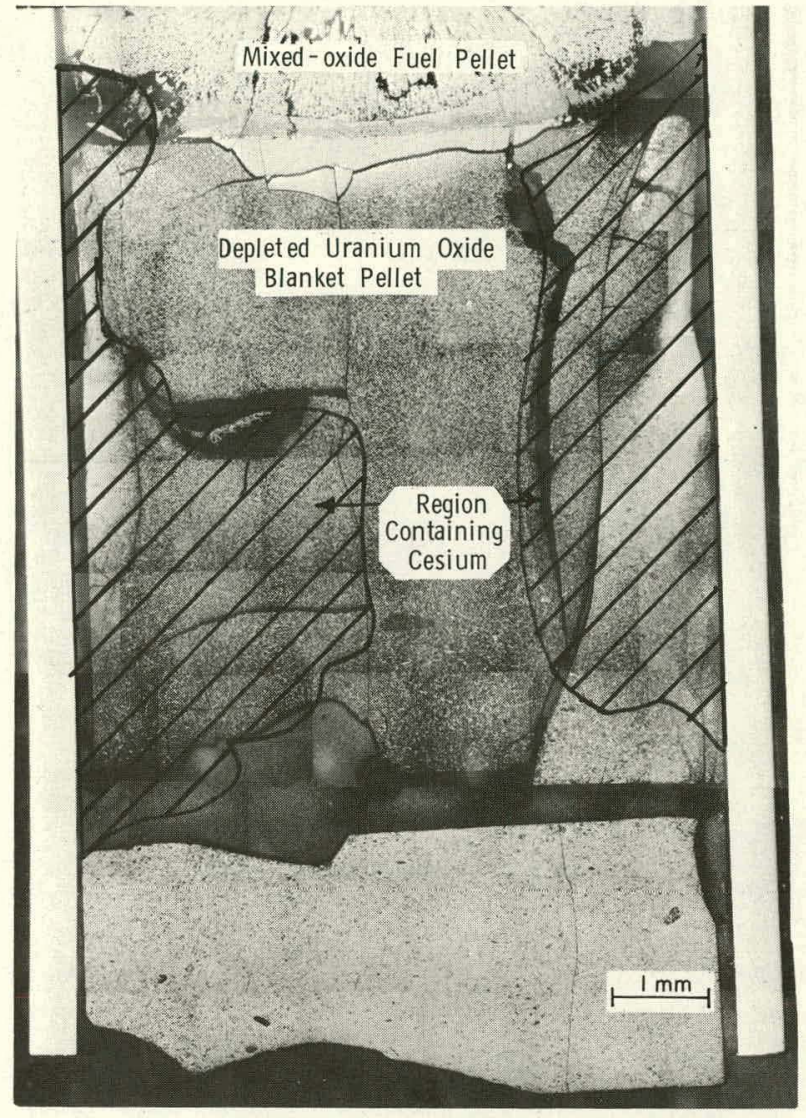

Fig. 46. Areas Containing High Cs Concentrations in the Blanket Pellet Adjacent to the Bottom of the G-1 Fuel Column. MSD Neg. No. 168786. pellets in these fuel pins did not appear to have reacted extensively with either the fuel or blanket pellets.

Cesium was found in the gaps between the pellets and the cladding and in cracks in the blanket pellets. Iodine was found concurrently with the $\mathrm{Cs}$ in several of the deposits but not in all cases. A typical area of the gap between the first blanket pellet and the cladding at the top of the G-7 fuel column is shown in Fig. 47. This deposit was $\sim 25 \mu$ wide and $1500 \mu$ long and appears to be CsI.

\section{(d) Fuel-Cladding Chemical $\underline{\text { Interaction }}$}

Fuel-cladding chemical interaction (FCCI) was observed in all metallographic samples from the fueled region of the fuel pins except those at the bottom of the fuel column. In general, the FCCI was least severe in the lower regions ( $3 \frac{1}{4}$ in. above core bottom) and most severe near the top of the fuel column. Examples of the most severe FCCI for each fuel pin are shown

in Figs. 48 through 51. The results of photographic measurements of the FCCI depths are summarized in Table XI. The depth of the FCCI was obtained by measuring the thickness of unattacked regions of the cladding and subtracting the remaining thickness of unaffected cladding in the regions where FCCI occurred. This method of measurement is more reliable than measuring only the width of the attacked zone because the material generally increases in volume as the chemical interaction occurs. Therefore, the width of the attacked zone may be twice as great as the reduction in the unaffected cladding wall thickness.

The FCCI in most of the specimens was nonuniform around the circumference of the fuel. In fuel pin G-1, a striking lack of attack occurred in the cladiling where radial cracks in the fuel intersected the cladding. Also, evidence of this correlation existed between cracks in the fuel and lack of FCCI in G-2 and G-7, but it was less obvious because the attack was less severe.

The fuel-cladding interface regions near the midplane of fuel pins G-1 and G-6 were examined by electron-microprobe analysis to determine 
the chemical elements that were present and to determine if the FCCI extended deeper into the cladding than was apparent from optical microscopy. The depth of FCCI, as indicated by the deepest penetration of Cs, I, and Te, agreed quite well with the results of optical microscopy. The FCCI in fuel pin G-1 varied from insignificant adjacent to radial cracks in the fuel to as deep as $2.5 \mathrm{mils}$ when measured from the original ID of the cladding. The maximum depth of FCCI observed in the sample from G-6 was 1 mil when the thickness of the unaffected cladding was subtracted from the original cladding thickness. The width of the FCCI zone in G-6 was as great as 2 mils, illustrating the inward displacement of the low-density reaction products from the FCCI.

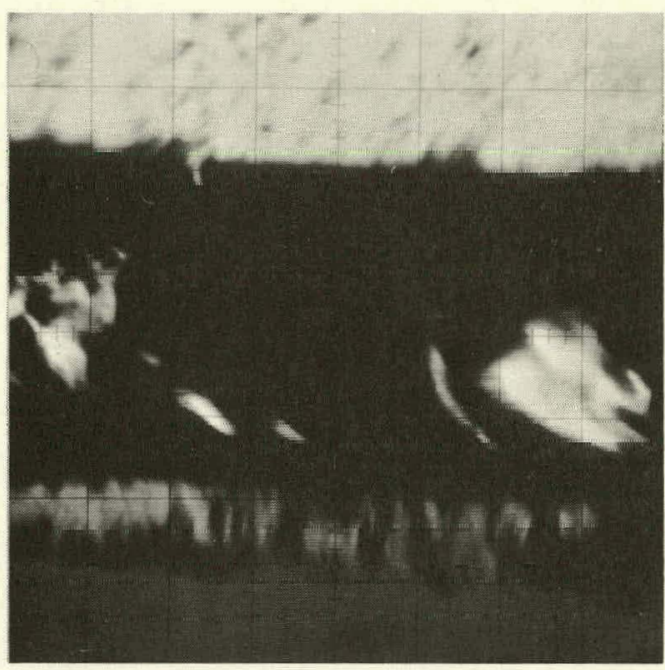

Sample Current

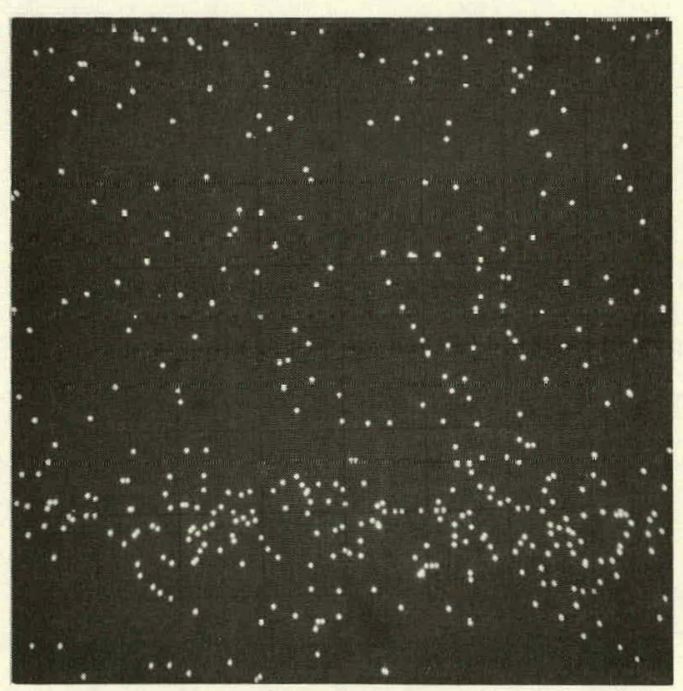

Indine.

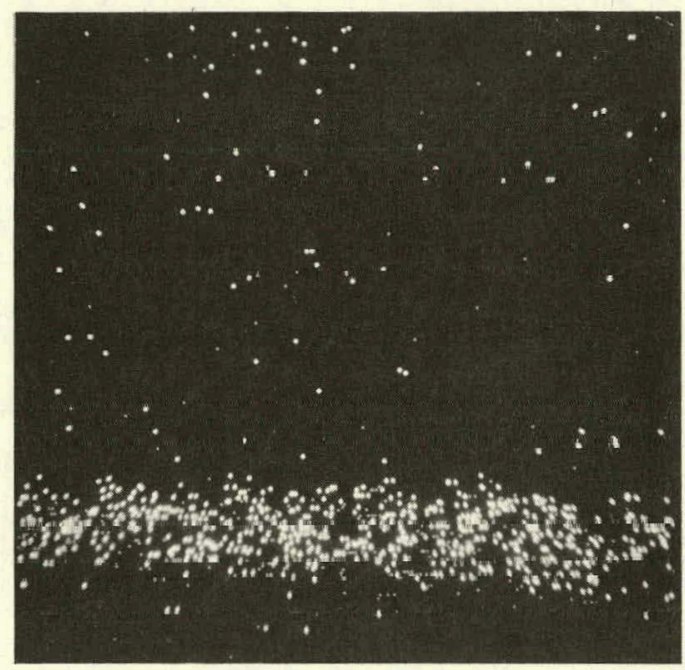

Cesium

Fig. 17

Part of a Deposit of CsI in the Upper Blanket Region of G-7. Mag. $\sim 500 X$. ANL Neg. No. $306-78-451$. 


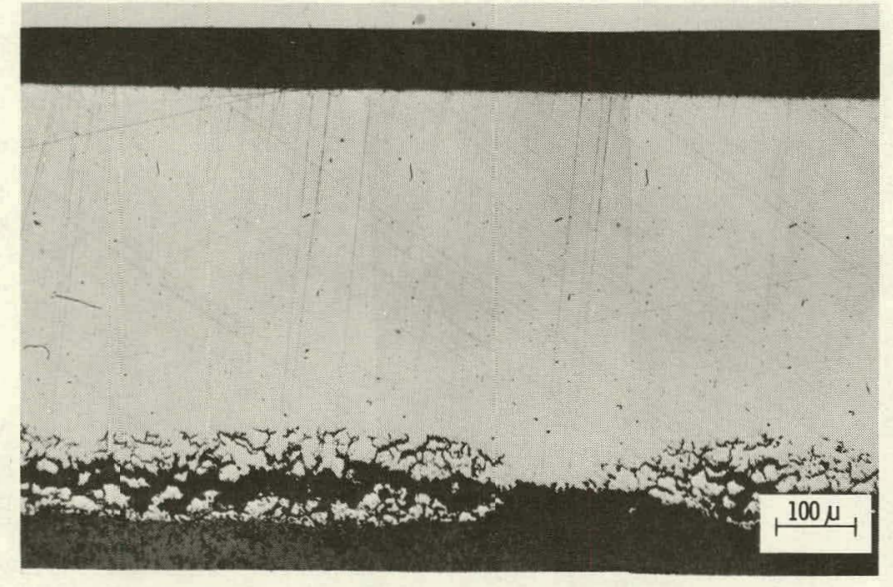

(a)

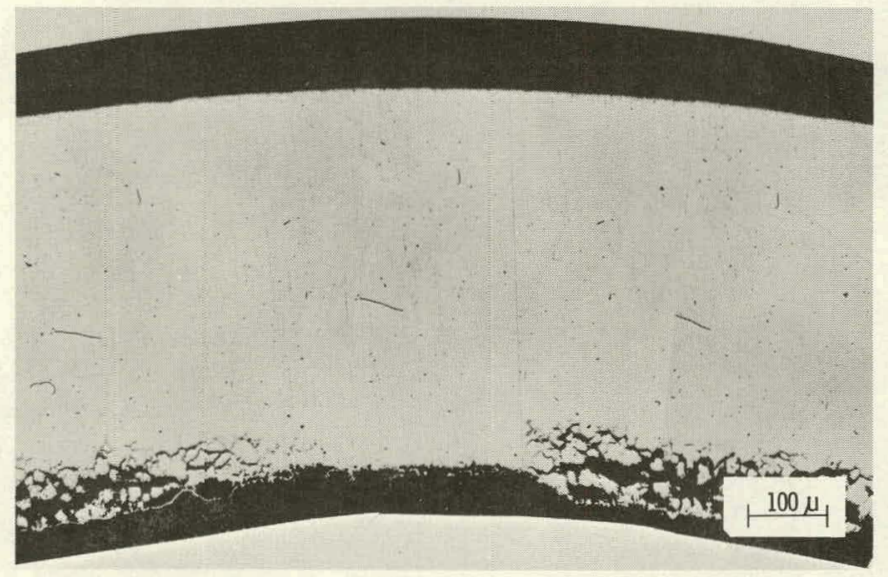

(c)

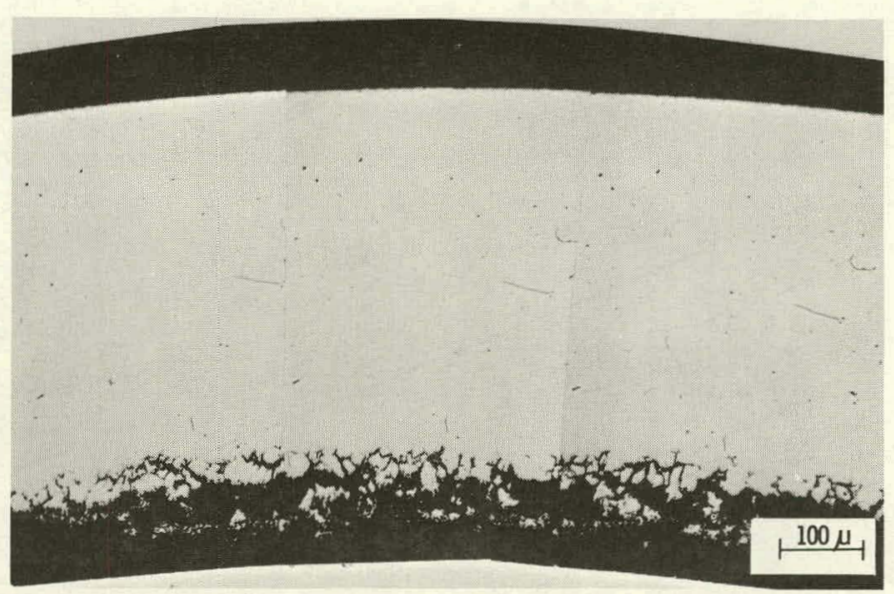

(b)

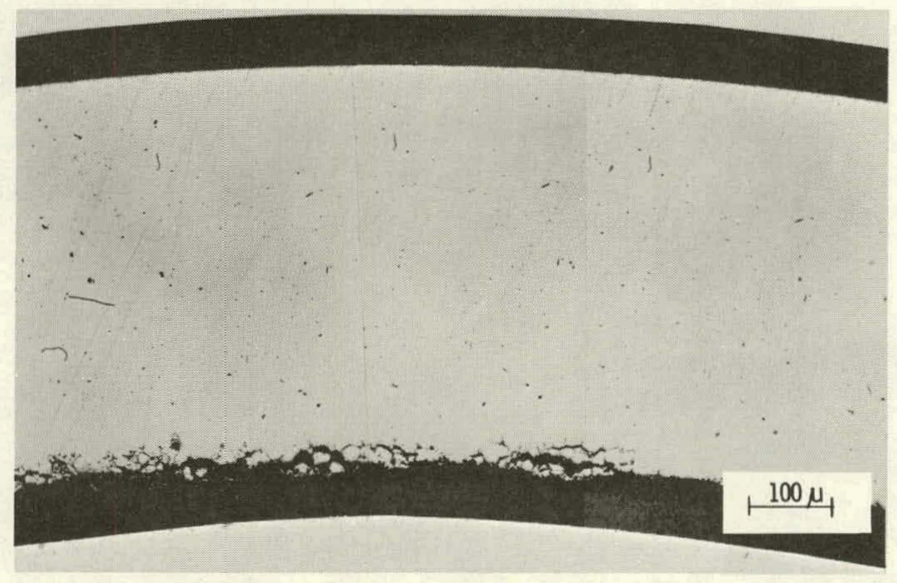

(d)

Fig. 48. Typical Fuel-Cladding Chemical Interaction in the Metallographic Sample from Fuel Pin G-1. (a) Top longitudinal section. (b) Transverse section 11.3 in. above core bottom. (c) Transverse section 6.75 in. a bove core bottom. (d) Transverse section 3.3 in. above core bottom. MSD Neg. No. 169258. 


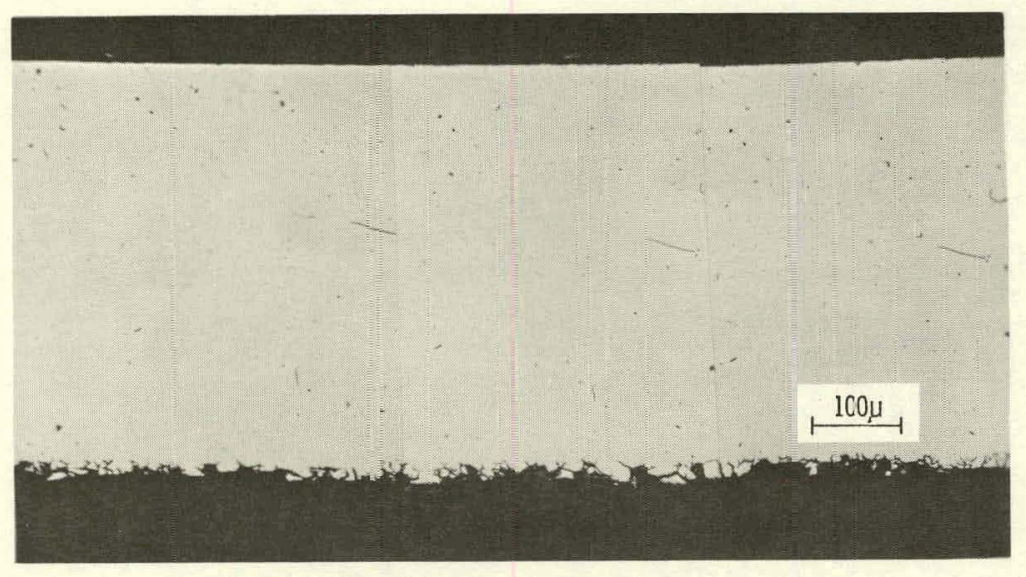

(a)

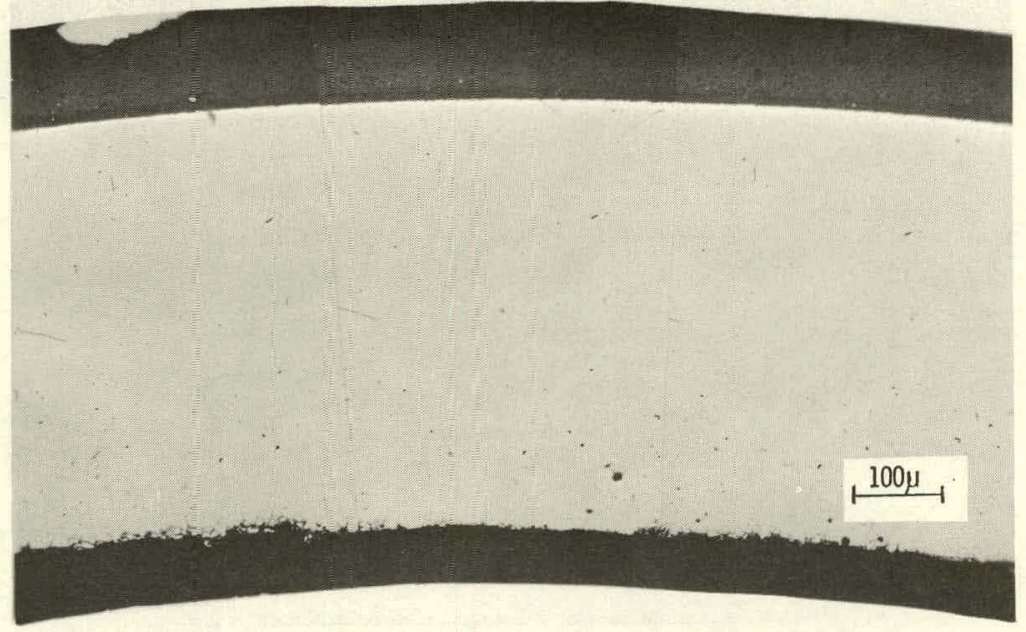

(b)

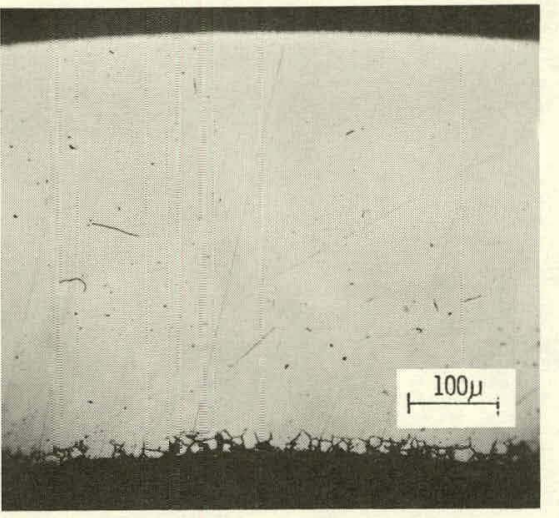

(d)

Fig. 49. Typical Fuel-Claciding Chemical Interaction in the Metallographic Sections from Fuel Pin G-2. (a) Top longitudinal section. (b) Transverse section 11-1/4 in. above ccre bottom. (c) Transverse section 6-3/4 in. above core bottom. (d) Transverse section 3-1/4 in. above core bottom. MSD Nes. No. 181707. 


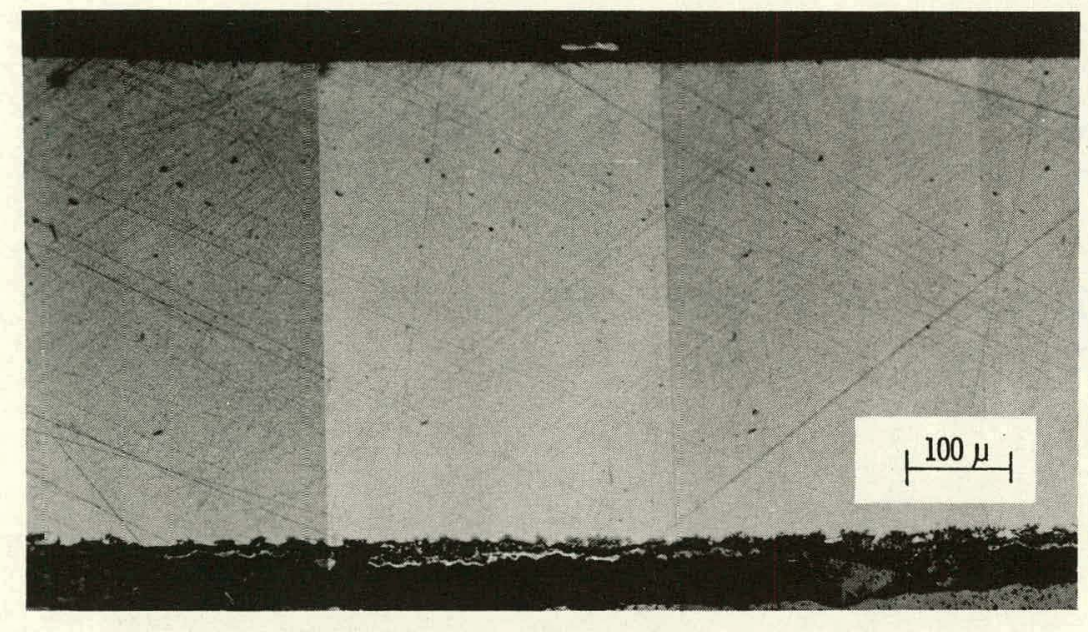

(a)

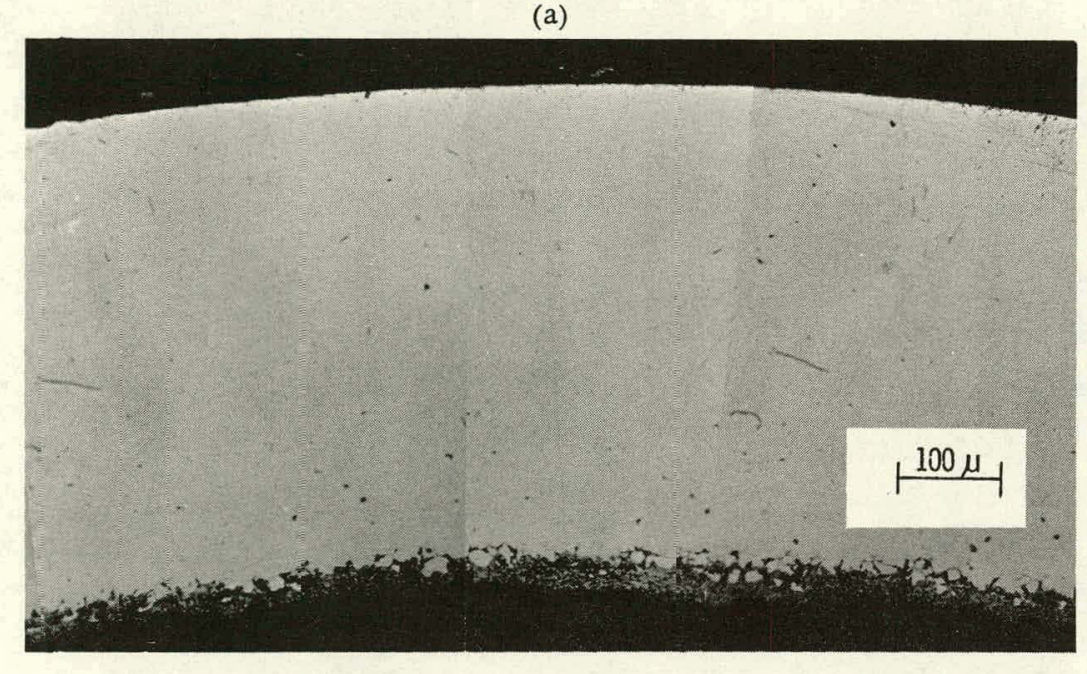

(c)

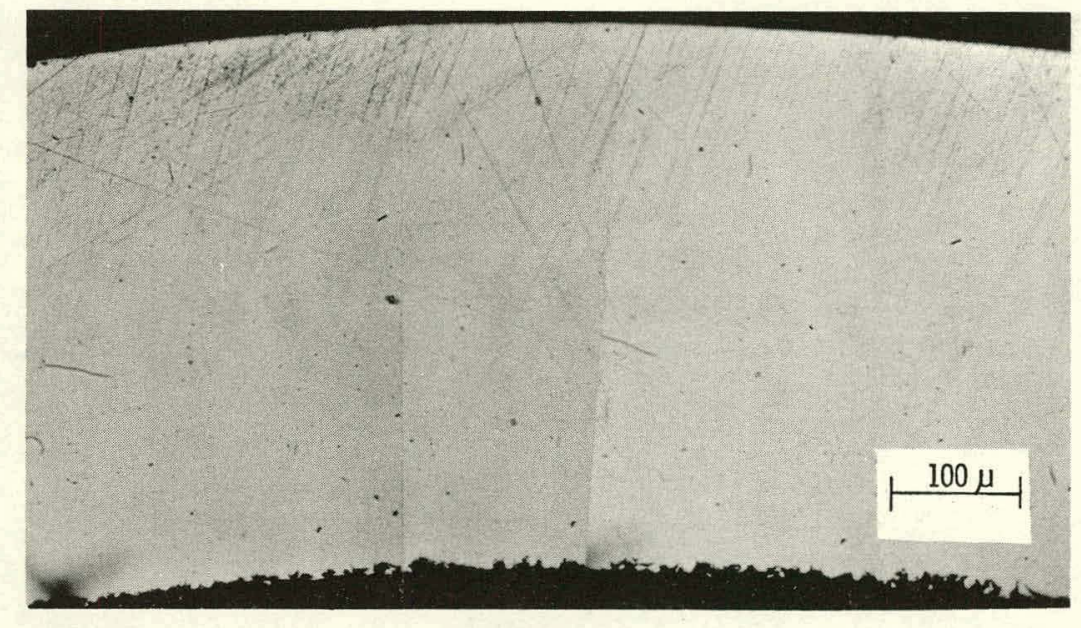

(b)

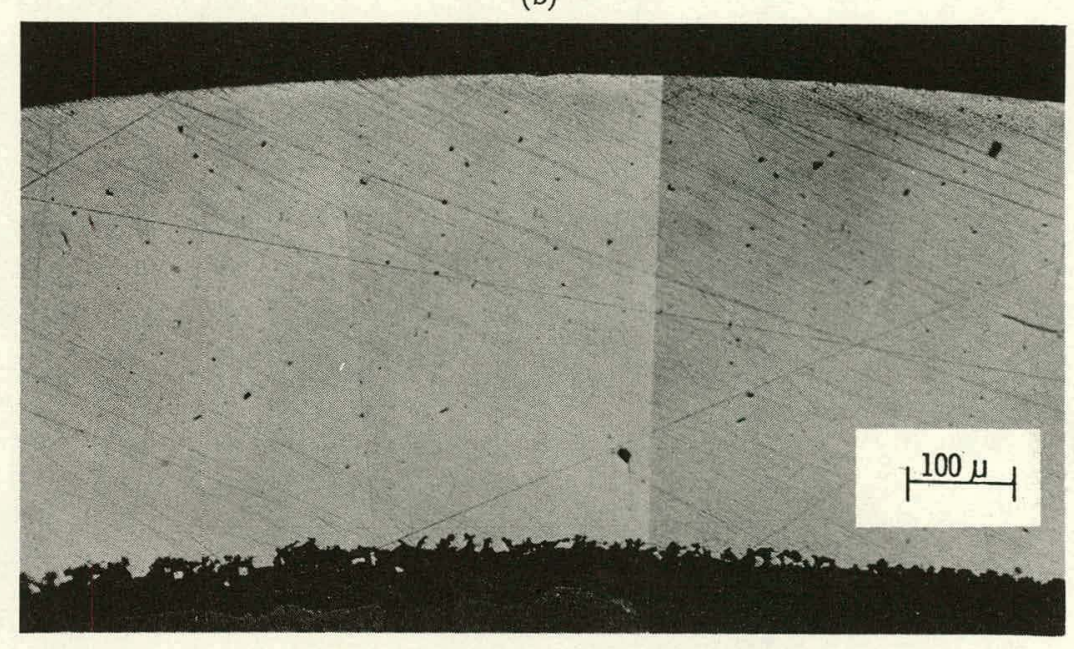

(d)

Fig. 50. Typical Fuel-Cladding Chemical Interaction in the Metallographic Sections from Fuel Pin G-6. (a) Top longitudinal section. (b) Transverse section 11.15 in. above core bottom. (c) Transverse section 6.75 in. above core bottom. (d) Transverse section 3.25 in. above core bottom. MSD Ne६. No. 169958. 


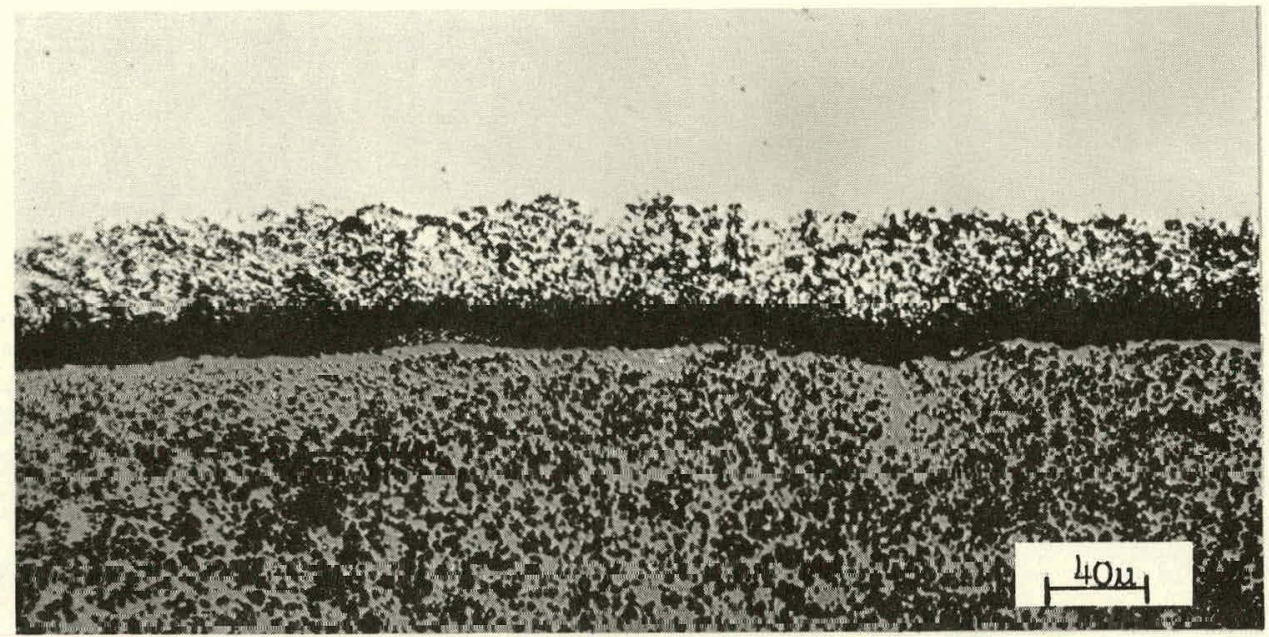

CLADDING

(a)

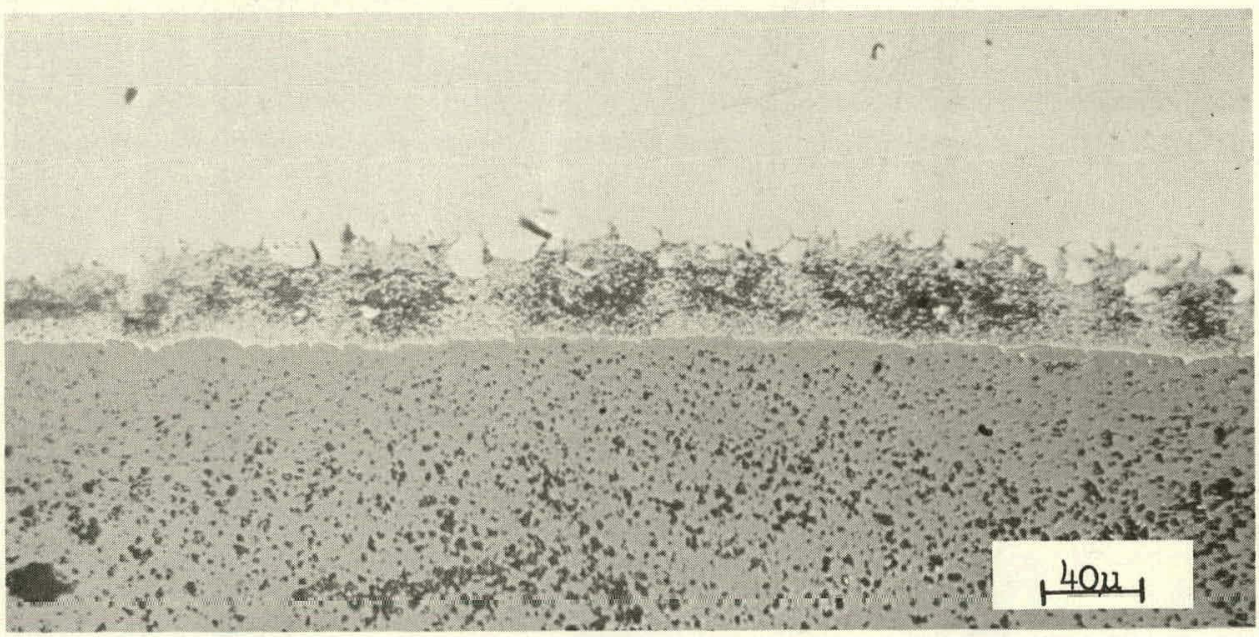

CLADDING

(b)

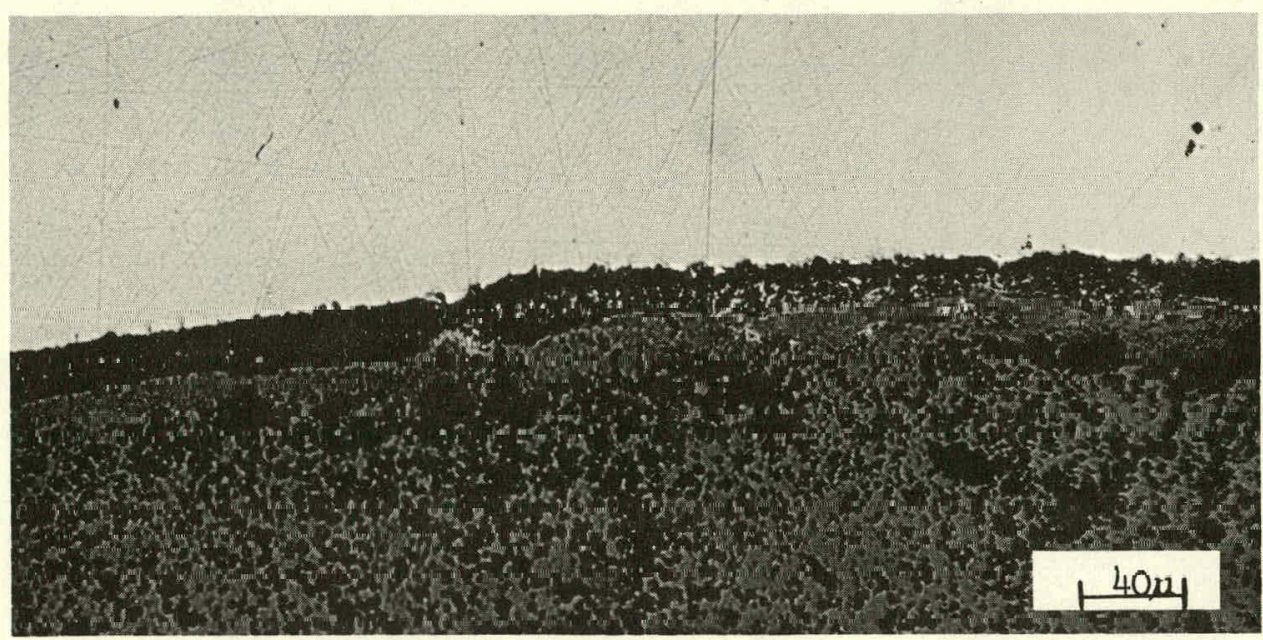

CLADDING

(c)

Fig. 51. Typical Fuel-Cladding Chemical Interaction in the Transverse Metallographic Sections from Fuel Pin G-7. (a) 11-1/4 in. above core bottom. MSD Neg. No. 182496. (b) 6-3/4 in. above core bottom. MSD Neg. No. 182493. (c) 3-1/4 in. above core bottom. MSD Neg. No. 182490. 
TABLE XI. Fuel-Cladding Chemical Interaction Data for GCFR F-1 Series Irradiation

\begin{tabular}{|c|c|c|c|c|c|c|}
\hline $\begin{array}{l}\text { Fuel } \\
\text { Pins }\end{array}$ & $\begin{array}{c}\text { Axial } \\
\text { Position }\end{array}$ & $\begin{array}{c}\text { Estimated } \\
\text { Burnup, } \\
\text { at. } \%\end{array}$ & $\mathrm{O} / \mathrm{M}$ & $\begin{array}{c}\text { Time-averaged } \\
\text { Cladding ID } \\
\text { Temperature, } \\
{ }^{\circ} \mathrm{C}\end{array}$ & $\begin{array}{l}\text { Maximum } \\
\text { Depth of } \\
\text { Attack } \\
\text { mils }\end{array}$ & Comments ${ }^{a}$ \\
\hline G-3 & Midplane & 2.7 & 1.99 & 680 & 0.3 & Uniform; Matrix \\
\hline$G-3$ & Top & 2.4 & 1.99 & 680 & 0.3 & Uniform; Matrix \\
\hline G-1 & Midplane & 5.6 & 1.99 & 735 & 2.5 & Nonuniform; Combination \\
\hline G-1 & Top & 4.9 & 1.99 & 735 & 2.6 & Nonuniform; Combination \\
\hline G-2 & Midplane & 5.4 & 1.97 & 720 & 1.0 & Nonuniform; Intergranular \\
\hline$G-2$ & Top & 4.7 & 1.97 & 720 & 1.2 & Nonuniform; Intergranular \\
\hline G-6 & Midplane & 4.9 & 1.97 & 660 & 0.6 & Uniform; Intergranular \\
\hline$G-6$ & Top & 4.2 & 1.97 & 660 & 1.0 & Uniform; Intergranular \\
\hline G-7 & Midplane & - & 1.98 & 615 & 1.0 & Nonuniform; Intergranular \\
\hline $\mathrm{G}-7$ & $11 \frac{1}{4}$ in. ${ }^{b}$ & - & 1.98 & 625 & 1.3 & Nonuniform; Intergranular \\
\hline
\end{tabular}

${ }^{a}$ Uniform or nonuniform refers to the variation or lack of variation in the depth attack around the circumference of the interface. Matrix, intergranular, or combination refers to the nature of the attack. Combination means the attack exhibited both matrix and intergranular types of attack.

${ }^{b}$ Distance above core bottom.

The $x$-ray images from two regions of the deepest FCCI from G-1 are shown in Figs. 52 and 53. These results show a depletion of Fe and $\mathrm{Ni}$ and an enhancement of $\mathrm{Cr}, \mathrm{Mn}$, and $\mathrm{Cs}$ in the FCCI zone. Trace amounts of $I$ and Te were also observed in the attack zone. No Mo was found in this zone, which is unusual when compared with previous postirradiation results. The FCCI in this section appears to be intergranular at its leading edge, but entire grains (matrix attack) near the fuel-cladding interface have been consumed or lost during sample preparation.

The $x$-ray images and line scans of the FCCI zone from near the midplane of G-6 (Figs. 54 and 55) were representative of the deepest attack observed in G-6. These results indicate that Fe, Ni, and $\mathrm{Cr}$ were depleted in the FCCI zone but Cr was greatly enhanced near the fuel-cladding interface and $\mathrm{Cs}$ and Mo were enhanced in the FCCI zone. No I or Te was observed in the attacked zone of G-6, but this examination was performed on the shielded microprobe, which has higher limits of detection than the microprobe used on the sample from G-1. Therefore, the small quantities of I and Te detected in G-1 may have been undetectable in G-6. The FCCI in G-6 was primarily intergranular but grains were also partially consumed near the fuel-cladding interface.

(e) Cladding Microstructure

The microstructures of the cladding in the transverse sections $\left(3 \frac{1}{4}, 6 \frac{3}{4}\right.$, and $11 \frac{1}{4} \mathrm{in}$. above reactor core bottom) were examined by electroetching the cladding using either $5 \% \mathrm{HCl}$ in methanol or $10 \%$ oxalic acid in water. When these etchants are used, the characteristics of the microstructures developed for a specimen are similar in appearance, except thal the oxalic acid attacks the carbides and intermetallic phase, whereas the $\mathrm{HCl}$ attacks the chromium-depleted regions surrounding the precipitates but does not attack the precipitates. In structures where the precipitates are fine, the appearance after etching is the same for both etchants. 


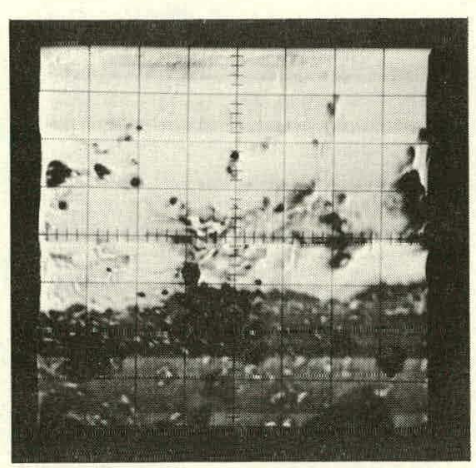

a Sample Current

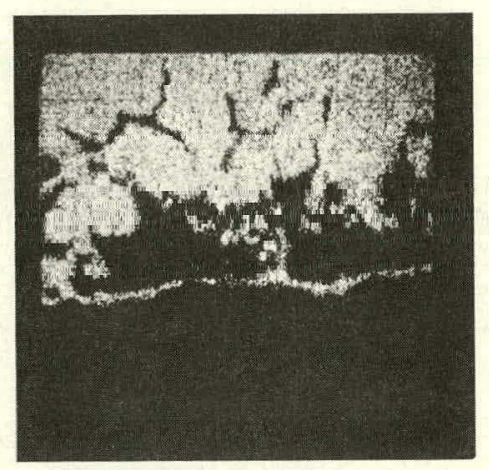

d. Iron

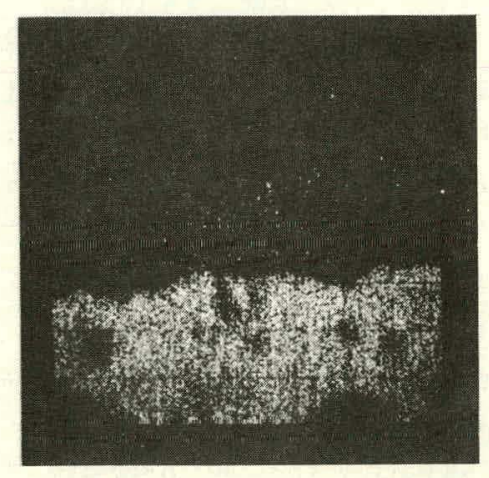

g. Uranium-Plulunium

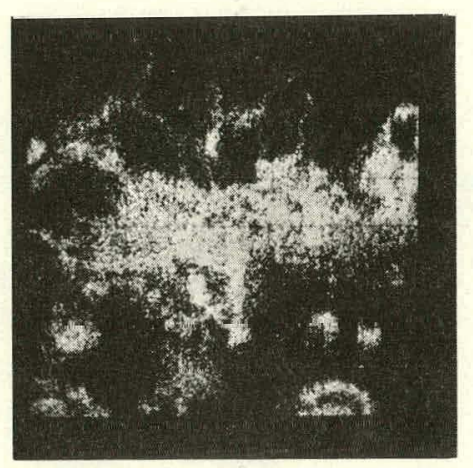

b. Cesium

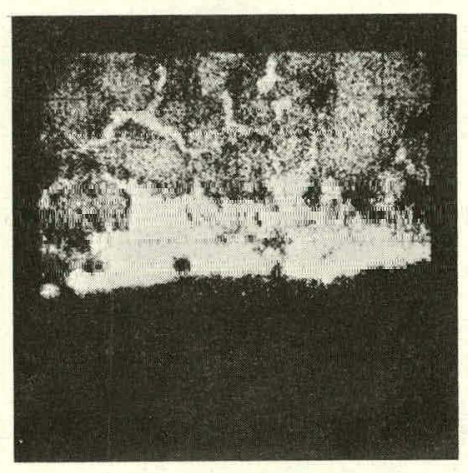

e. Chromium

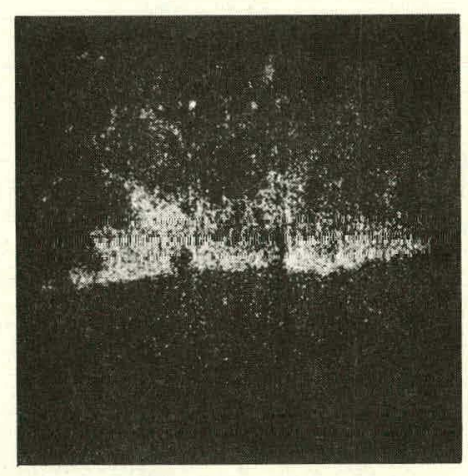

h. Manganese

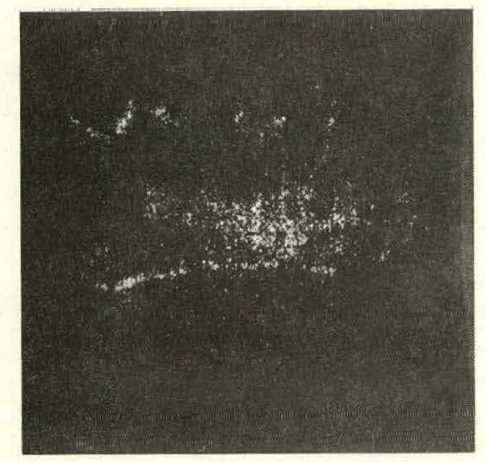

c. Télluı ium

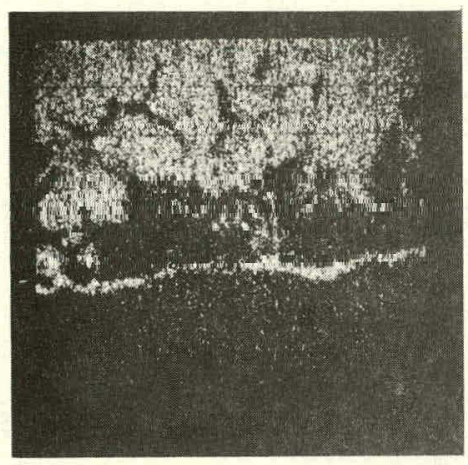

f. Nickel

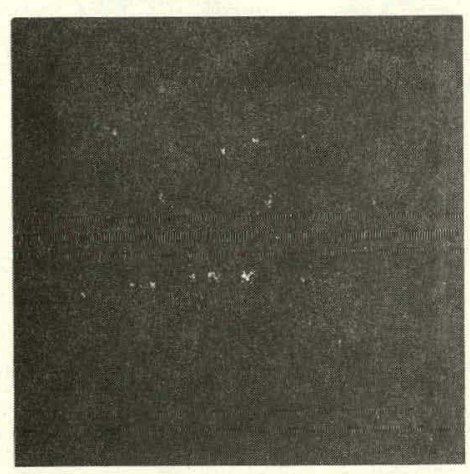

i. Iodine

Fig. 52. Electron-microprobe Scanning Images of GA Fuel Pin G-1 at Core Midplane. All images $190 \mu \mathrm{m}^{2}$. ANL Neg. No. 308-3866. 


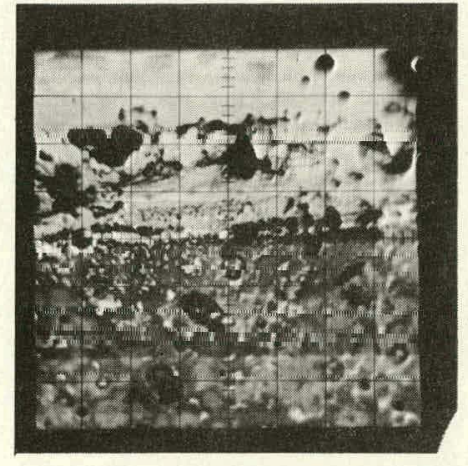

a. Sample Current

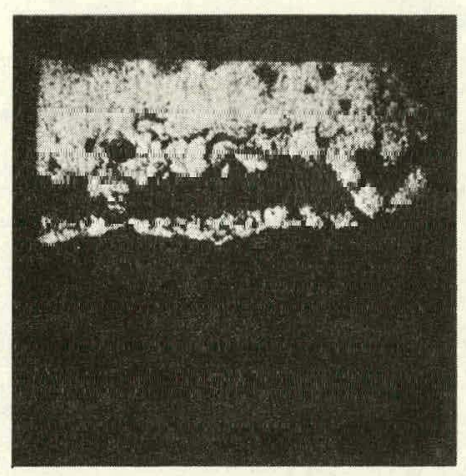

d. Iron

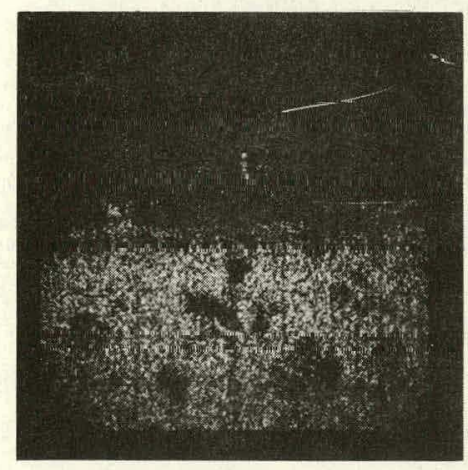

g. Uranium-Pluttonium

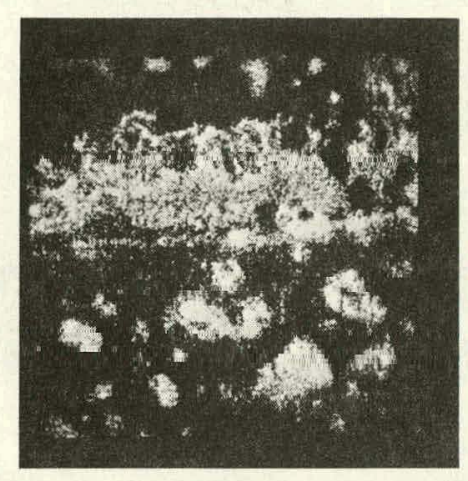

b. Cesium

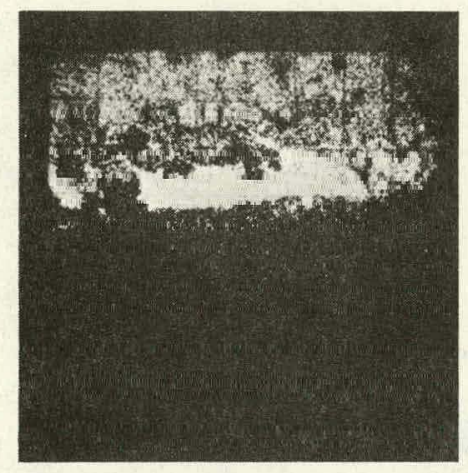

e. Chromium

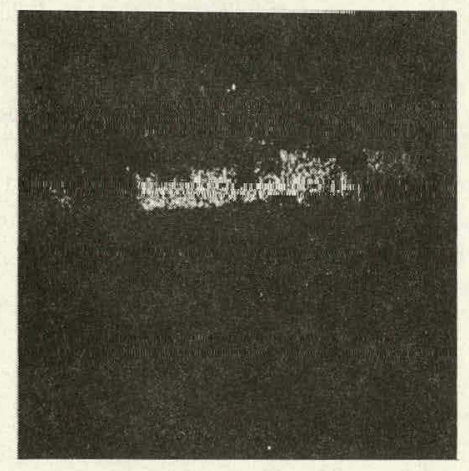

h. Manganese

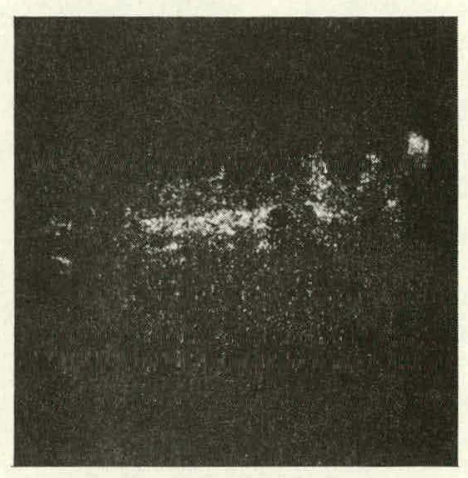

c. Tellurium

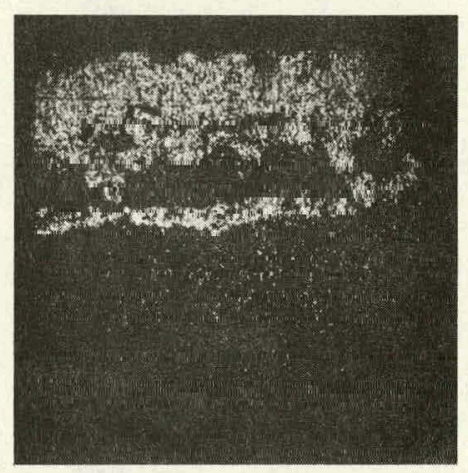

f. Nickel

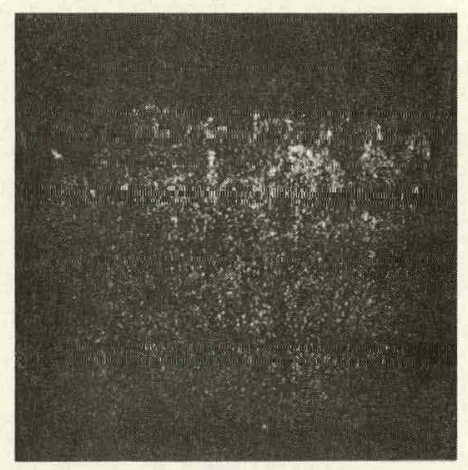

i. Iodine

Fig. 53. Electron-micrnprnhe Scanning Images of GA Fuel Pin G-1 from a Second Location on the Sample. All images $190 \mu \mathrm{m}^{2}$. ANL Neg. No. $308-3862$. 


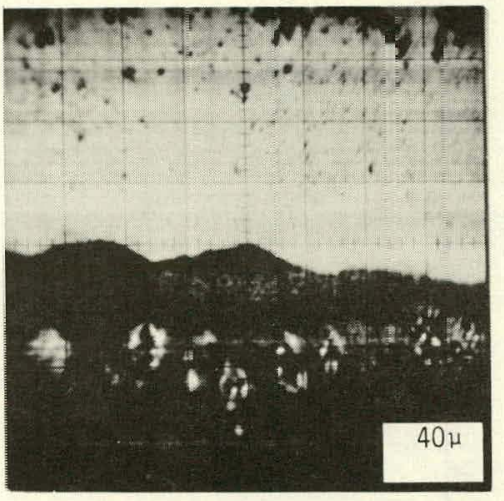

SPECIMEN CURRENT

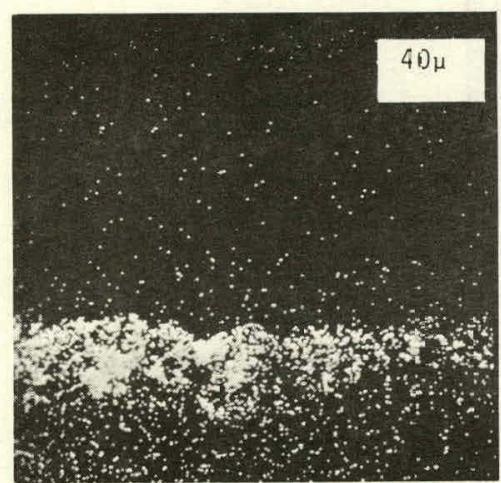

MOLYBENUM

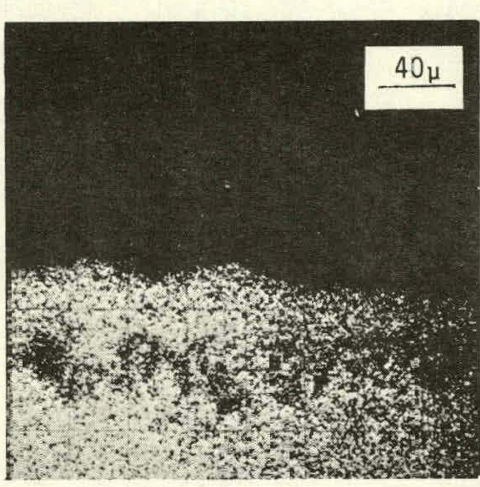

IRON

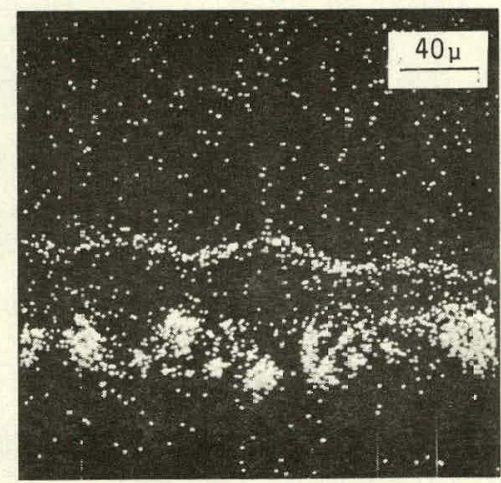

CESIUM.

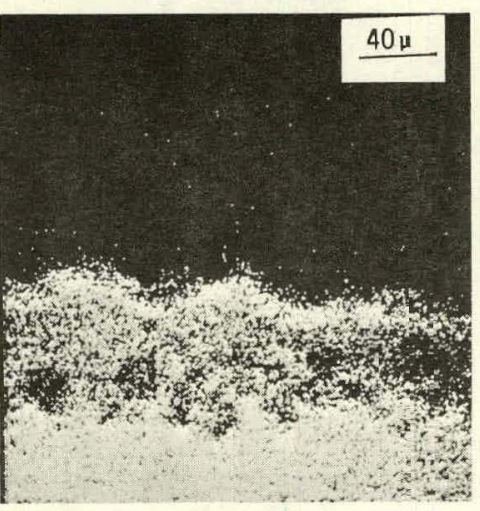

CHROMIUM

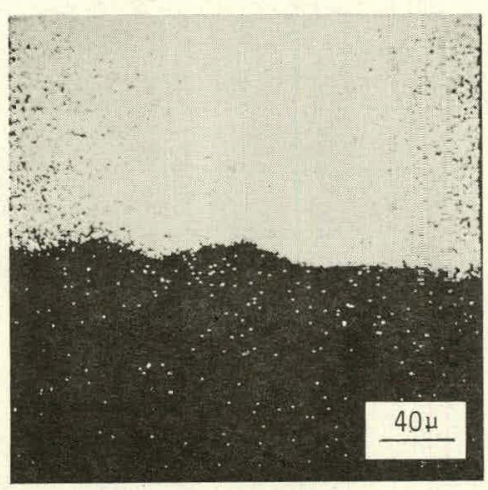

URANIUM

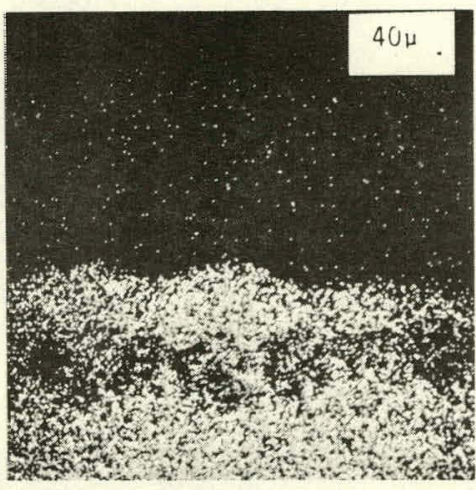

NICKEL

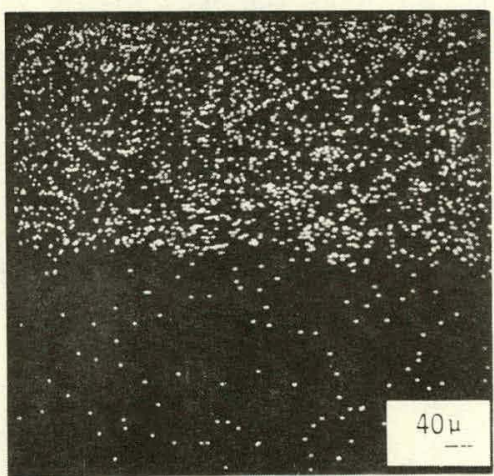

PLUTONIUM

Fig. 54. Electron-microprobe Scanning Images of Typical FCCI at Core Midplane of G-6. MSL Neg. No. 181578. 


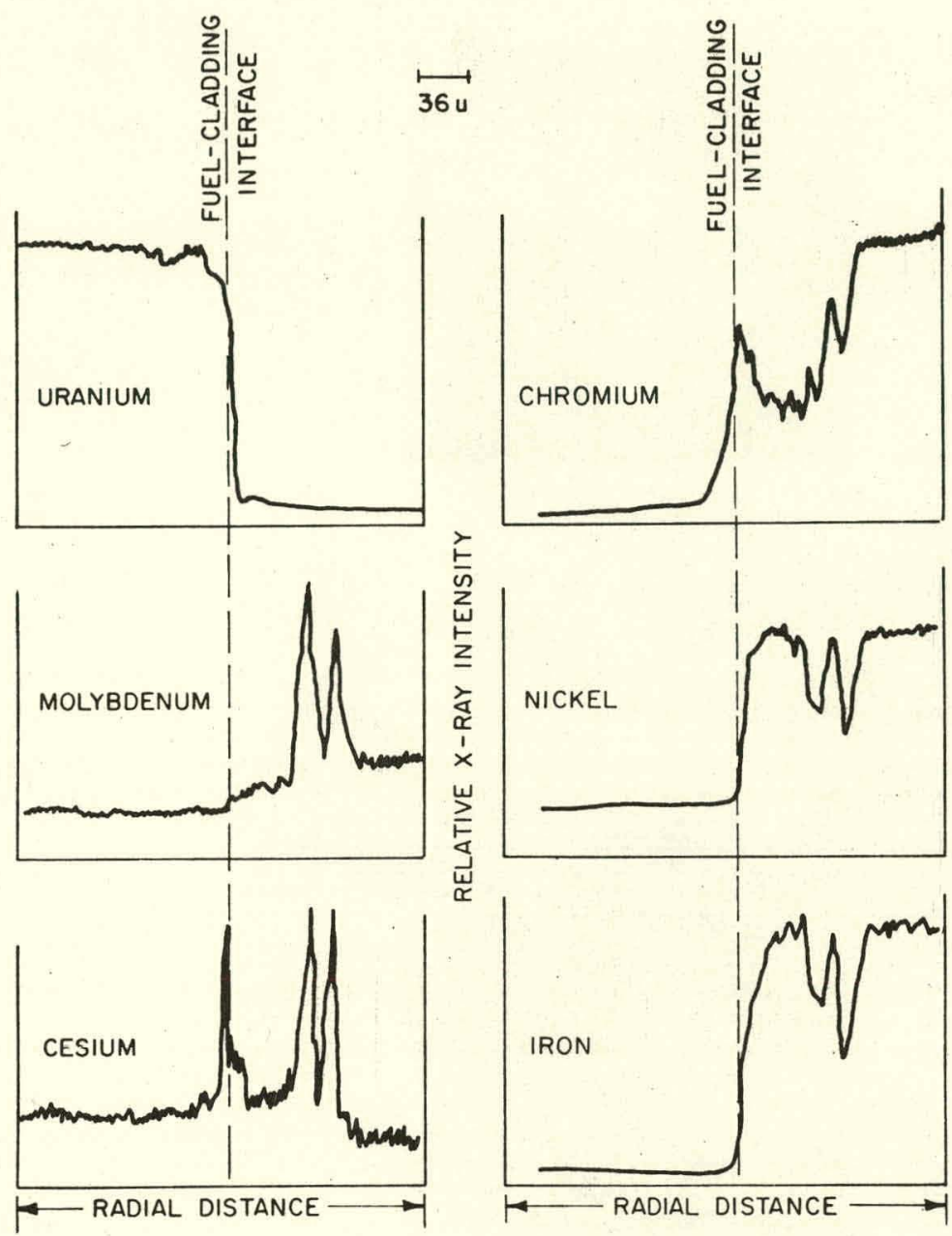

Fig. 55

Line Scans of FCCI at Core Midplane of G-6. MSD Neg. No. 63992 .

The microstructures typical of each of the transverse sections from G-1 and G-6 are shown in Figs. 56 through 61. None of the samples showed evidence of circumferential variations in the microstructures. Significant differences existed in the microstructure from specimen to specimen from a fuel pin and from pin to pin, as would be expected from the axial temperature gradients and pin-to-pin temperature differences. The most striking microstructures were observed in the cladding from the high-temperature regions of pin G-1. Fairly large intermetallic precipitates were present near the ID and midwall of the cladding in the sections $6 \frac{3}{4}$ and $11 \frac{1}{4} \mathrm{in}$. above the core bottom. The presence of intermetallic precipitates in G- 1 are in agreement with the calculated operating temperatures for the cladding and with annealing studies that have been performed on archive tubing. The microstructures in the remaining specimens indicate that the cladding has been sensitized (carbide precipitates on the grain and twin boundaries). The precipitates in the section from G-2 are fairly coarse, indicating that the carbide precipitates have agglomerated. Additional comments on the microstructure of the cladding are included in Sec. II.E. 


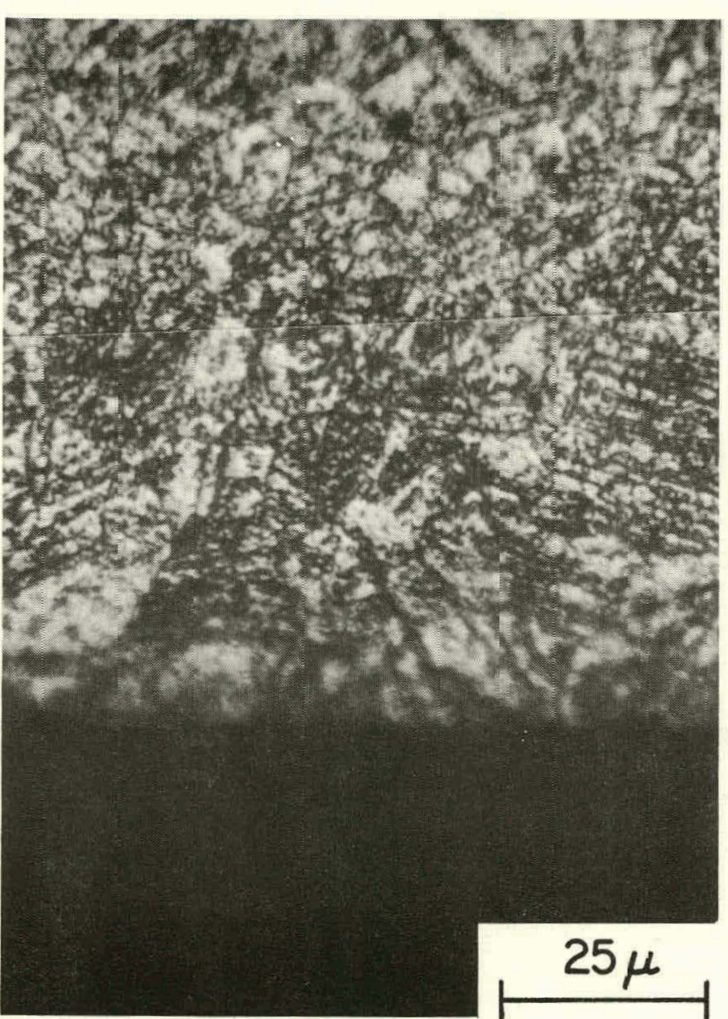

(a)

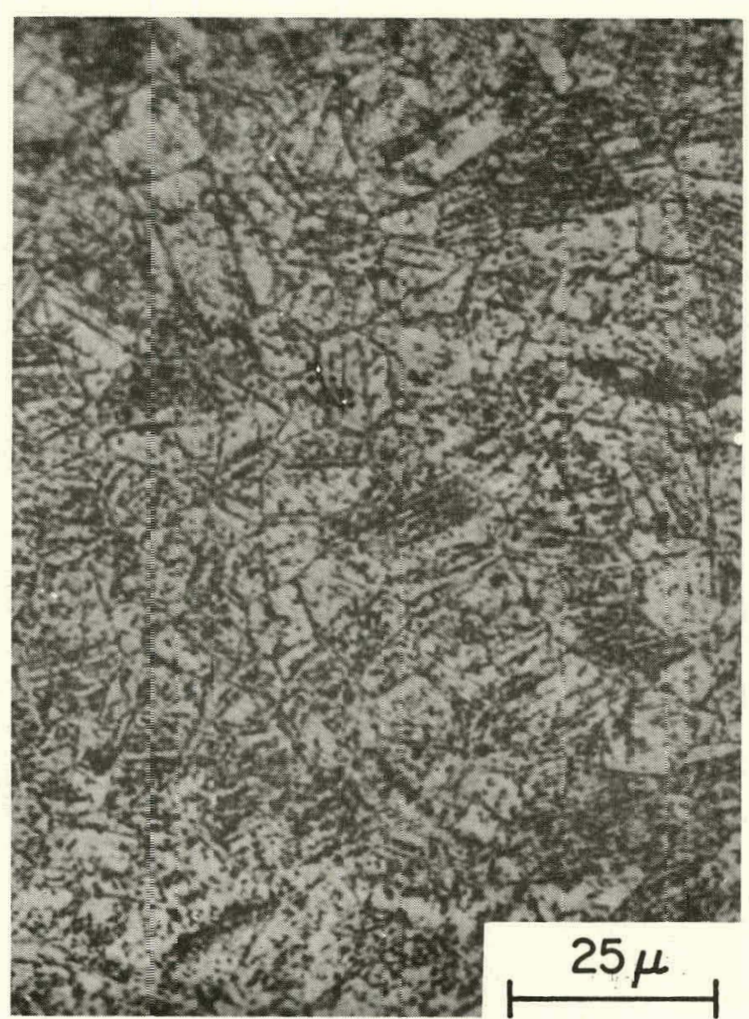

(b)

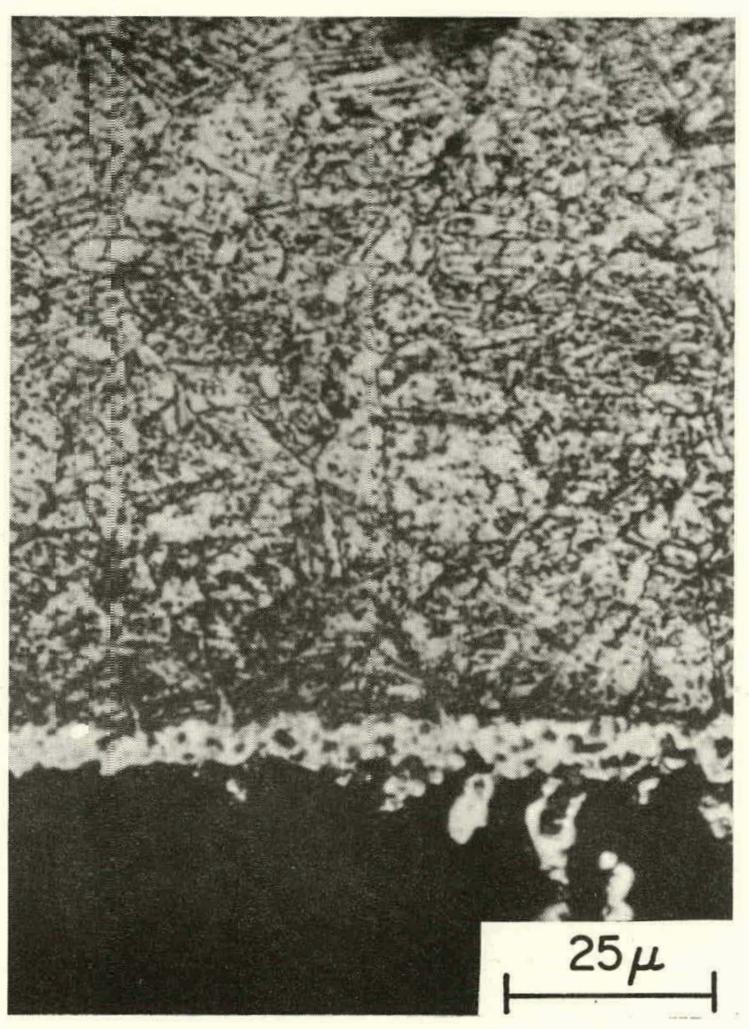

(c)

Fig. 56. Cladding Microstructure 3.3 in. above the Bottcm of Core in G-1. Sample was electroetcted in $5 \%$ : $1 C 1$ in methanol. (a) Cladding OD. MSD Neg. No. 169152. (b) Claddirg midwall. MSD Neg. No. 169149. (c) Cladding ID. MSD Neg. No. 169148. 


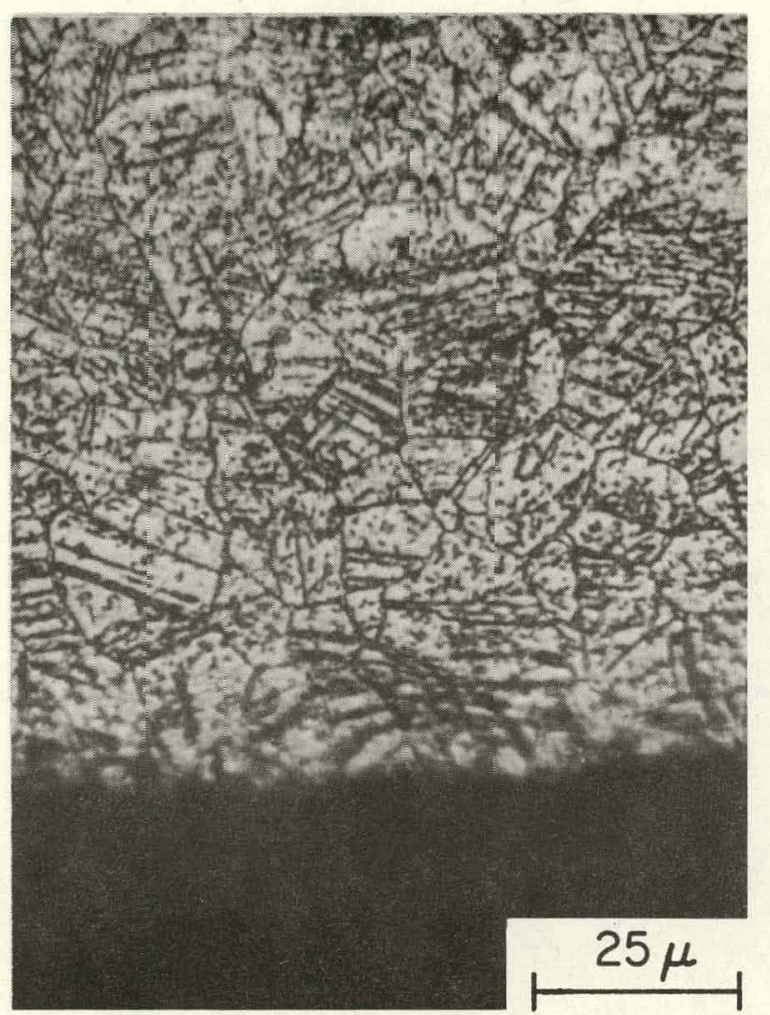

(a)

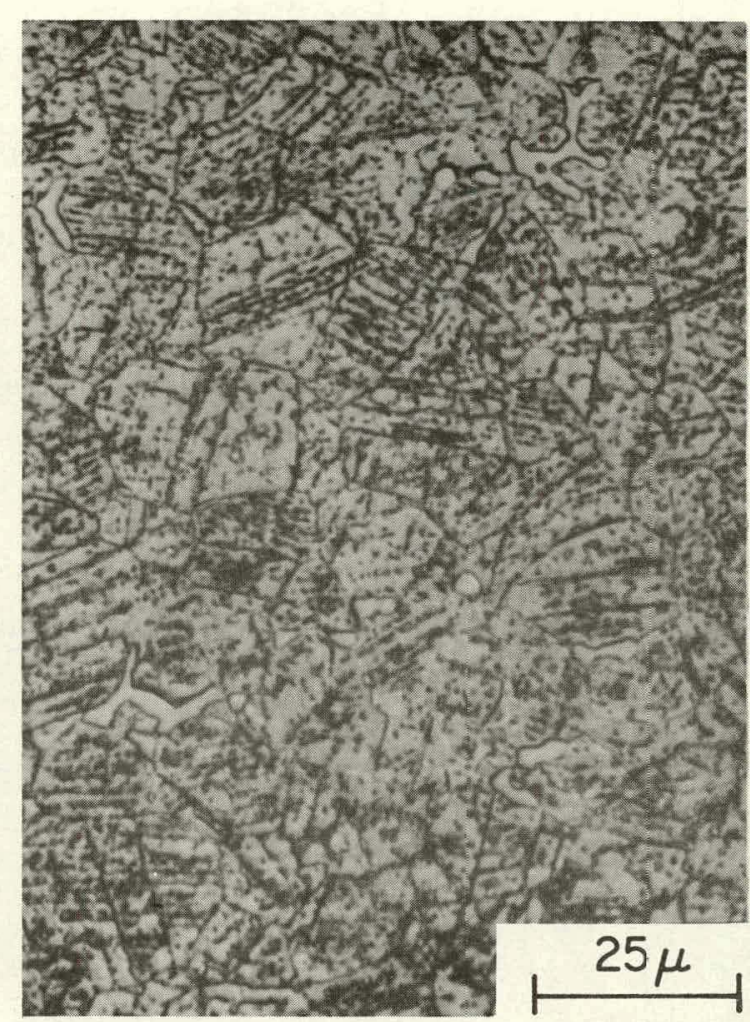

(b)

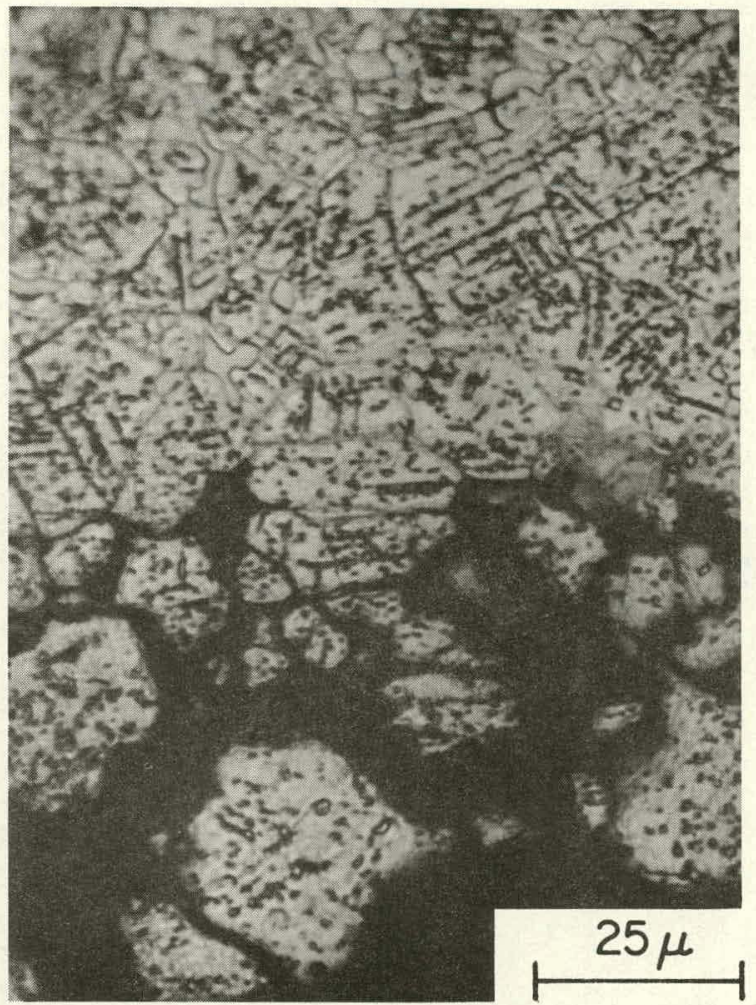

(c)

Fig. 57. Cladding Microstructure 6.75 in. above the Bottom of Fuel Column G-1. Sample was electroetched in $5 \% \mathrm{HCl}$ in methanol. (a) Cladding OD. MSD Neg. No. 16Э158. (b) Cladding midwall. MSD Neg. No. 169156. (c) Cladding ID. MSD Neg. No. 169153. 


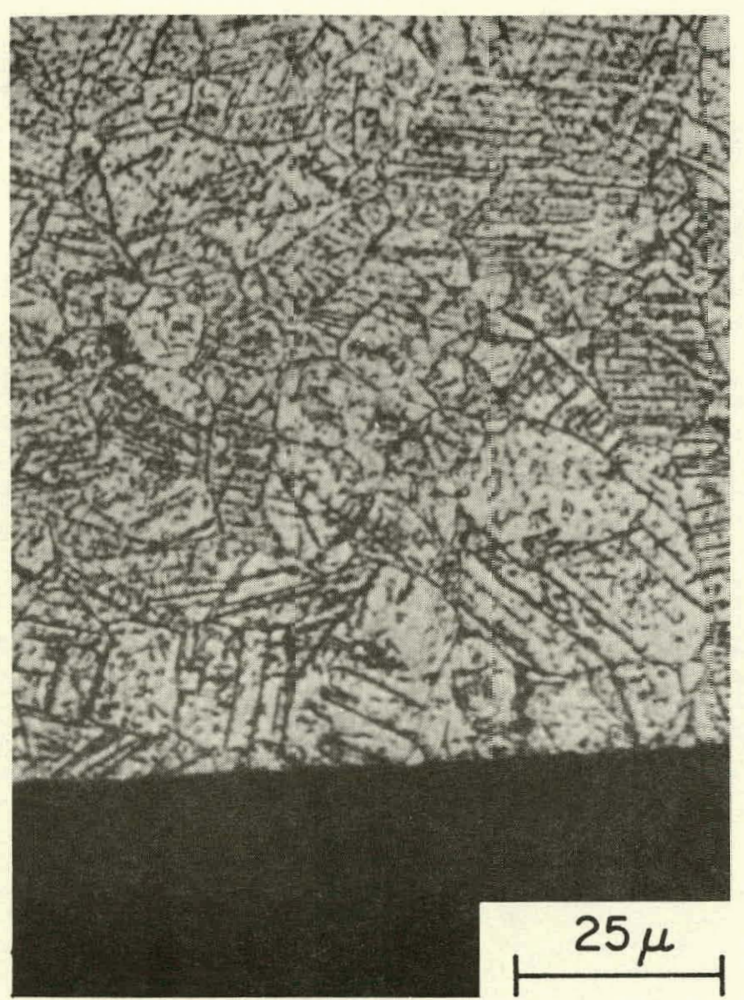

(a)

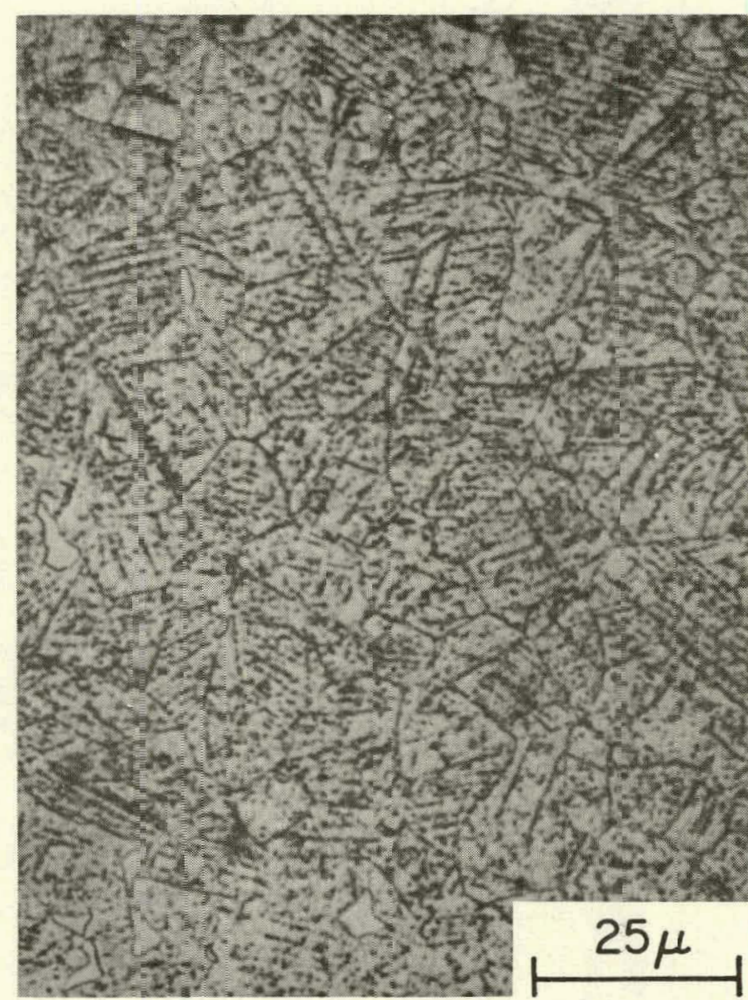

(b)

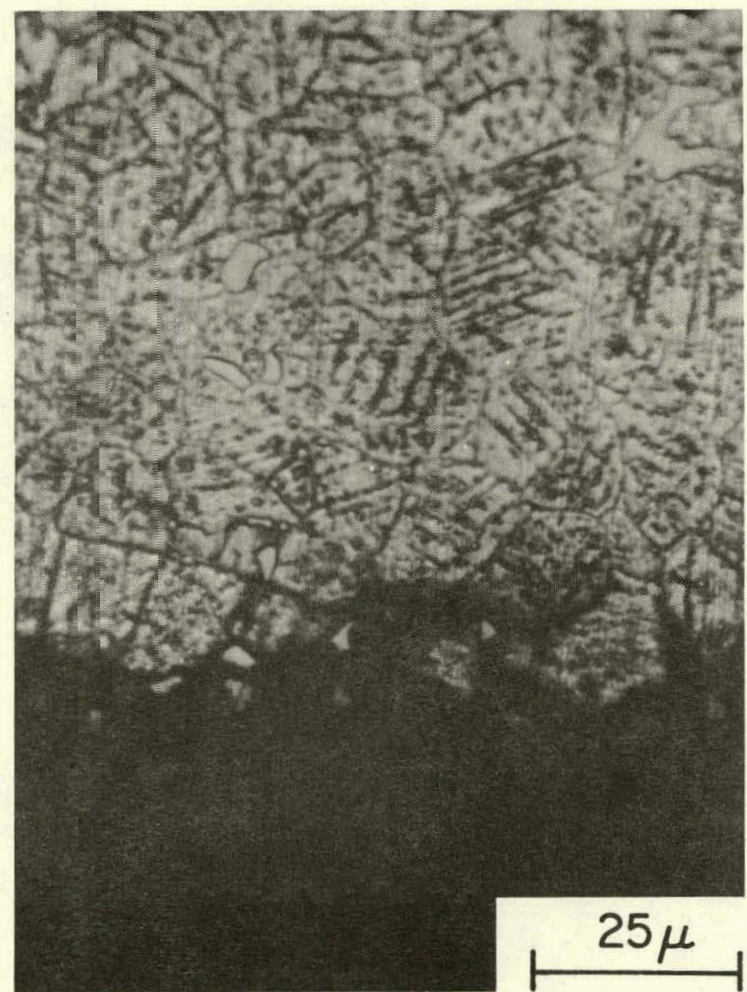

(c)

Fig. 58. Cladding Microstructure 11.3 in. above the Bottom of Fuel Column G-1. Sample was electrcetched in $5 \%$ HCl in methanol. (a) Cladding OD. MSD Neg. No. 169-64. (b) Cladding midwall. MSD Neg. No. 169161. (c) Cladding ID. MSD Neg. No. 169159. 


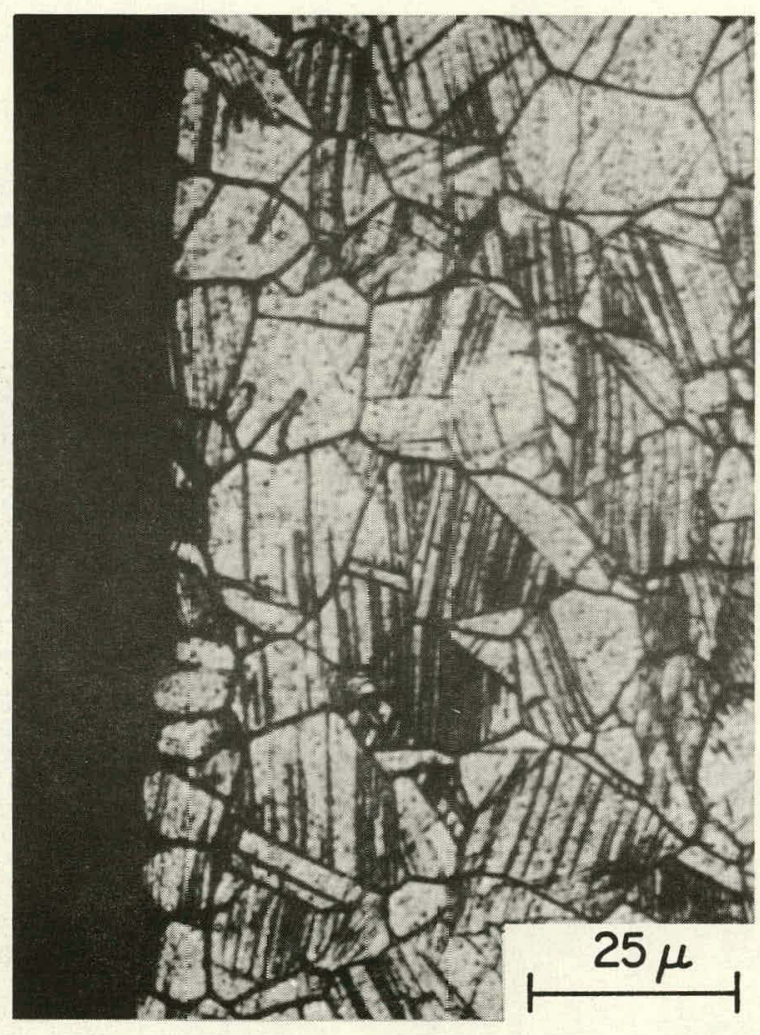

(a)

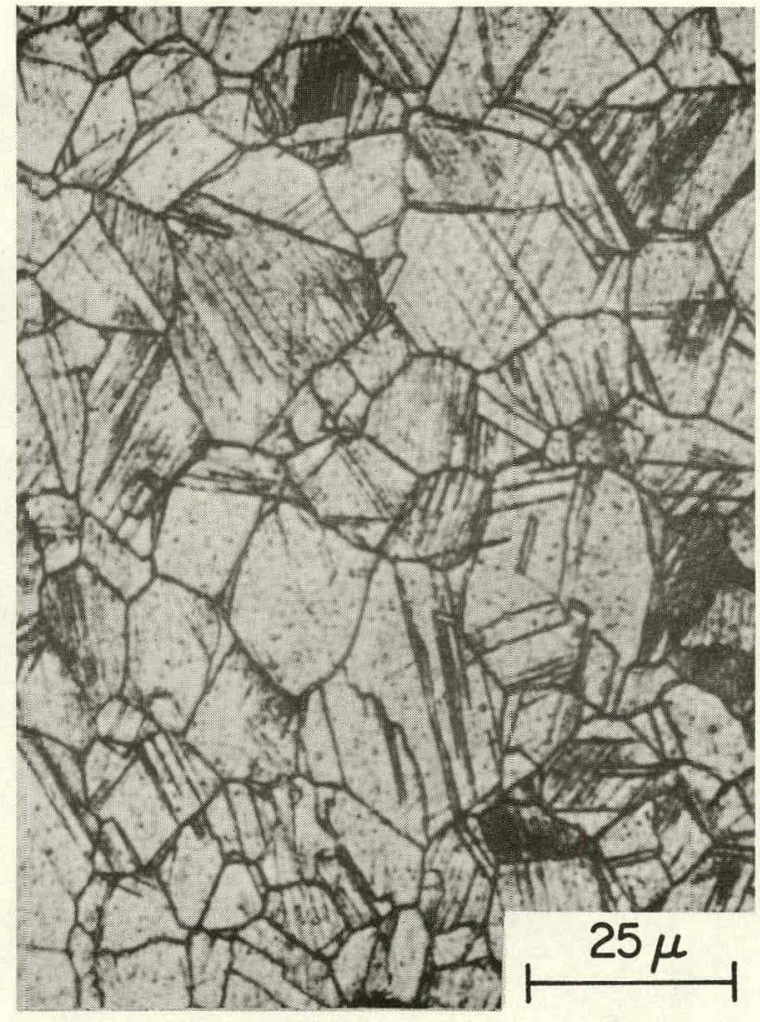

(b)

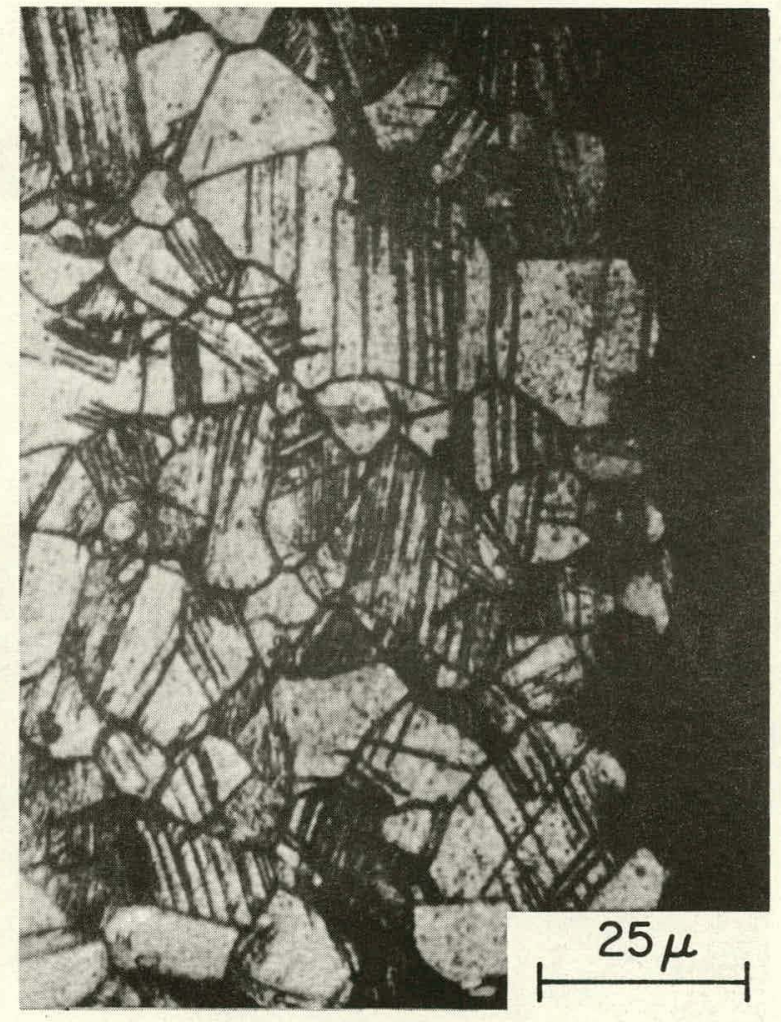

(c)

Fig. 59. Cladding M:crostructure 3.25 in. above the Bottom of Core in G-6. Sample was electroetched in 5\% $\mathrm{HCl}$ in methanol. (a) Cladding OD. MSD Neg. No. 169738. (b) Cladding midwall. MSD Neg. No. 169736. (c) Cladding ID. MSD Neg. No. 169734. 


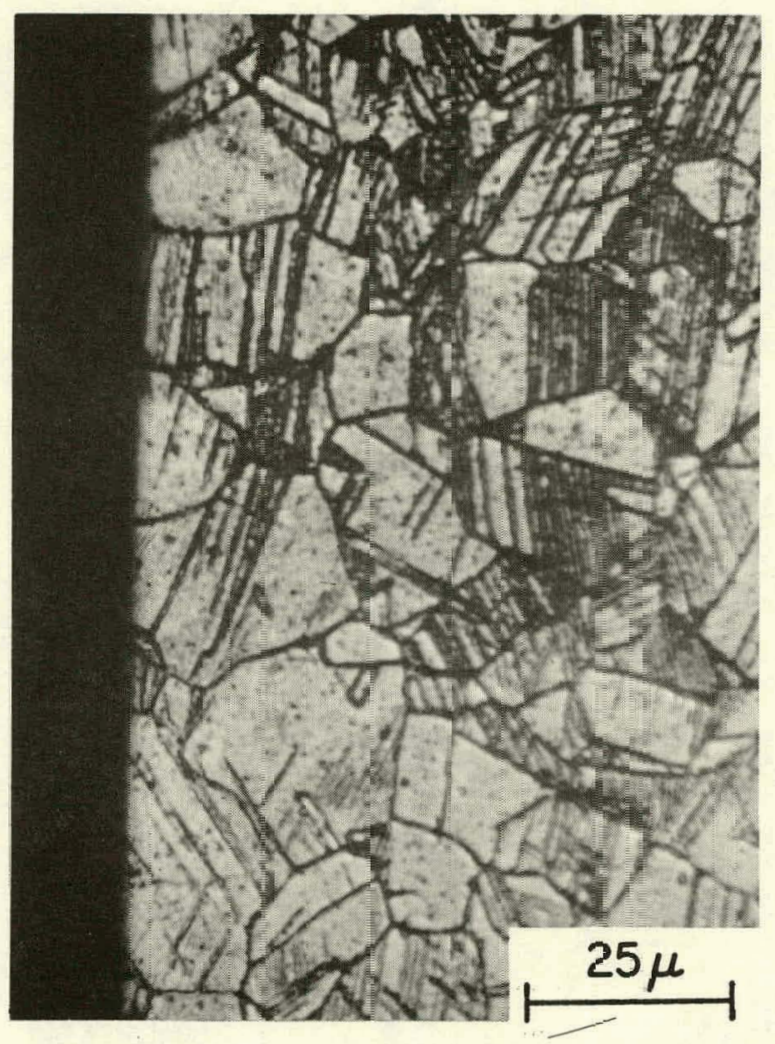

(a)

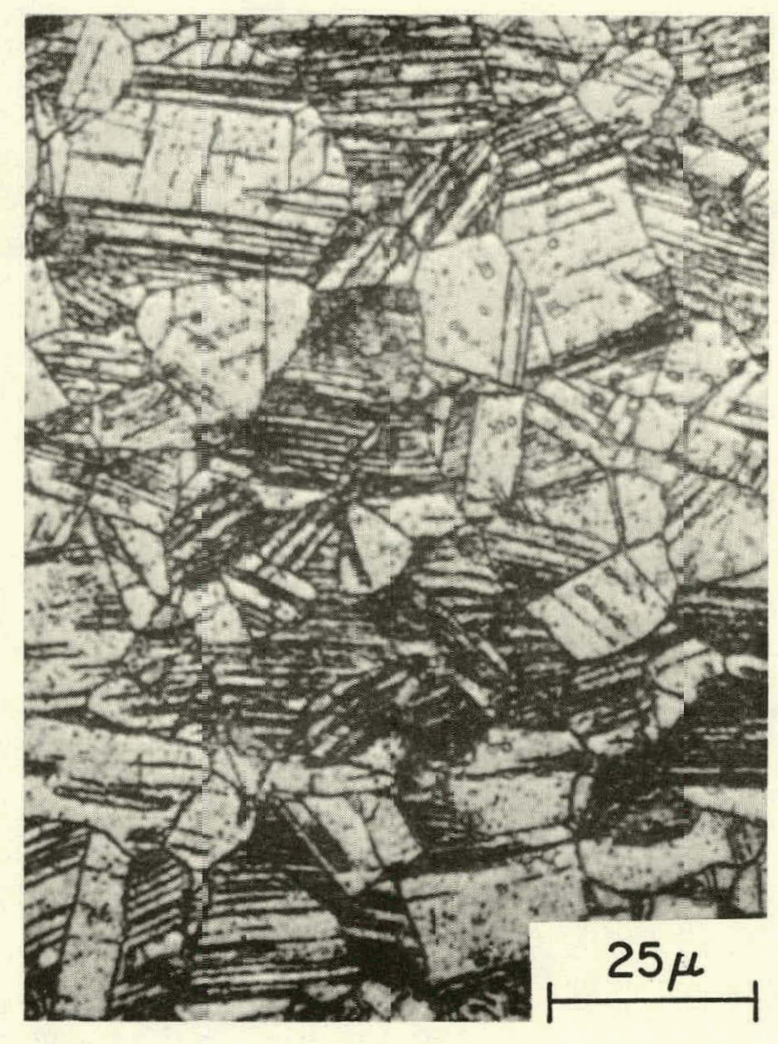

(b)

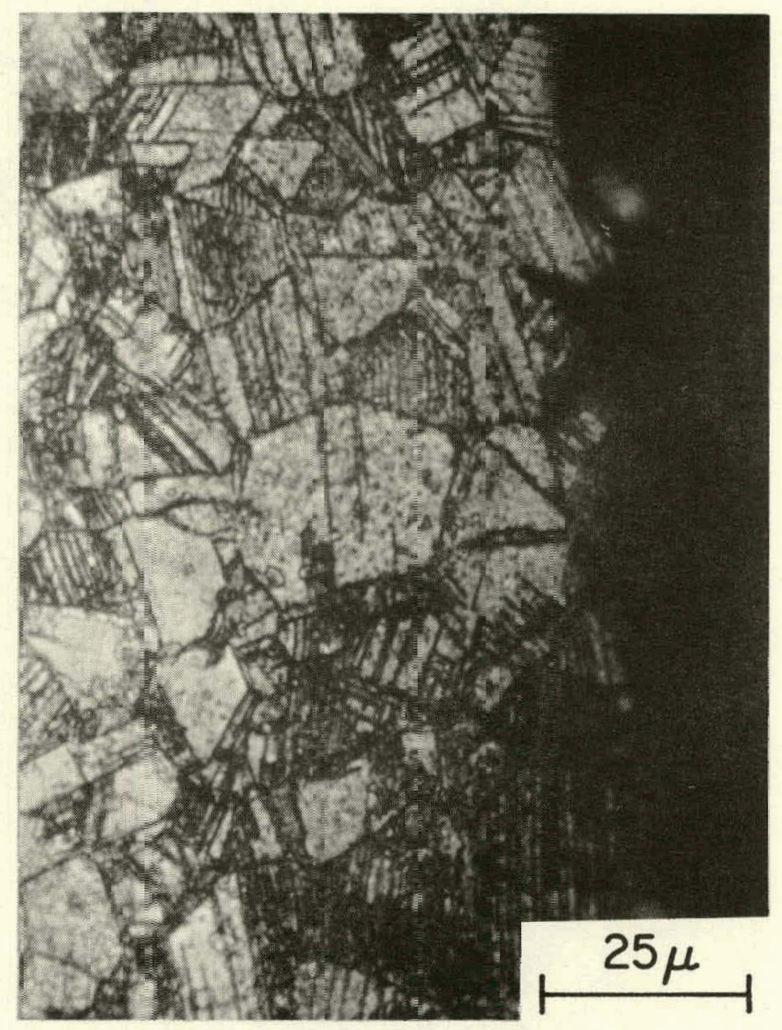

(c)

Fig. 60. Cladding Microstructure 6.75 in. above the Bottom of Core in G-6. Sample was electroetched in 5\% Hב1 in methanol. (a) Cledding OD. MSD Neg. No. 169758. (b) Cladding midwall. MSD Neg. No. 169756. (c) Cladding ID. MSD Nəg. No. 169753. 


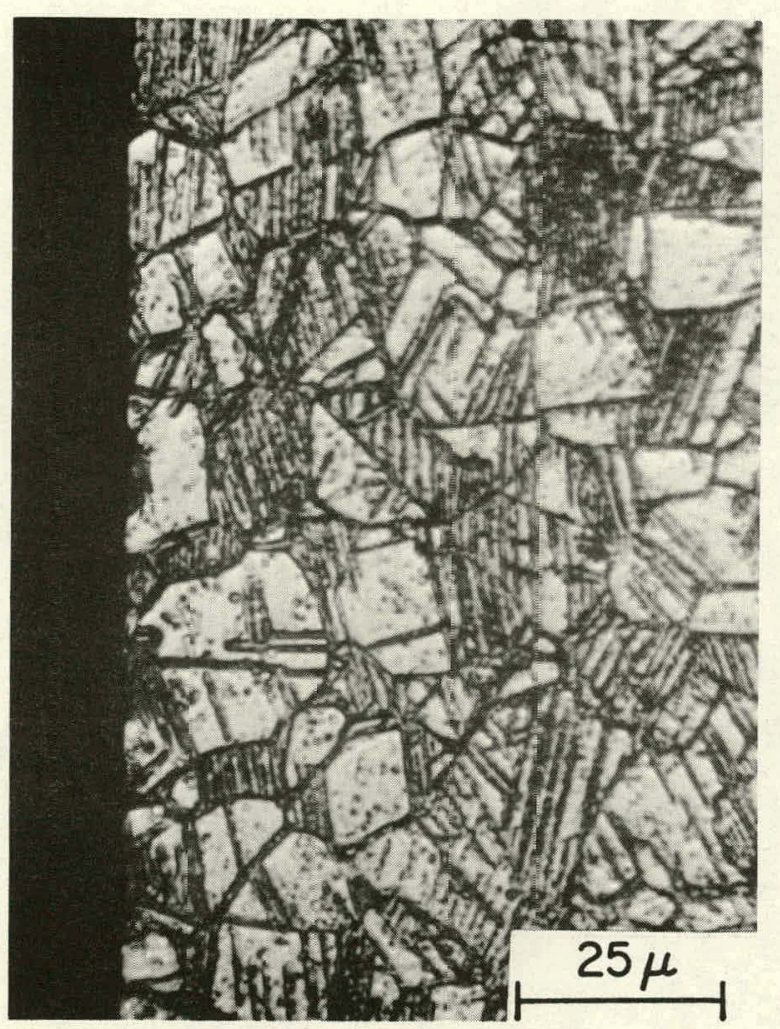

(a)

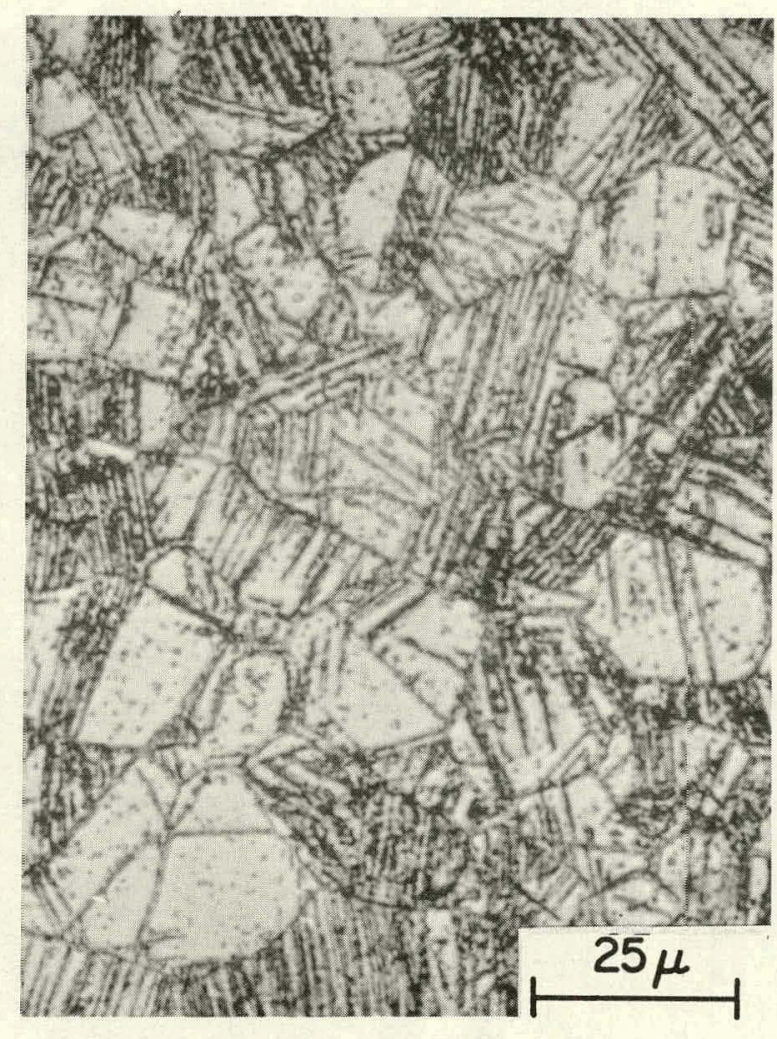

(b)

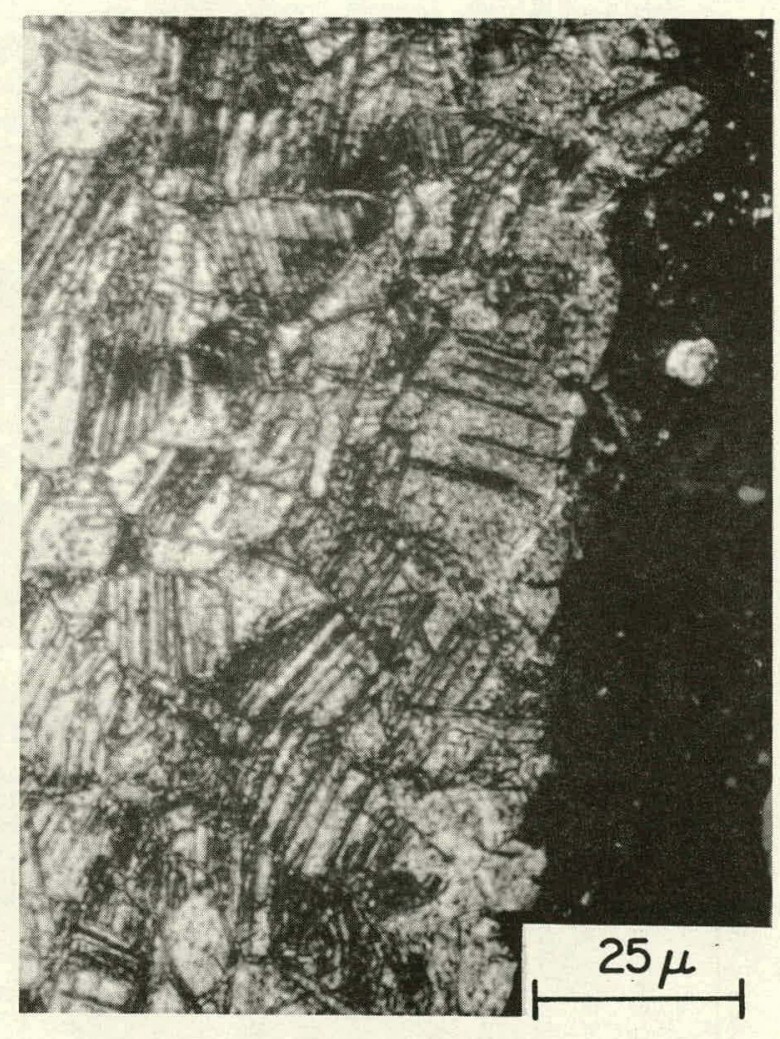

(c)

Fig. 61. Cladding Microstructure 11.15 in. above the Bottom of Core in G-6. Sample was electroetched in 5\% $\mathrm{HCl}$ in methanol. (a) Cladding OD. MSD Neg. No. 169781. (b) Cladding midwall. MSD Neg. No. 169779. (c) Cladding ID. MSD Neg. No. 169776. 
(f) Cladding-density Determinations

Immersion-density determinations were performed on samples from near the core midplane of fuel pins G-1, G-2, and G-6. The fuel was removed from 1/4-in.-long cladding samples and the IDs of the samples were cleaned using a brass brush followed by electropolishing in $40 \%$ sulphuric$60 \%$ phosphoric acid.

The density determinations were performed using a Model M-4 Mettler semi-microbalance in a shielded glovebox. Water, to which a few drops of Photoflo* had been added, was used as the immersion medium. The specific gravity of the water was determined before and after each series of density measurements. The density of the archive samples used in fabricating fuel pins G- 1 through G- 8 was also determined periodically. The temperature of the water was measured during each density measurement. The temperature remained nearly constant and had a negligible effect on the specific gravity of the water.

The accuracy of immersion-density measurements is a funrtion of the sample size and shape and is dependent on the apparatus and technique employed. Therefore, the absolute accuracy of the density measurements was not determined. The results from 15 measurements on archive specimens had a standard deviation of $\pm 0.00537 \mathrm{~g} / \mathrm{cc}$. Five determinations were made on each of the irradiated samples, and if the precision on the irradiated samples were as good as for the archive samples the $95 \%$ confidence interval for the se measurements would be $\pm 0.006 \mathrm{~g} / \mathrm{cc}$.

The results of the density measurements are given in Table XII. These data show that, to within the experimental error, no irradiation-induced change occurred in the density of the cladding of these three fuel pins.

TABLE XII. Cladding-density Measurements

\begin{tabular}{ccccc}
\hline $\begin{array}{c}\text { Fluence } \\
\begin{array}{c}\mathrm{E}>1 \mathrm{MeV}), \\
\mathrm{n} / \mathrm{cm}^{2}\end{array}\end{array}$ & $\begin{array}{c}\text { I'ime-averaged } \\
\text { Midwall }\end{array}$ & $\begin{array}{c}\text { Measured } \\
\text { Density, } \\
\mathrm{g} / \mathrm{cm}^{3}\end{array}$ & $\begin{array}{c}\text { Measured } \\
\text { Vnlıme } \\
\text { Change, } \\
\%\end{array}$ & $\begin{array}{c}\text { Calculated } \\
\text { Vnlume } \\
\text { Change, } \\
\%\end{array}$ \\
\hline $4.0 \times 10^{22}$ & 718 & 7.976 & -0.06 & +0.25 \\
$3.7 \times 10^{22}$ & 705 & 7.967 & +0.05 & +0.06 \\
$3.2 \times 10^{22}$ & 659 & 7.966 & +0.06 & +0.67 \\
Archive Sample & - & 7.971 & - & - \\
\hline
\end{tabular}

${ }^{\mathrm{a}}$ Values were calculated using equation for radiation-induced swelling in $20 \%$ cold-worked Type 316 stainless steel from the Nuclear Systems Materials Handbook, TID-26666, Revision 2, June 19, 1974.

*Trade name for a wetting agent used to reduce the surface tension of the water. 


\section{DISCUSSION}

A. Volatile Fission-product Migration

The axial gamma scans show that significant quantities of ${ }^{137} \mathrm{Cs}$ have migrated to the fuel-blanket interfaces in these fuel pins. Gamma scanning shortly after irradiation ${ }^{6}$ showed that, in fuel pin G-1, ${ }^{131}$ I exhibited behavior similar to the ${ }^{137} \mathrm{Cs}$. Plotting the combined ${ }^{137} \mathrm{Cs}$ activity and the profilometry results for pins G-1 and G-2, Figs. 62 and 63 show that the peak in the Cs gamma activity at the bottom of G-1 and at the top of G-2 coincide with localized diametral increases. These localized diametral increases are caused by chemical reactions between the $\mathrm{UO}_{2+\mathrm{x}}$ blanket pellets and the $\mathrm{Cs}$ or $\mathrm{Cs}$ compounds to form a lower density material that stresses the cladding locally. The flow restrictions at the ends of the fuel columns found during the flow tests were probably the result of migration of the volatile fission products and their subsequent reaction with the $\mathrm{UO}_{2+\mathrm{x}}$ blanket pellets. The electron-microprobe examination that showed significant quantities of $\mathrm{Cs}$ in the top pellet of the lower blanket region of G-1 is corroborative evidence of this $\mathrm{Cs}-\mathrm{UO}_{2+\mathrm{x}}$-reaction cladding deformation mechanism. Fuel-pin failures that result from this mechanism have been observed ${ }^{7}$ at the bottom and top fuel-blanket interfaces in high burnup mixed-oxide fuel pins which contained low $\mathrm{O} / \mathrm{M}$ fuel and slightly hyperstoichiometric blanket pellets.

The extent of the volatile fission-product migration, as indicated by the Cs gamma scans, was significantly greater in fuel pins G-1, G-2, and G-5 (all exhibited Cs peaks near the top of the fuel column) than in pins G-6 and G-7. Pins G-6 and G-7 were unique in that they contained active charcoal traps, i.e., the charcoal was exposed to the plenum gases. Pins G-6 and G-7 also operated at lower linear powers and lower cladding temperatures than the other three pins. The effect of the lower powers and temperatures rather than the presence of the charcoal traps is believed to be the cause of the differences in volatile fission-producl mingaliun.

During gamma scanning of pin G- $1,{ }^{137} \mathrm{Cs}$ was detected at the bottom of the lower blanket region and at the lower end plug. Although the amount of ${ }^{137} \mathrm{Cs}$ at the bottom end plug ( $\sim 15$ in. below the core bottom) was quite small, these results indicate that ${ }^{137} \mathrm{Cs}$ can be transported relatively long distances in the fuel pin. In G-l the movement of ${ }^{137} \mathrm{Cs}$ to the bottom end plug was probably aided by gravity. However, ${ }^{137} \mathrm{Cs}$ was found to have reacted with a stainless steel connector $2 \frac{1}{2}$ in. above the top of the fuel column in a vibratorily compacted fuel pin at 10 at. $\%$ burnup, ${ }^{8}$ indicating significant vapor transport of ${ }^{137} \mathrm{Cs}$ can occur. 


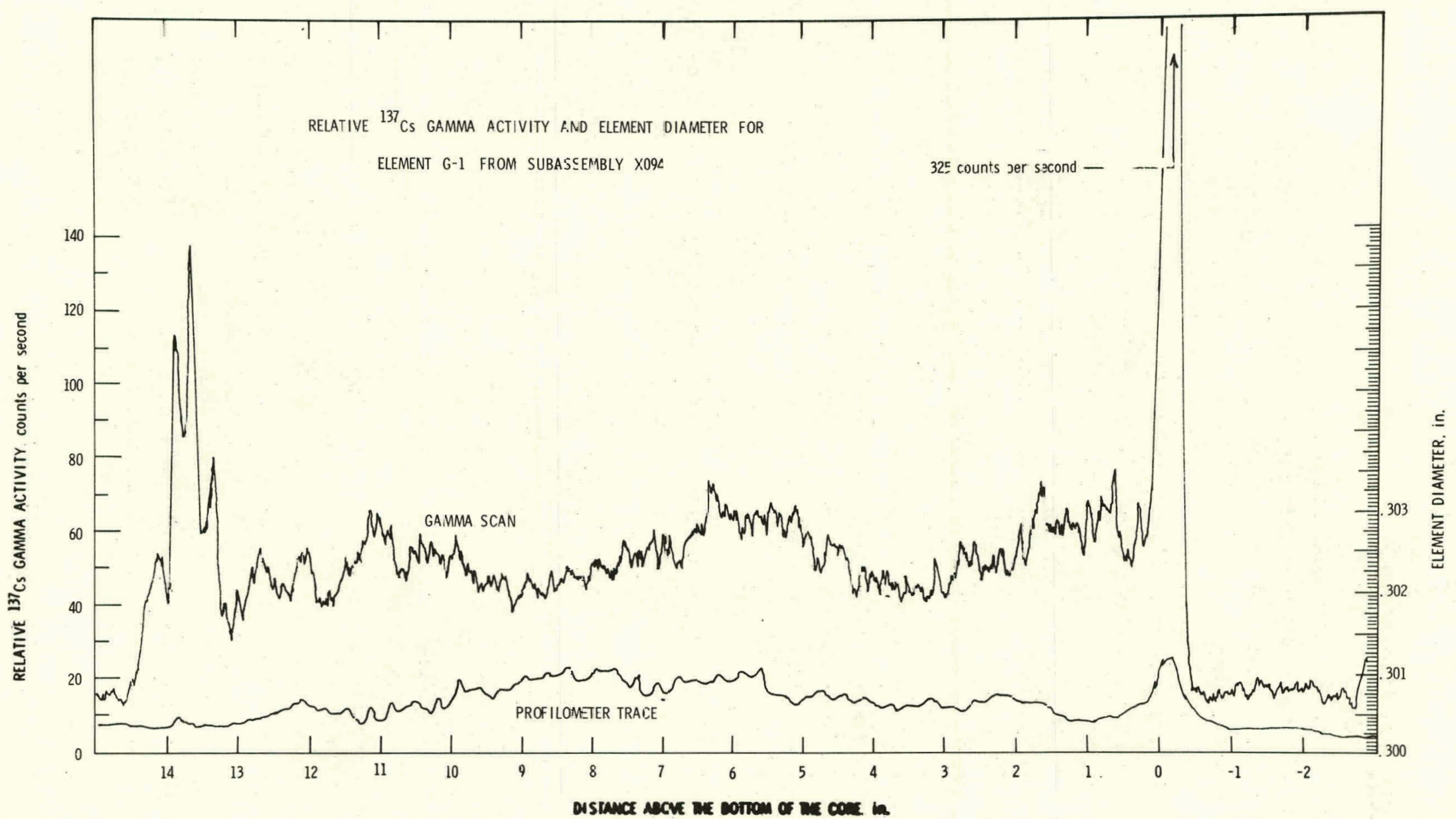

Fig. 62. Relative Axial ${ }^{137}$ Cs Gamma Activity and the Axial Diametral Profile of Pin G-1 Shcwirg a Local Cladding Diametral Increas a at the same Axial Location as the Peak in the ${ }^{137} \mathrm{Cs}$ Activity nea: the Bottom Fuel-Blanket Interface. MSD Neg. No. -82439. 


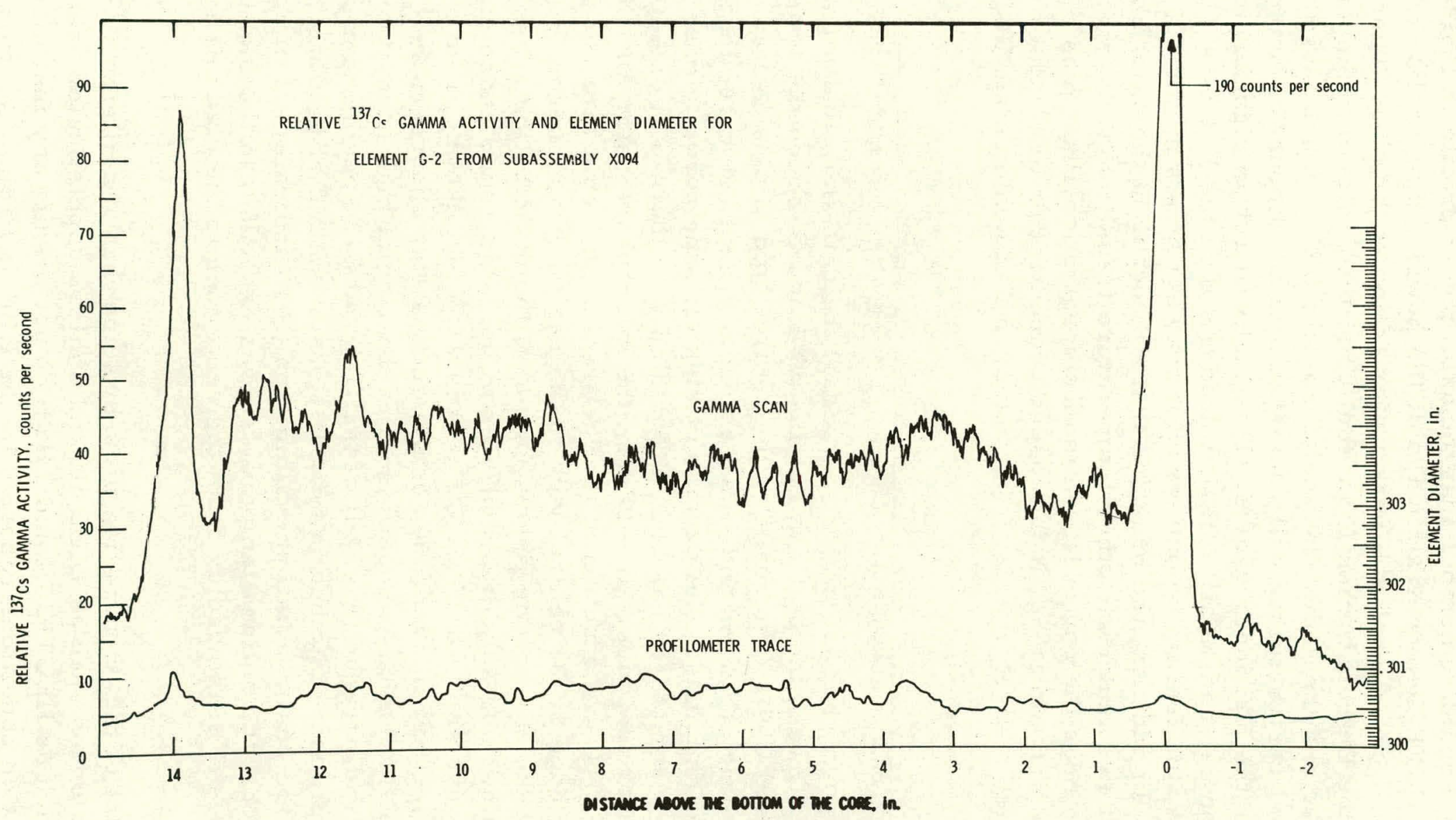

Fig. 63. Relative Axial ${ }^{137}$ Cs Gamma Activity and the Axial Diametral Profile for Pin G-2 Showing a Local Cladding Diametral Increase at the Same Axial Location as the Peak in the ${ }^{137} \mathrm{Cs}$ Activity near the Top Fuel-Blanket Interface. MSD Neg. No. 182442 . 
In assessing the axial migration of volatile fission products in the F-1 fuel pins, one should remember that the axial power profile in EBR-II is quite flat. In the GCFR Demonstration Plant, the power rating at the ends of the fuel column will be only half the peak power rating of the pins. Therefore, near the ends of the Demonstration Plant fuel pins, the centerline temperature will be much lower and the radial thermal gradients will be much less than in the F-l pins. Fuel restructuring will consist of a small amount of equiaxed grain growth near the fuel inner radius. This fuel will retain significantly more of its fission gas and volatile fission products than the F-1 pins. Under certain conditions, the fuel in the outer radius may act as a sink for the volatile fission products. In addition, the breeding that will occur in the axial blanket pellets will result in a much smoother temperature transition at the fuelblanket interfaces near the end of life in the Demonstration Plant pins than in the F-1 pins. This should result in a reduced concentration of volatile fission products at the fuel-blanket interface, particularly if stoichiometric $\mathrm{UO}_{2}$ blanket pellet.s are used.

B. Fuel Melting

The ceramographic and electron-microprobe data show that significant differences exist between the high power pins (G-1 and G-2) and the lower power pins (G-6 and G-7). The shape of the central void in pins $G-1$ and G-2 indicates fuel melting occurred and small amounts of fuel relocated to the bottom end of the fuel columns. The prominent ring of large porosity observed in the G-1 and G-2 structures has been associated with the radial extent of fuel melting in other fuel pins. ${ }^{9}$ In addition, the microprobe determination of the $\mathrm{Pu}-\mathrm{U}$ ratio in $\mathrm{G}-1$ as a function of the fuel radius showed a straight-line function from the edge of the central void to the region of high porosity. The $\mathrm{Pu}-$ to-U ratios at the ends of the linear portion of the distribution agree quite well with the liquidus and solidus boundaries of the solid-liquid phase diagram for the $\mathrm{UO}_{2}-\mathrm{PuO}_{2}$ system ${ }^{10}$ for 15 wt $\% \mathrm{PuO}_{2}-85$ wt $\% \mathrm{UO}_{2}$ cooling from a liquid to a solid. The electron-microprobe results show a step change in the composition of the metallic fission-product ingots at the ring of high porosity. The beta-gamma autoradiographs (Fig. 64) of the G-1 and G-2 specimens also show a unique fission-product distribution typically observed in fuel that has melted. These data from the postirradiation examination (PIE) indicate fucl melting occurred, or at least the solidus temperature was exceeded, in thr fuel to a distance equal to $\sim 0.7$ of the radius from the centerline to the cladding inner surface.

The results of the examination present somewhat of a dilemma because fuel-performance codes such as LIFE-III and the less sophisticated heattransfer codes such as HECTIC III and THTB do not predict any fuel melting under the irradiation conditions reported by the EBR-II Project for subassemblies X094 and X094A. The peak fuel inner surface temperature for G-1 using 
LIFE-III, HECTIC, and THTB at startup are given in Table XIII. A LIFE-III calculation using the power history presented in Sec. I.B showed that the peak fuel temperatures were reached during startup, and therefore the temperatures given in Table XIII represent the most severe condition which could be expected during the life of these fuel pins. The power-to-melt tests in the LMFBR Program (P-19 and F-20) also indicate powers in excess of $18 \mathrm{~kW} / \mathrm{ft}$ should have been required to initiate any melting in these pins.

The apparent difference in the PIE results and calculated fuel temperatures can be explained in several ways; however, none are particularly acceptable. The fuel pins may have been subjected to an over-power condition that was reactor initiated. This is unlikely because other experimenters have not reported anomalous results, and the $20 \%$ over-power required to cause melting
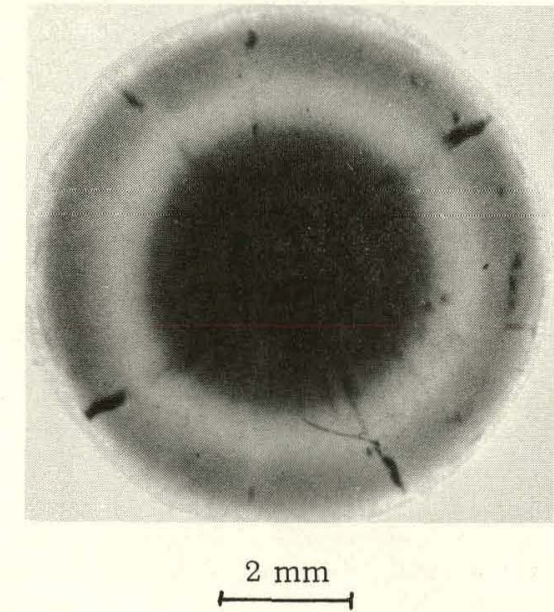

G-1

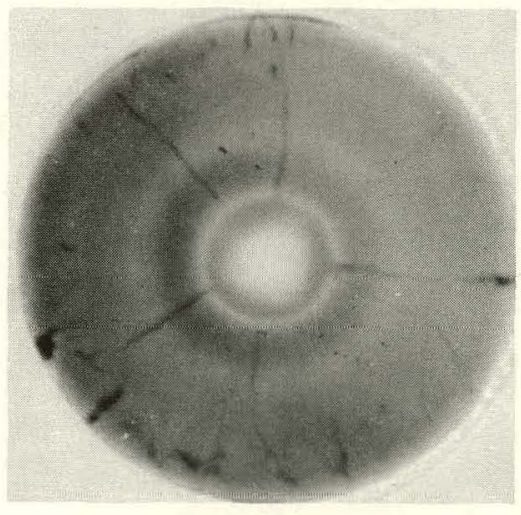

$2 \mathrm{~mm}$

G-6
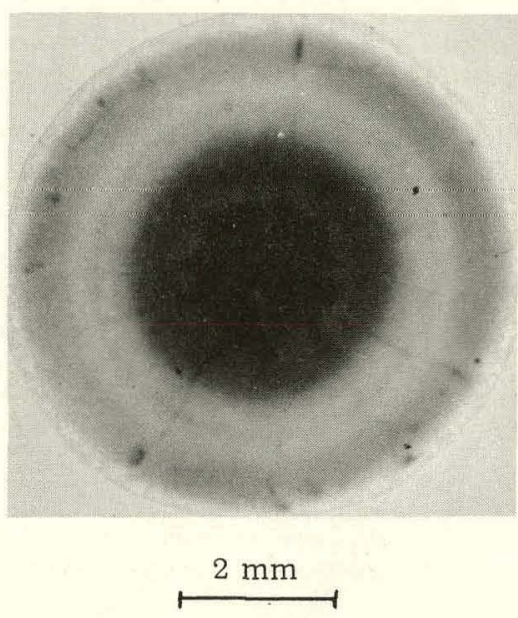

G-2

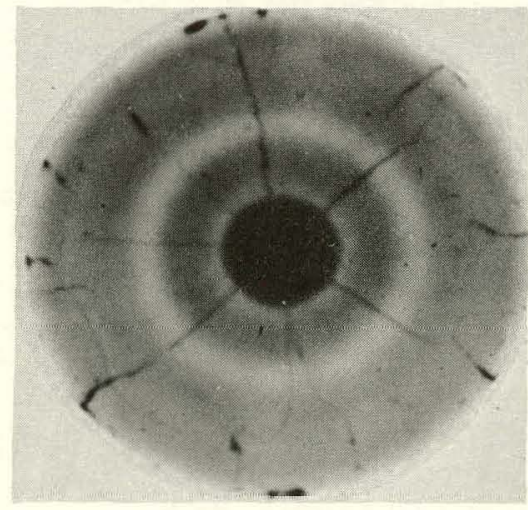

$2 \longdiv { \mathrm { mm } }$

G-7

Fig. 64. Beta-Gamma Autoradiographs of the Midplane Cross Section from Fuel Pins $G-1, G-2, G-6$, and $G-7$. The dark areas represent areas of lower radioactivity. MSD Neg. No. 185614. 
TABLE XUI. Peak Fuel Inner Surface Temperatures for G-1 Calculated Using Three Thermal Performance Codes

\begin{tabular}{|c|c|c|}
\hline $\begin{array}{l}\text { Computer } \\
\text { Codes }\end{array}$ & $\begin{array}{c}\text { Peak Fuel } \\
\text { Inner Surface } \\
\text { Temperature, } \\
{ }^{\circ} \mathrm{C}\end{array}$ & Gap Conditions \\
\hline LIFE-III & 2204 & Gap conductance calculated by the code \\
\hline THтв & 2283 & $\begin{array}{l}\text { Gap conductance of } 3000 \mathrm{Btu} / \mathrm{ft}^{2}-\mathrm{h} \text { was } \\
\text { as sumed }\end{array}$ \\
\hline HECTIC-III & 2418 & $\begin{array}{l}\text { Gap conductance of } 1000 \mathrm{Btu} / \mathrm{ft}^{2}-\mathrm{h} \text { was } \\
\text { assumed }\end{array}$ \\
\hline
\end{tabular}

would have been detected by the plant protective systems. The pins may have been subjected to an over-power condition because of improper positioning of the subassembly in the core. The fuel-handling techniques used at EBR-II make this possibility extremely unlikely. In addition, the calculated burnup using the peak power data from Table XII and the measured burnup differ by only $\pm 3 \%$, as shown in Table XIV. This good agreement between the measured and calculated burnups indicates that calculated powers were close to the actual operating conditions. These burnup results indicate that if the melting was caused by an over-power condition the extent was of short duration.

TABLE XIV. Measured and Calculated Burnups for F-1 Pins G-1, G-2, and G-6

\begin{tabular}{|c|c|c|c|c|c|}
\hline $\begin{array}{l}\text { Sample } \\
\text { Numbers }\end{array}$ & $\begin{array}{l}\text { Fuel } \\
\text { Pin }\end{array}$ & $\begin{array}{c}\text { Distance } \\
\text { above } \\
\text { Core Bottom, } \\
\text { in. }\end{array}$ & $\begin{array}{c}\text { Measured } \\
\text { Burnup, d } \\
\text { at. } \%\end{array}$ & $\begin{array}{c}\text { Calculated } \\
\text { Burnup, } \\
\text { at. } \%\end{array}$ & $\begin{array}{c}\text { Difference, } \\
\%\end{array}$ \\
\hline $119 A-13$ & $G-1$ & $6 \frac{3}{8}$ & 5.35 & 5.18 & $-3,18$ \\
\hline $119 \mathrm{~A}-20$ & $\mathrm{G}-1$ & $12 \frac{3}{4}$ & 4.35 & 4.24 & -2.53 \\
\hline $119 \mathrm{~B}-7$ & $G-2$ & 2 & 4.91 & 4.44 & -9.57 \\
\hline $119 B-12$ & $G-2$ & $6 \frac{3}{8}$ & 5.19 & 5.05 & -2.70 \\
\hline $119 \mathrm{~B}-19$ & $G-2$ & $12 \frac{3}{4}$ & 4.26 & 4.14 & -2.82 \\
\hline $119 D-5$ & $G-6$ & 2 & 4.44 & 4.22 & -4.95 \\
\hline $119 D-10$ & $G-6$ & $6 \frac{3}{8}$ & 4.68 & 4.78 & +2.14 \\
\hline $119 D-16$ & $G-6$ & $12 \frac{3}{4}$ & 3.95 & 3.93 & -0.51 \\
\hline \multicolumn{6}{|c|}{ 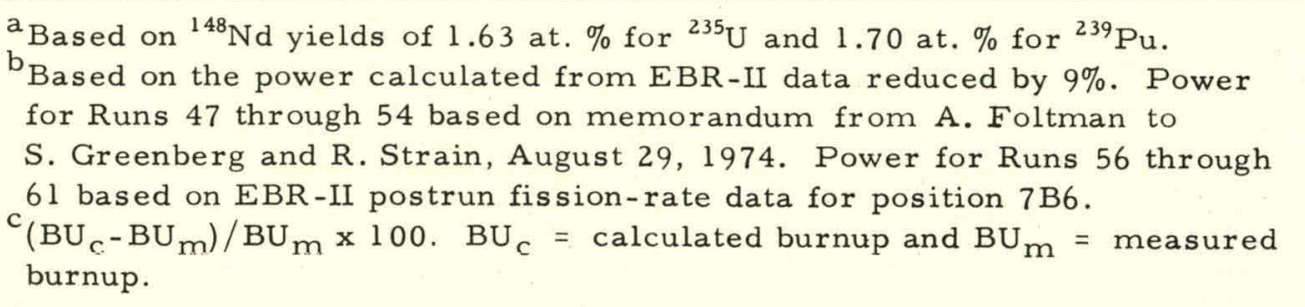 } \\
\hline
\end{tabular}


The experiment design required the use of a thermal barrier in the capsule to attain the desired cladding temperatures. Therefore, the elements were, in effect, doubly encapsulated and had two annular sodium bonds. Defects in the sodium bonds could have caused the fuel melting observed in fuel pins G-1 and G-2. However, observation of melting in the higher power fuel pins and not in the lower power pins indicates that the higher power caused the bond defects, or the defects occurred only in the higher power pins by coincidence.

Another possible explanation is that relatively low-melting fissionproduct fuel mixtures formed as burnup proceeded. The materials were located radially in a position where the temperature was below their melting point during normal reactor operation. However, when the linear power rating went through a significant step increase, such as at the beginning of Run 56 at the time the stainless reflector was installed, the low-melting materials may have formed eutectic mixtures with the fuel, which caused melting. The fissionproduct $\mathrm{Ba}$ has been found as $\mathrm{BaO}-\mathrm{SrO}$ inclusions at the outer edge of the columnar-grain region in a number of fuel pins at burnups above 6 at. \%. A phase diagram for the $\mathrm{BaO}-\mathrm{UO}_{2}$ system ${ }^{11}$ shows two compounds $\left(\mathrm{BaUO}_{3}\right.$ and $\mathrm{Ba}_{3} \mathrm{UO}_{6}$ ) with a eutectic at $\sim 2100^{\circ} \mathrm{C}$ for the $\mathrm{UO}_{2}-\mathrm{BaUO}_{3}$ solid solution and a eutectic at $\sim 1800^{\circ} \mathrm{C}$ for the $\mathrm{BaO}-\mathrm{Ba}_{3} \mathrm{UO}_{6}$ solid solution. The relatively low boiling point of $\mathrm{BaO}\left(\sim 2000^{\circ} \mathrm{C}\right)$ indicates $\mathrm{BaO}$ should have a high vapor pressure and migrate to the cooler regions of the fuel. However, the presence of material containing quite high $\mathrm{Ba}$ concentrations at the centerline near the bottom of the G-1 fuel column (Fig. 45) shows that compounds containing Ba can exist in the hotter regions of the fuel. Similar dendritic oxide structures have been observed in other fuel pins that underwent fuel melting ${ }^{12}$ and in extremely high burnup pins ( 15 at. \%). At present, no analytical explanation exists for the presence of the dendritic material in the central void.

Although compounds of $\mathrm{BaO}$ have been found near the outer edge of the columnar grains and these compounds could form low-melting eutectics with the fuel, an insufficient amount of $\mathrm{Ba}$ is present, which will significantly reduce the melting point of the entire columnar-grain zone at one time. Melting could occur if the Ba caused a small radial zone to melt and the melted zone migrated up the temperature gradient to the central void. Migration of the $\mathrm{Ba}$ up the temperature gradient in a molten zone would explain the presence of the $\mathrm{Ba}$ containing dendritic oxide material at the centerline near the bottom of the fuel column.

\section{Actinide Redistribution}

The radial actinide distribution in fuel pins G-1 and G-2, discussed in Sec. I.E, appears to be the result of fuel melting rather than the normal vaporphase redistribution mechanism. The actinide distribution at the centerline of G-6 can be considered normal; Pu has the highest concentration at the inner edge of the fuel and reduces hyperbolically to nominal values in the equiaxed 
and unrestructured zones of the fuel. The fuel can be displaced axially in a fuel pin by annular pellets slumping as a result of fuel melting, fuel fragments falling to the bottom of the central hole as a result of fracture of the fuel from thermal shock on start-up, and evaporation-condensation processes during operation. The lower $\mathrm{Pu}$ content at the inner surface of the sample taken near the top of the G-6 fuel column appears to be the result of fuel transport by evaporation from the highest temperature regions and condensation in the region operating at a lower temperature. The higher vapor pressure of uranium oxides, in contrast to plutonium oxides, results in a reduced $\mathrm{Pu}$ content in the material that is condensed from the vapor. The material with the lower Pu content, the downturn at the fuel inner surface (Fig. 43), must have been deposited, since the Pu-containing material is closer to the centerline than the radius of the original hole in the annular pellets.

The location of fuel that has condensed from the vapor phase is dependent on the temperature of the inner surface of the fuel. This is illustrated by the location of deposited fuel near the top of the fuel columns of G-1, G-3, and G-6, as shown in Fig. 65. In G-1, the inner surface temperature was quite high adjacent to the fuel-blanket interface; therefore, the condensed fuel is located near the top of the fuel column and is quite dense. In G-3, the deposited fuel extends farther from the fuel-blanket interface, and the fuel at the centerline is quite porous. The fuel in G-6 has been deposited as far as $1 / 2$ in. from the top fuel-blanket interface, and the fuel that has been deposited at the centerline is extremely porous. These results indicate that, as the power rating and therefore the inner surface temperatures are lowered, fuel can be deposited by condensation nearer the peak power (and temperature) region of the fuel pin. The deposition of uranium-rich fuel significant distances from the fuel-blanket interfaces indicates that, in fuel pins for the Demonstration Plant with low power ratings ( $\sim 6$ or $7 \mathrm{~kW} / \mathrm{ft}$ ) at the ends, the fuel will be deposited over a significant length, and solid closures at the top of the central hole, similar to those in G-1 and G-2, probably will not occur.

D. Radial Uxygen Potential

The Mo-concentration data (Fig. 44) for the oxide phase was combined with the noble metal inclusion measurements given in Table XI to calculate the oxygen potential gradient at the midplane of G-1. The method ${ }^{13}$ used to calculate the oxygen potential gradient is based on the distribution of Mo between the alloy and the oxide phases. The basic concept of the method involved the assumptions that (1) at each point in the fuel during irradiation a local equilibrium exists between oxidized Mo in the fuel matrix and reduced Mo in the noble metal inclusions, and (2) this equilibrium is retained as the fuel pin is cooled.

With the assumption that during irradiation a local equilibrium exists between the oxide and reduced forms of Mo, the oxygen potential is calculated from the equation 


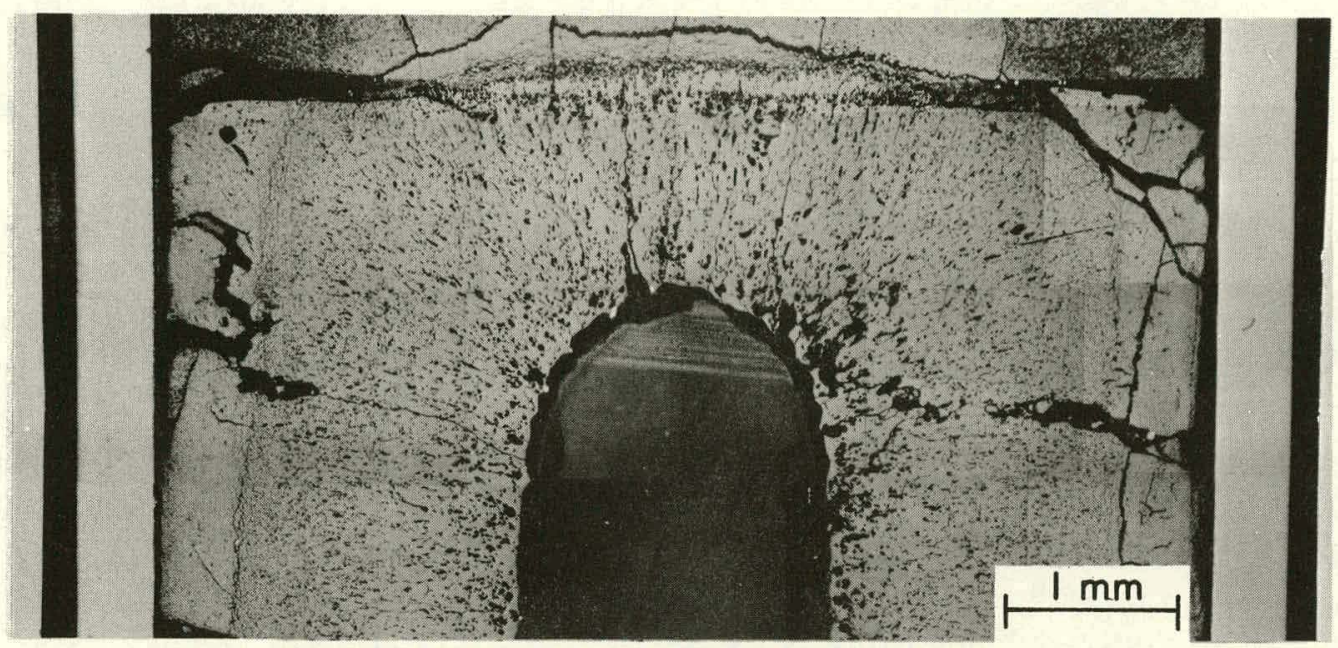

(a)

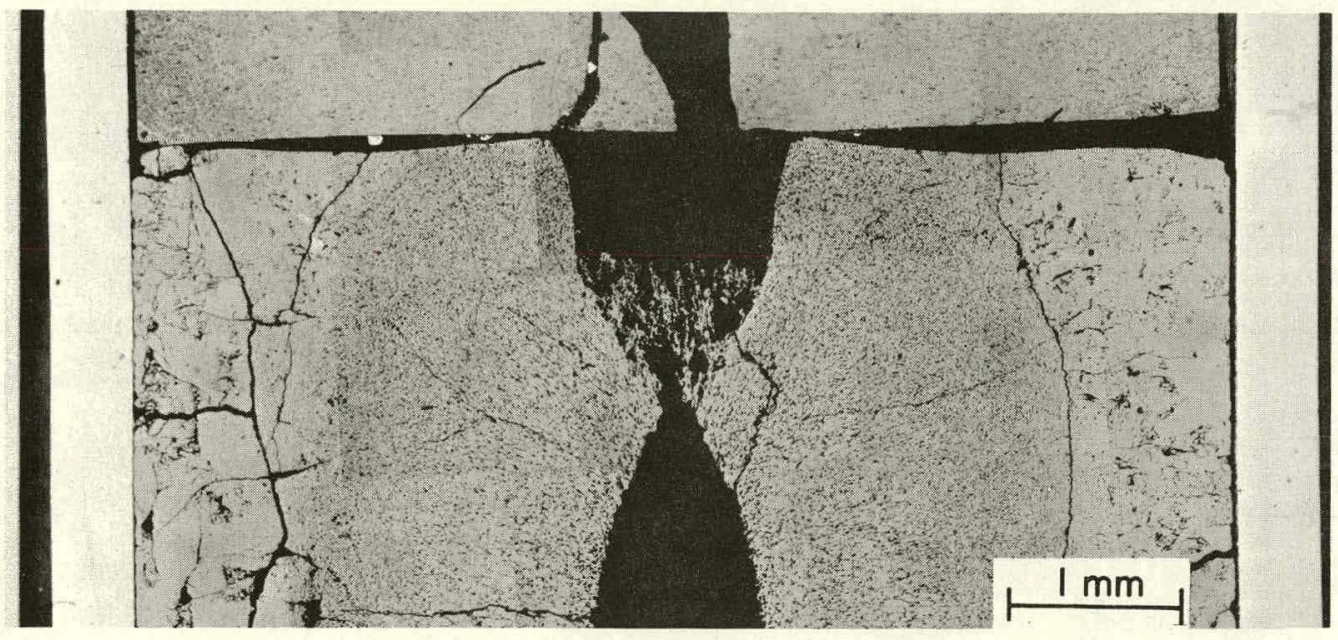

(b)

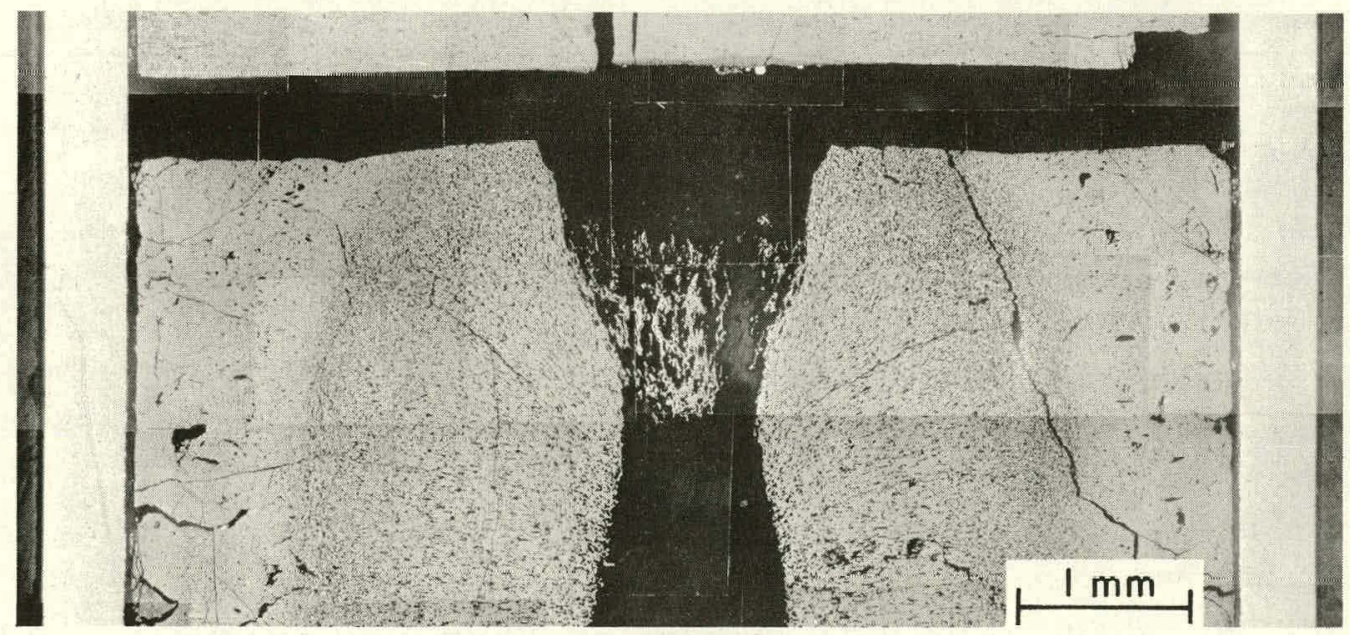

(c)

Fig. 65. Amount of Central Hole Closing at the Top of the Fuel Columns. (a) Fuel pin G-1 peak power $15.0 \mathrm{~kW} / \mathrm{ft}$. MSD Neg. No. 168784. (b) Fuel pin G-3 peak power $14.4 \mathrm{~kW} / \mathrm{ft}$. MSD Neg. No. 165602. (c) Fuel pin G-6 peak power $13.3 \mathrm{~kW} / \mathrm{ft}$. MSD Neg. No. 169838. 


$$
\Delta \overline{\mathrm{G}}_{\mathrm{O}_{2}}=\Delta \mathrm{G}_{\mathrm{foO}_{2}}^{0}+\mathrm{RT} \ln \mathrm{a}_{\mathrm{MoO}_{2}} / \mathrm{a}_{\mathrm{Mo}}
$$

where $\Delta \mathrm{G}_{\mathrm{f}_{\mathrm{MOO}_{2}}^{0}}$ is the standard free energy of formation of $\mathrm{MoO}_{2}$, a ${ }_{\mathrm{Mo}}$ is the activity of $\mathrm{Mo}$ in the noble metal inclusion, and ${ }^{\mathrm{a}} \mathrm{MoO}_{2}$ is the activity of Mo (as the dioxide) in the oxide matrix adjacent to the metallic inclusion. The calculations for G-1 at the core midplane are given in Table XV. The oxygen potential gradient found is similar to that measured for other oxide fuels. Also, the data show a smooth changing oxygen potential with no abrupt changes as observed with the actinide elements or Nd. Thus, the fuel microstructure and composition typical of melting, which probably occurred at midlife of the irradiation period, has been altered and the oxygen potential gradient is now smooth and continuous. These results are consistent with solid-state diffusion of oxygen throughout the irradiation period as the major mechanism of attaining overall oxygen equilibrium.

TABLE XV. Oxygen Potential Data for G-1 at the Core Midplane

\begin{tabular}{cccccc}
\hline $\begin{array}{c}\text { Fuel } \\
\text { Radius } \\
\mathrm{cm}\end{array}$ & $\begin{array}{c}\text { Temperature, } \\
{ }^{\mathrm{K}}\end{array}$ & $\begin{array}{c}\mathrm{O} / \mathrm{M} \\
\text { Ratio }\end{array}$ & $\begin{array}{c}\Delta \mathrm{G}_{\mathrm{O}_{2}{ }^{\prime}} \\
\mathrm{kcal} / \mathrm{mole} \times 10^{-4}\end{array}$ & $\begin{array}{c}\mathrm{P}_{\mathrm{O}_{2}{ }^{\prime}} \\
\mathrm{atm} \times 10^{8}\end{array}$ & $\begin{array}{l}\ln \mathrm{P}_{\mathrm{O}_{2}} \\
0.1182\end{array}$ \\
2543 & 1.968 & -7.647 & 26.79 & -15.13 \\
0.1472 & 2468 & 1.973 & -7.802 & 12.39 & -15.91 \\
0.1796 & 2334 & 1.980 & -8.004 & 3.203 & -17.26 \\
0.2157 & 2131 & 1.988 & -8.299 & 0.317 & -19.57 \\
0.2412 & 1965 & 1.992 & -8.601 & 0.0271 & -22.03 \\
0.2448 & 1938 & 1.991 & -8.671 & 0.0167 & -22.52 \\
\hline
\end{tabular}

E. Cladding Characterization

The irradiation of mixed-oxide fuel pins generally has three major effects on the cladding: fuel-cladding chemical interaction, dimensional changes (cladding swelling and inelastic deformation), and microstructural changes. The FCCI results given in Table $\mathrm{X}$ and shown in Fig. 66 indicate that the severity of FCCI in these pins increases with temperature and the initial O/M of the fuel, which is in agreement with other reported data. ${ }^{14}$ The maximum FCCI of 2.5 mils in G-1 is also in good agreement with values calculated by means of the cladding wastage equation that is used in the LIFE-II fuel-element performance code. That is, the F-l data for the depth of FCCI and its dependence on temperature and initial $\mathrm{O} / \mathrm{M}$ of the fuel are in agreement with LMFBR data on FCCI. The only unique features of the FCCI in the F-l pins were the lack of 


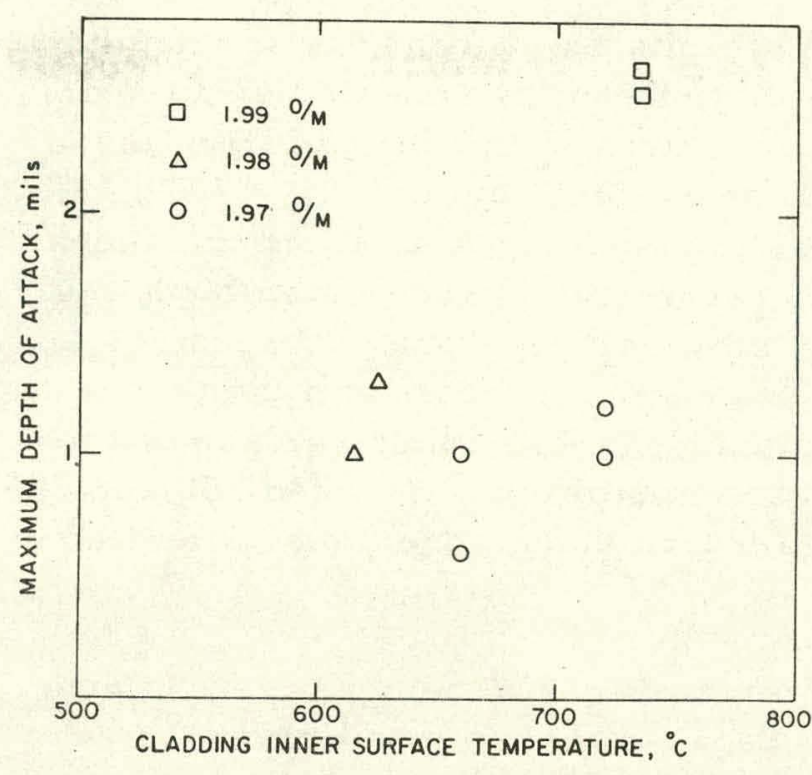

Fig. 66. Maximum FCCI Depth for the F-1 Series Fuel Pins at $\sim 5$ at. \% Burnup. MSD Neg. No. 63991.
Mo in the attack zone and the lack of FCCI at the ends of the radial cracks in the fuel in G-1. The lack of Mo in the FCCI zone and the high Mo content of inclusions in radial cracks in the fuel near the cladding in G-1 may indicate that material moved down the cracks as $\mathrm{Cs}_{2} \mathrm{MoO}_{4}$ and the $\mathrm{Cs}$ and $\mathrm{O}_{2}$ reacted with $\mathrm{Cr}$ in the stainless steel cladding, leaving Mo in the cracks. The lack of attack at the crack openings may be caused by reduced stress in the cladding at the opening. The stress is high on either side of the crack and where the fuel is in contact with the cladding; stress may be accelerating the corrosion.

The cladding density data given in Table XII show that no measurable swelling occurred in the cladding from the F-l fuel pins. Calculation of swelling, using the current design equation for $20 \%$ cold-worked Type 316 stainless steel, ${ }^{15}$ resulted in swelling values from 0.067 to $0.67 \%$ volume change for the density specimens (Table XII). The overprediction of swelling is not surprising since this is a conservative design equation. Based on the density results, it appears that the diametral changes indicated by the postirradiation profilometry are due to inelastic deformation of the cladding. The deformation is assumed to be caused by fuel-cladding mechanical interaction because the stress resulting from the gas pressure in the fuel pins is quite small ( 2000 psi hoopstress).

Significant microstructural changes occurred in the cladding as a result of the irradiation. The cladding subjected to operating temperatures below $700^{\circ} \mathrm{C}$ exhibited microstructures that indicated precipitation of carbide along grain and twin boundaries. The microstructure of the samples from G-6 and G-7 fell into this category and were typical of the microstructure observed in $20 \%$ cold-worked Type 316 stainless steel cladding from the LMFBR Program. The cladding from $\mathrm{G}-1$ and $\mathrm{G}-2$ subjected to operating temperatures above $700^{\circ} \mathrm{C}$ exhibited much coarser precipitates, including intermetallics that were quite large (up to $10 \mu$ in diameter).

An extensive investigation of cladding samples from G-1 was performed using scanning-electron microscopy (SEM) to characterize the composition of the precipitates and the microstructural variation across the cladding wall. Samples of archive tubing from the fabrication of these F-1 fuel pins were annealed for $1000 \mathrm{~h}$ at $700,725,750,775$, and $800^{\circ} \mathrm{C}$ so that comparisons of microstructure could be made in an effort to determine the operating temperature of the G-1 cladding based on experimental data. The detailed results of this investigation will be reported elsewhere, but a summary of the results is included here. 
The distribution and size of the precipitates at locations across the cladding wall, which can be compared with those in the annealed specimens, were used to estimate the operating temperatures of the OD and ID of the cladding at the midplane and near the top of the fuel column in G-1. The SEM photographs of the microstructure across the cladding of G-1 and the annealed specimens are shown in Figs. 67 and 68, respectively. The outside edge of the cladding appears to have been subjected to temperatures between 700 and $725^{\circ} \mathrm{C}$, based on the lack of large intermetallic precipitates and the distribution of fine precipitates on grain and twin boundaries. The inner surface of the cladding appears to have been subjected to temperatures between 750 and $775^{\circ} \mathrm{C}$, based on the presence of numerous large intermetallic precipitates and strings of precipitates along twin boundaries.

The estimates of the operating temperatures were not based on the presence or lack of certain precipitates because the composition of the precipitates found in the irradiated cladding was not always the same as that found in the annealed cladding samples. Large $(\sim 0.5 \mu)$ carbide precipitates were found at the OD of the G-1 cladding, whereas carbide precipitates of sufficient size for positive identification were not present in the specimens annealed at temperatures below $775^{\circ} \mathrm{C}$. The composition of the chi phase in the irradiated cladding contained significantly more $\mathrm{Cr}$ than the annealed specimens. Several possibilities exist that could cause these differences. The annealing studies were only $1000 \mathrm{~h}$, whereas the G-1 cladding was at temperature for $-7000 \mathrm{~h}$. 'I'he G-1 cladding could have been altered chemically by the fuel at the cladding ID. In fact, the $\mathrm{Cr}$ content of the matrix was reduced near the cladding ID, as shown by the $\mathrm{Cr} / \mathrm{Fe}$ ratios shown in Fig. 69. The cladding ID in this case refers to the stainless steel adjacent to the FCCI zone not the initial cladding ID. The effect of the fast-neutron irradiation of the cladding on the diffusion rates of the substitution elements ( $\mathrm{Cr}$ and $\mathrm{Ni}$ ) must also be considered, but the enhancement of diffusion should be negligible at these temperatures.

\section{CONCLUSIONS}

The postirradiation examination of five fuel pins from the GCFR F-1 series irradiation after $\sim 5$ at. \% burnup has, in general, shown good pin performance. 'I'te fuel pins exhibited good dimensional stability, no significant axial growth of the fuel column, and only $0.3 \%$ maximum diametral increase. Maximum FCCI of $2.5 \mathrm{mils}$ was observed in the fuel pin that operated with a peak cladding temperature of $\sim 760^{\circ} \mathrm{C}$, and a maximum FCCI of $\sim 1$ mil was observed in the fuel pins that operated at $\sim 700^{\circ} \mathrm{C}$ or less. The two highest power fuel pins exhibited fuel melting near the centerline but only slight fuel slumping occurred. The fuel melting had no adverse effects on the overall performance of the fuel pins. A satisfactory cause for the fuel melting has not been found. In summary, the results of the PIE have indicated no new potential problem areas for GCFR fuel-pin performance. 


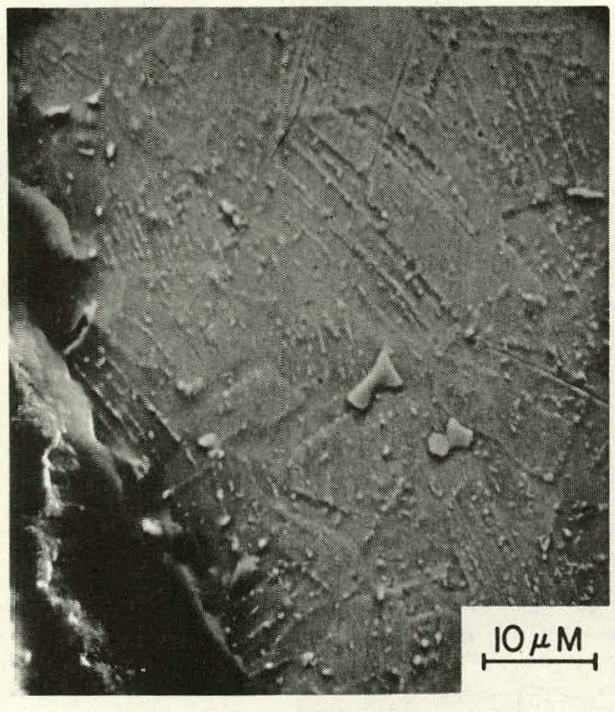

(a)

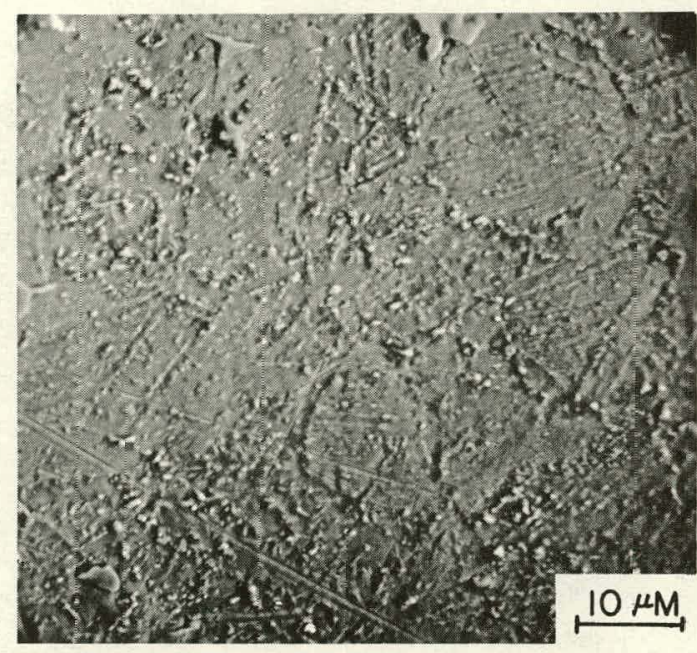

(d)

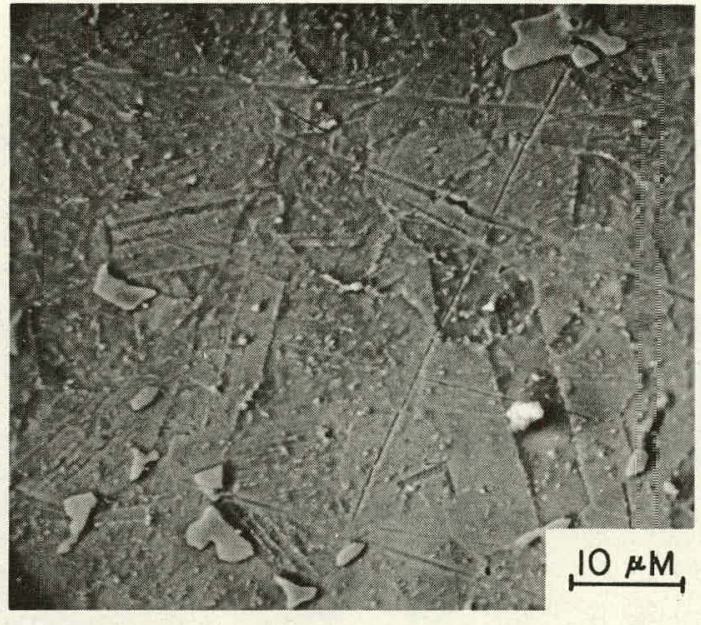

(b)

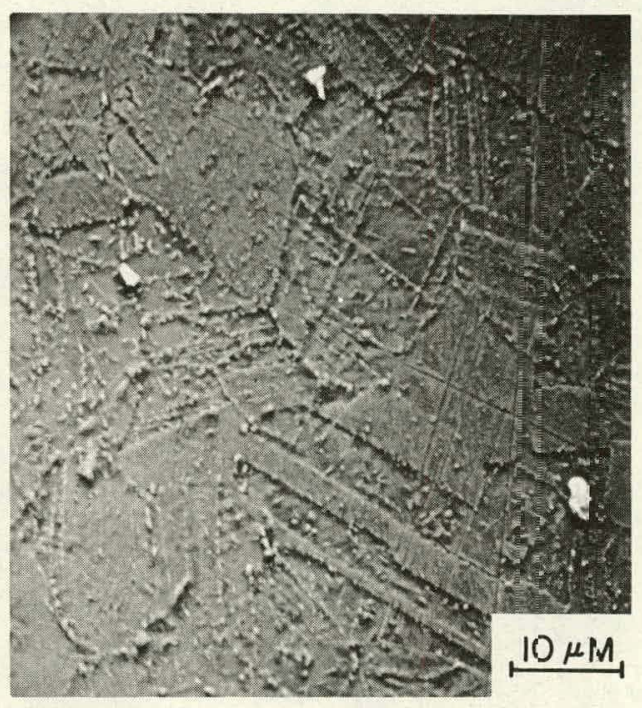

(e)

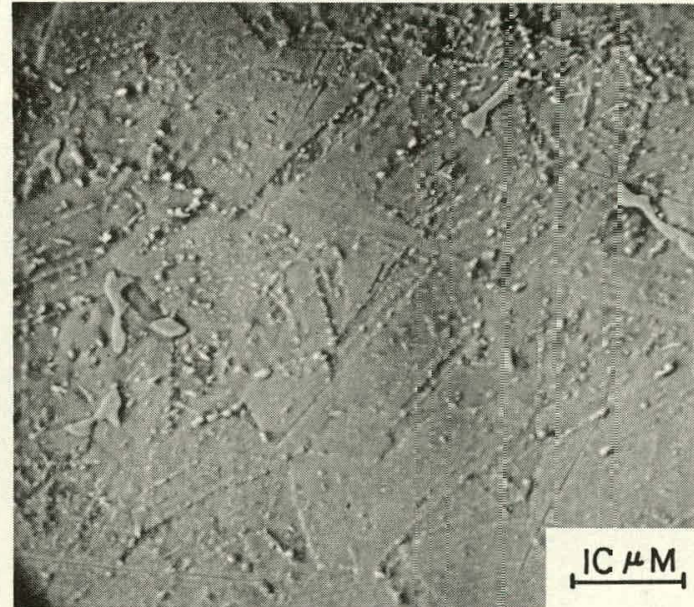

(c)

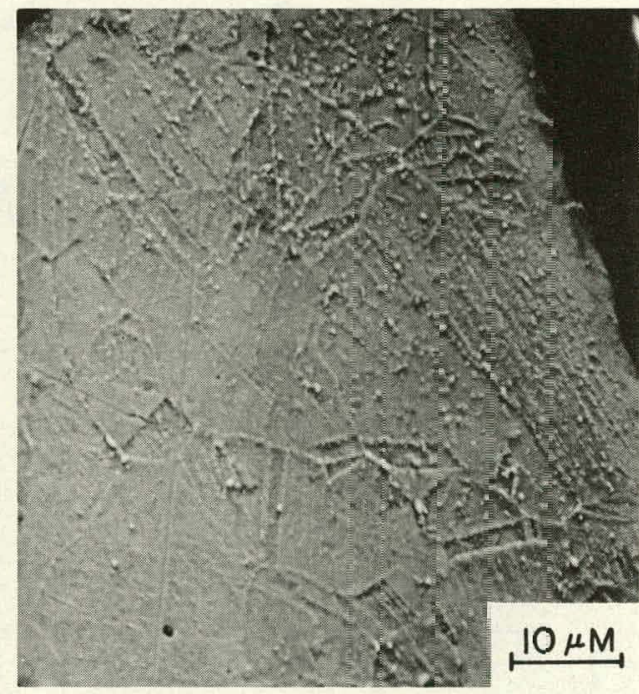

(f)

Fig. 67. SEM Photographs of G-1 Cladding Microstructures at the Reactor-core Midplene. (a) Cladding ID. MSD Neg. No. 201021. (b) Near cladding ID. MSD Neg. No. 201019. (c) Near cladding midwall. MSD Neg. No. 201017. (d) Near cladding midwa.1. MSD Neg. No. 201015. (e) Near cladding OD. MSD Neg. No. 201013. (f; Cladding OD. MSD Neg. No. 201011. 


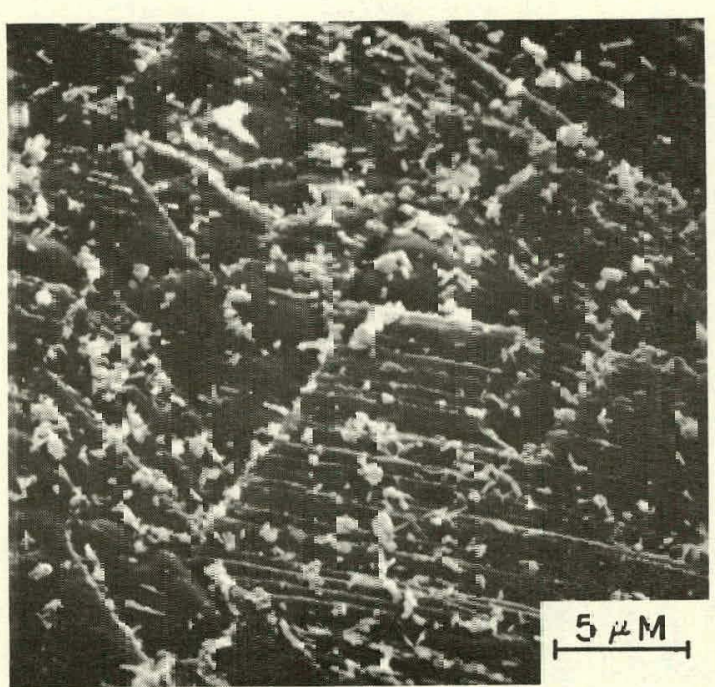

a)

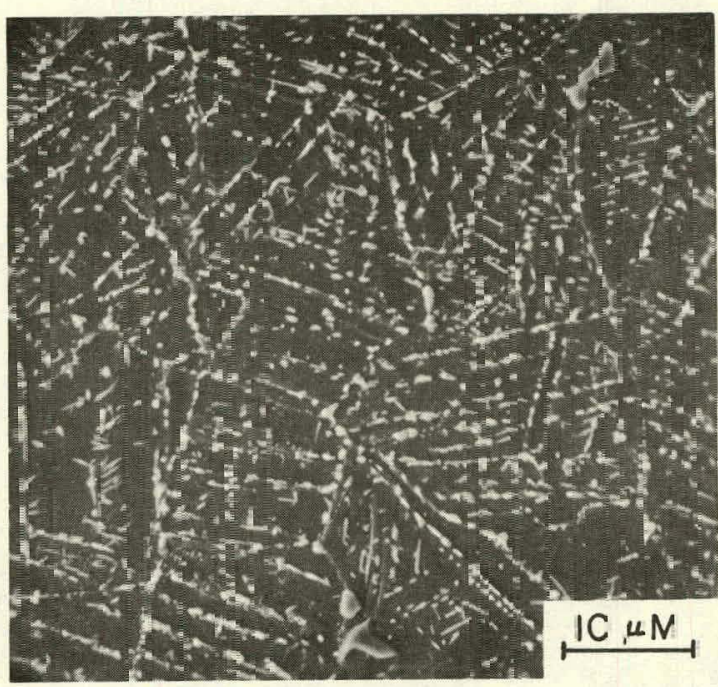

(b)

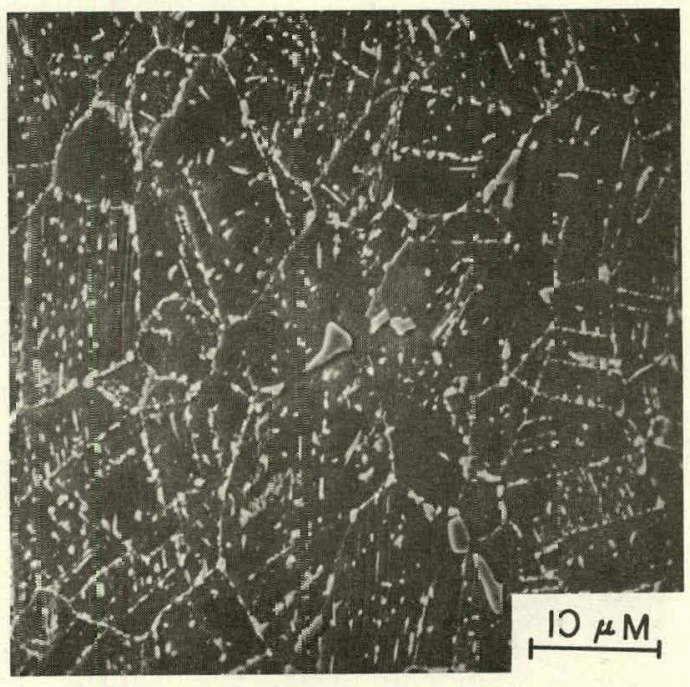

(c)

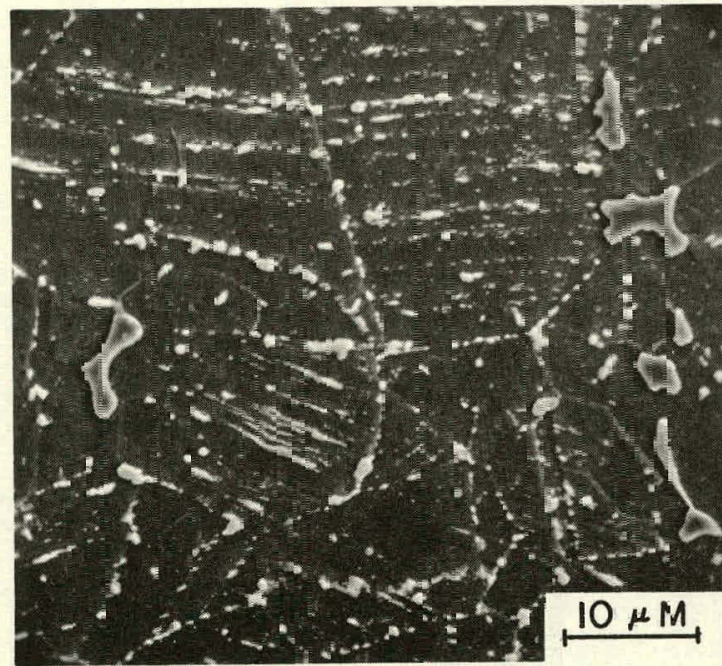

(d)

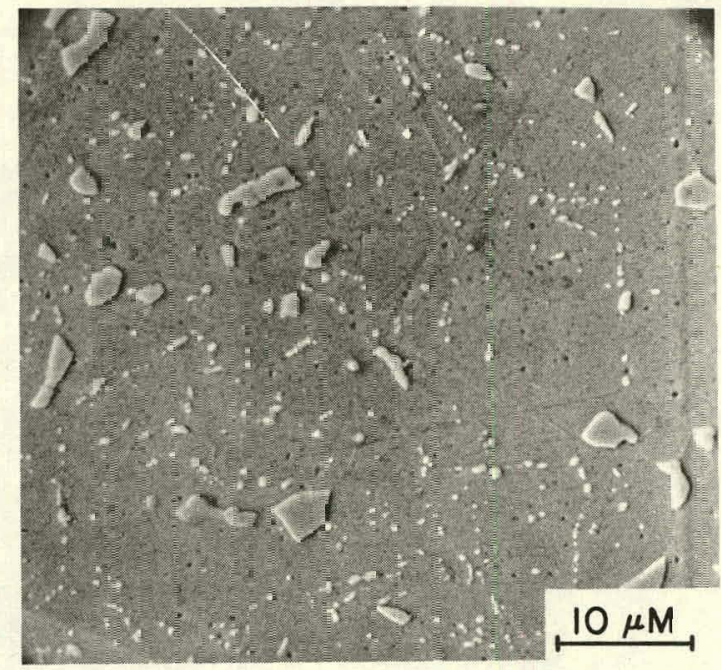

(e)

Fig. 68. SEM Phctographs of Unirradiatec Archive Cladding Anrea ed $1000 \mathrm{~h}$ at Temparatures from 700 to $8100^{\circ} \mathrm{C}$. (a) $700^{\circ} \mathrm{C}$. MSD Neg. No. 200305.

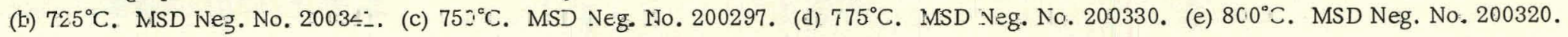




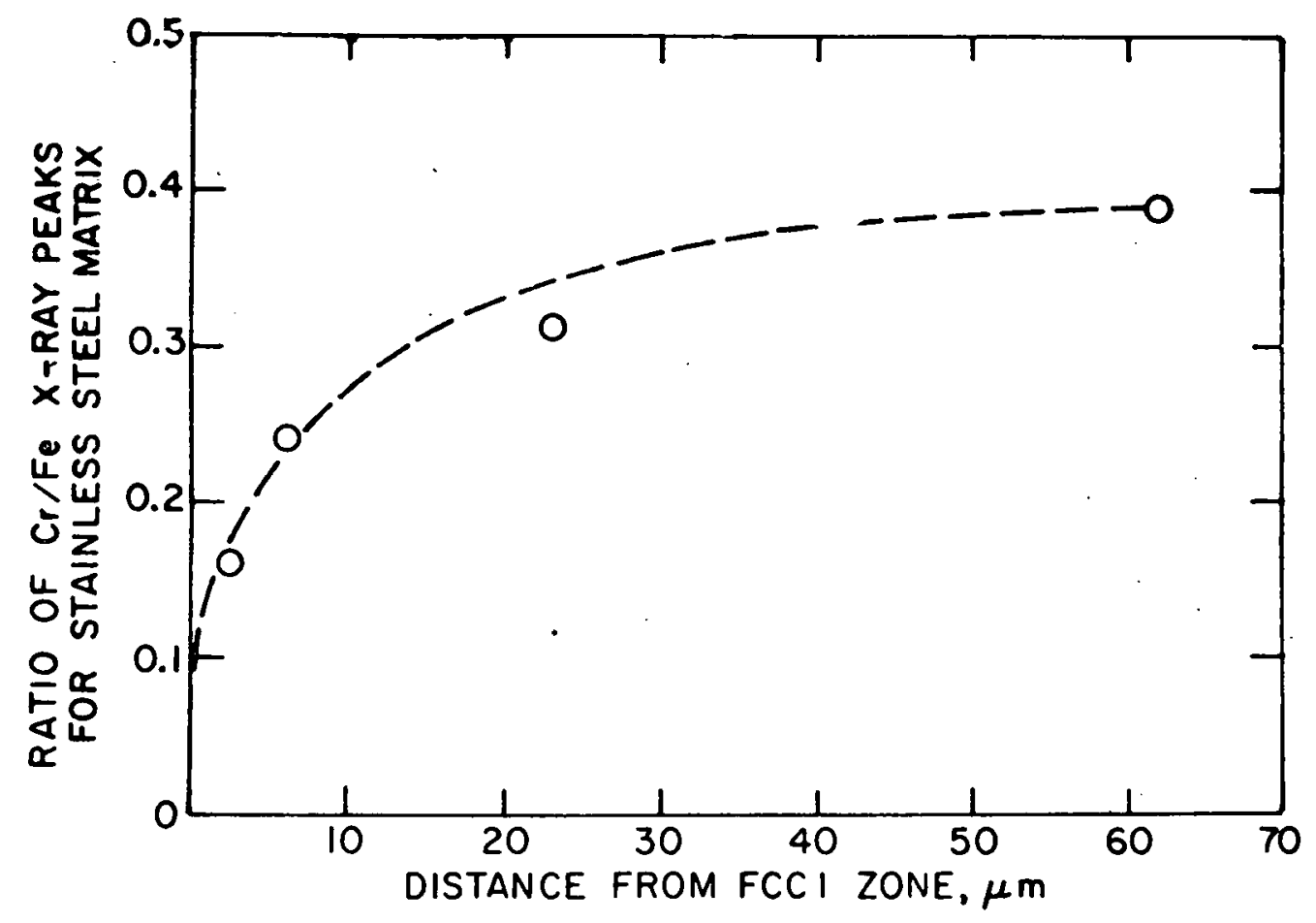

Fig. 69. Depletion of $\mathrm{Cr}$ Adjacent to the FCCI in the Cladding from the Midplane of Fuel Pin G-1. MSD Neg. No. 63989. 


\section{APPENDIX}

Results of Fuel-density Measurements Made with Quantitative Metallography

1. Radial Fuel-density Distributions of $\mathrm{G}-1$ and $\mathrm{G}-6$

The density of the fuel in the metallographic sections of elements G-1 and G-6 was determined using a Quantimet image analyzer. As mentioned in Ref. 2, these measurements are subject to errors of $\sim 2 \%$ and an unknown systematic error that arises from sample preparation and fuel cracking. Therefore, the absolute values shown in Figs. 70 through 74 are low by an unknown amount. The usefulness of the measurements is therefore limited to the relative densities of the fuel in the cross sections.

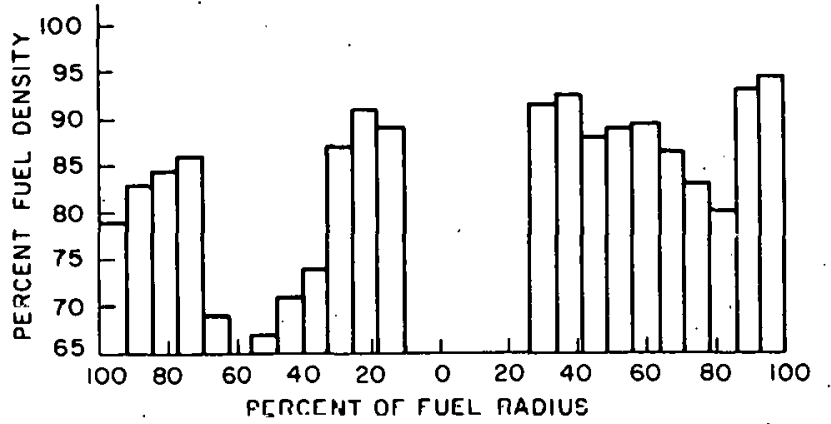

(a)

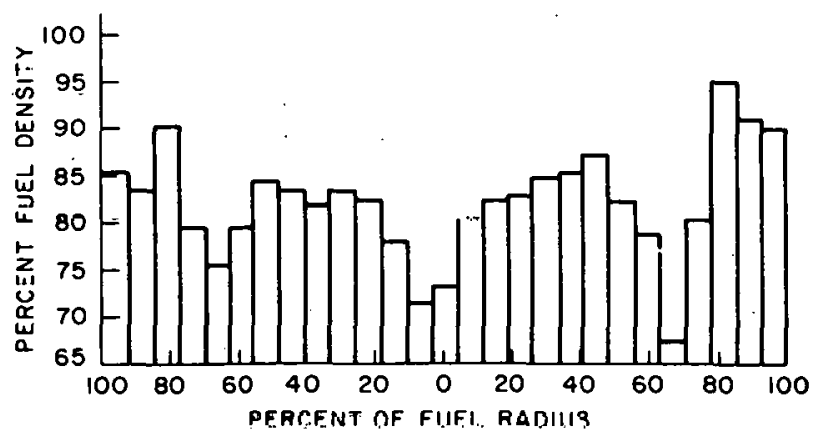

(b)

Fig. 70. Diametral Fuel-density Distribution for Top and Bottom of G-6 Fuel Column. (a) Top longitudinal section. (b) Bottom longitudinal section. MSD .Neg. No. 63963.

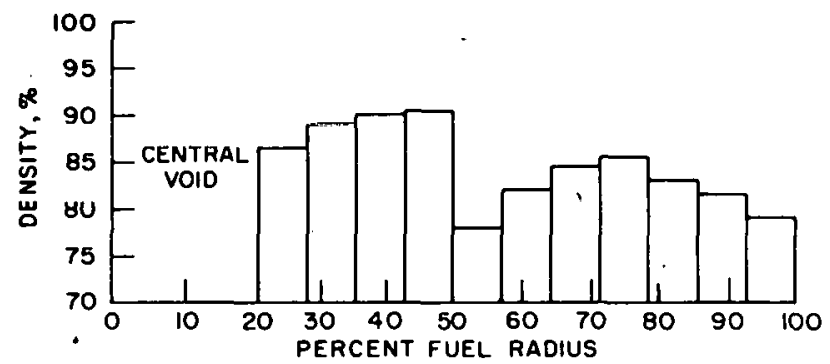

(a)

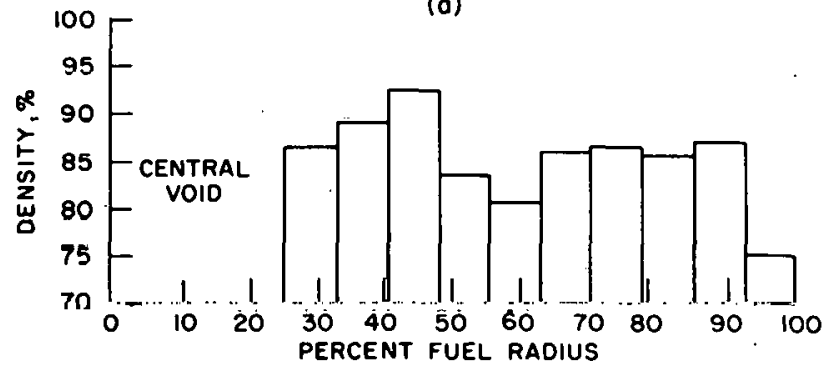

(b)

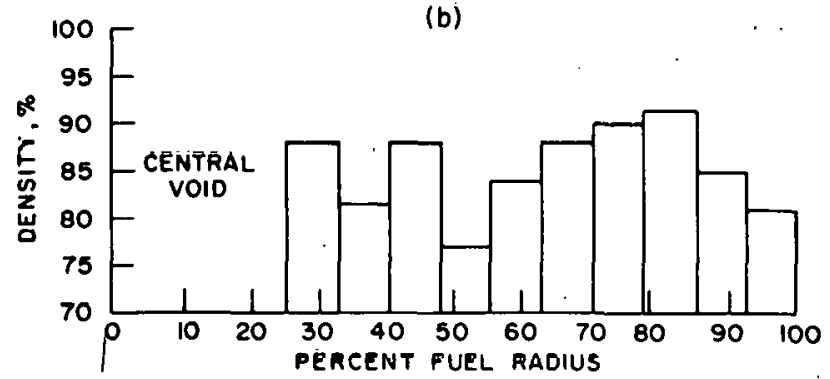

(c)

Fig. 71. Radial Fuel-density Distribution for the Transverse Sections from $G-6$. (a) 11.15 in. above core bottom. (b) 6.75 in. above core bottom. (c) 3.25 in. above core bottom. MSD Neg. No. 63965 . 


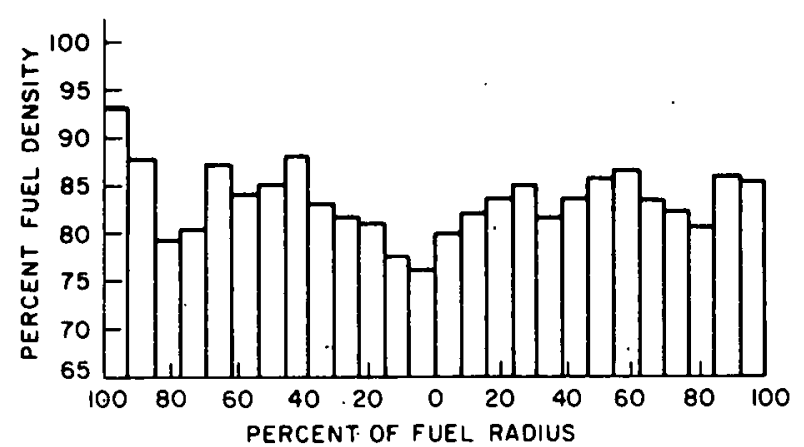

(a)

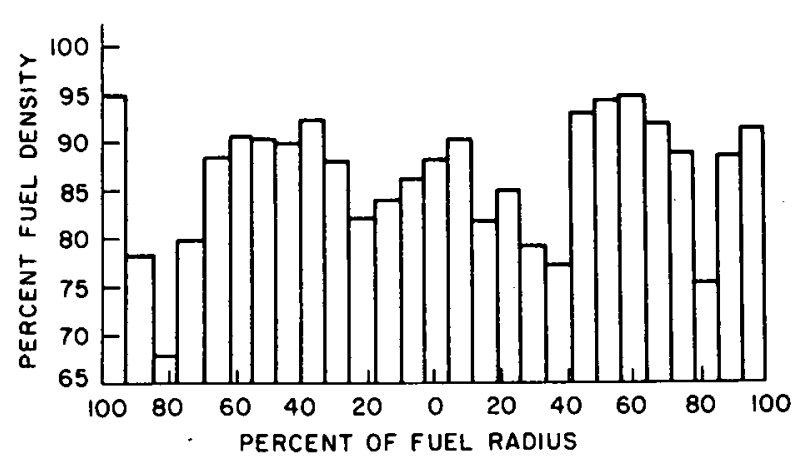

(b)

Fig. 72. Diametral Fuel-density Distribution for Top (a) and Bottom (b) of G-1 Fuel. Column. MSD Neg. No. 63964.

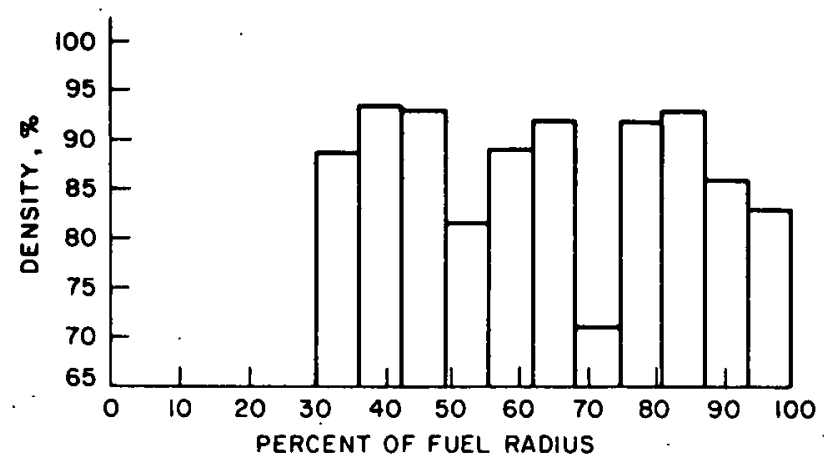

(a)

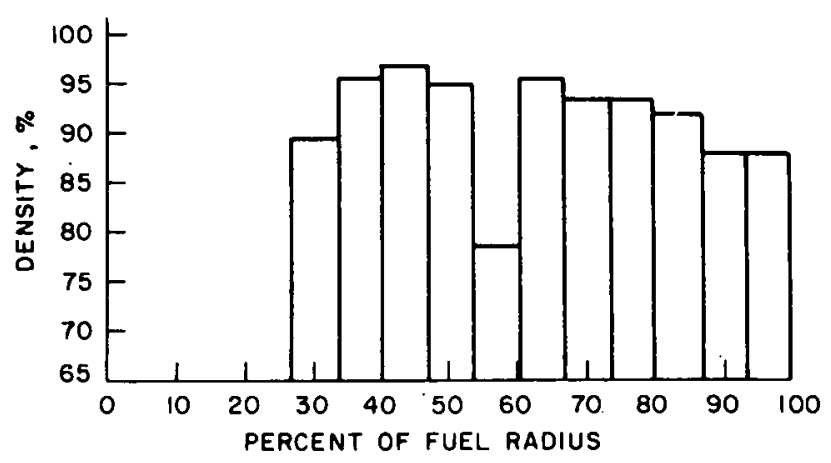

(b)

Fig. 73. Radial Fuel-density Distribution for Sections from G-1. (a) 6.75 in. above core bottom. (b) 3.3 in. above core bottom. MSD Neg. No. 63966 .

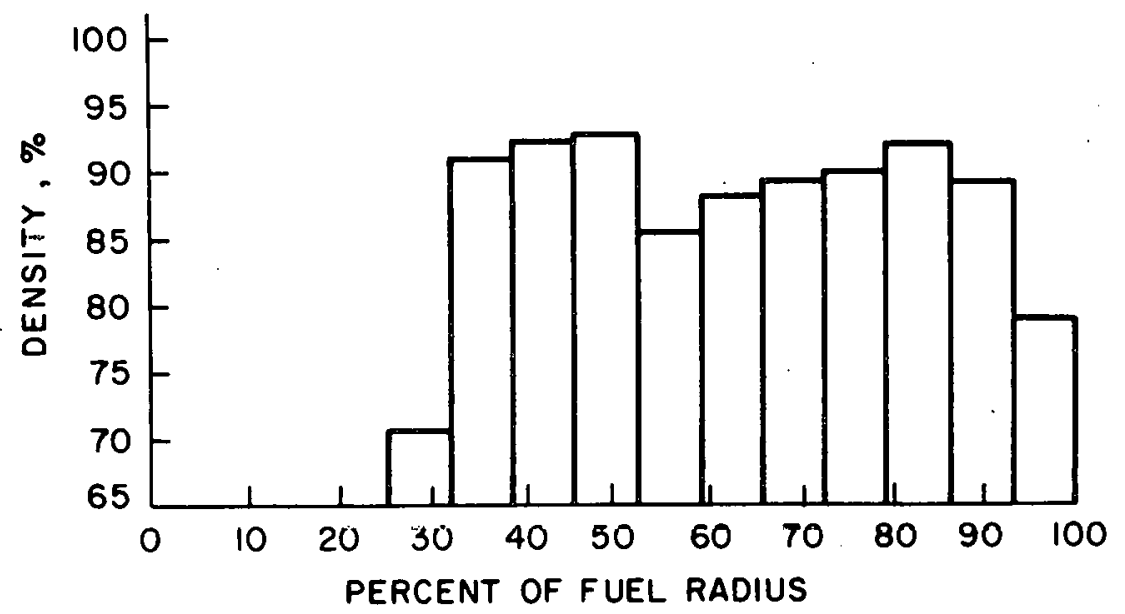

Fig. 74. Radial Fuel-density Distribution for Sections from G-1 11.3 in. above Core Bottom. MSD Neg. No. 63959. 
2. Fuel-density Determination

The measurements were made by projecting an image of the fuel microstructure on a Vidicon scanner. Features in the microstructure can then be detected according to their gray level. The threshold of detection is selected by the operator, and the area corresponding to that gray level is calculated by the computer portion of the system.

The Quantimet determination of void area has an accuracy of $2 \%$, as determined by calibrated measurements on $\mathrm{UO}_{2}$ specimens of known density at a magnification of $250 \mathrm{X}$. The main source of error in the measurement is the result of operator judgment; required to set the threshold of detection, which, in turn, affects the detected void size. The threshold of detection remains unchanged during a traverse across the fuel radius. Therefore, the measurement of the relative density across a specimen is more accurate than from specimen to specimen. Other factors affecting the accuracy of the measurement are the extent of fuel pull-out during sample preparation and the presence of large cracks in the fuel. Both of these errors are difficult to quantify, but they can be minimized by careful selection of the radii to be traversed and by careful sample preparation. It should be noted that both of these errors tend to make the measured density less than the actual density. 


\section{ACKNOWLEDGMENTS}

The authors wish to thank the operating personnel of the Materials Science Division's Alpha-Gamma Hot-Cell Facility for their efforts to obtain the bulk of the data in the present report. In particular, we wish to thank W. A. Shinn and C. A. Seils for obtaining the microprobe data and J. A. Sanecki for performing the scanning-electron microscopy of the cladding. We also thank L. A. Neimark for his thought-provoking discussions of the data. 


\section{REFERENCES}

1. P. W. Flynn, R. F. Hinz, S. Langer, J. R. Lindgren, R. J. Price, A. F. Weinberg, and T. N. Washburn, "High-Temperature Fast-Flux Irradiation Experiment for Mixed-Oxide Fuel Rods," General Atomic Co., GA-10264 (October 1970).

2. R. V. Strain, "Postirradiation Examination of Element G-3 from the GCFR F-1 Series of Mixed-oxide Elements after 3 at. \% Burnup," Argonne National Laboratory, ANL-76-128, in press.

3. A. J. Foltman, Argonne National Laboratory, EBR-II Project, personal communication (September 1974).

4. "HECTIC II, An IBM-7090 Fortran Computer Program for Heat-transfer Analyses of Gas or Liquid-cooled Reactor Passages," Aerojet-General Nuclear Corp., IDO-28595 (December 1965).

5. R. A. Laskiewicz, S. K. Evans, G. F. Melde, and P. E. Bohaboy, "Thermal Conductivity of Uranium-Plutonium Oxide," General Electric Co., GEAP-13733, p. '21' ('Geptember $19 / 1$ ).

6. S. Langer, J. R. Lindgren, G. O. Hayner, and R. Bono, "The Behavior of Volatile Fission Products in GCFR Fast Flux Irradiations," Trans. Am, Nucl. Soc. 17, 219 (November 1973).

7. J. D. B. Lambert, L. A. Neimark, and R. V. Strain, "A Failure Mechanism in Mixed-oxide Fuel Elements," Trans. Am. Nucl. Soc. 17, 193 (November 1973).

8. C. W. Renfro, Argonne National Laboratory, Materials Science Division, personal communication (June 1975).

9. C. N. Craig, J. L. Krankota, and W. E. Bailey, "Effective Thermal Conductivity of $\mathrm{PuO}_{2}-\mathrm{UO}_{2}$ at High Burnups," General Electric Co., GEAP-13703 (March 1971).

10. E. A. Aitken, M. S. Adamson, S. K. Evans, and T. E. Ludlow, "Thermodynamic Data Program Involving Plutonia and Urania at High Temperatures," Quarterly Report No. 16, May 1 to July 31, 1971, General Electric Co., GEAP-12229 (July 1971).

11. N. M. Voronov and R. M. Sofronova, "Reactions of Uranium Dioxide with Barium Oxide," Stroenie Splavov Nekotorykk System s Irronium i. Toriem, Moscow, Gasatomizdat, 1961, pp. 482-489.

12. L. A. Neimark and F. L. Brown, "Performance of Vibratorily Compacted Mixedoxide Fuel Elements Operating with Molten Fuel," Argonne National Laboratory, ANL-8U46 (November 1973).

13. I. Johnson, C. E. Johnson, C. E. Crouthame1, and C. A. Seils, "Oxygen Potential of Irradiated Urania-Plutonia Fuel Pins," J. Nucl. Mater. 48, 21. (1973).

14. J. A. Ellis and R. F. Hilbert, "Fast Flux Irradiation Data on the Stoichiometry of Fuel/Cladding Chemical Interaction in Mixed-oxide Fuel Rods," Trans. Am. Nucl. Soc. 19, 134 (October 1974).

15. "Nuclear Systems Materials Handbook," Vol. I, Design Data, TID-26666, June 19, 1974. 
Internal:

J. A. Kyger

R. Avery

L. Burris

D. W. Cissel

S. A. Davis

B. R. T. Frost

D. C. Rardin

R. J. Teunis

C. E. Till

R. S. Zeno

H. O. Monson

R. W. Weeks

F. Y. Fradin

F. A. Nichols

L. T. Lloyd

J. F. Schumar
M. F. Adams (2)

M. C. Billone

R. B. Poeppel

T. F. Kassner

L. A. Neimark

S. Greenberg (2)

F. L. Yaggee

H. R. Thresh

A. G. Hins

D. R. Diercks

A. Purohit

K. J. Reimann

D. Stahl

D. J. Lam

N. L. Peterson

B. S. Brown
K. L. Merkle

M. B. Brodsky

H. Wiedersich

U. F. Kocks

R. W. Siegel

M. H. Mueller

W. D. Jacks on

D. L. Johnson

J. E. Sanecki

J. T. Madell

R. V. Strain (10)

C. E. Johns on (10)

A. B. Krisciunas

ANL Contract File

ANL Libraries (5)

TIS Files (6)

\section{External:}

DOE-TIC, for distribution per UC-77 (181)

Manager, Chicago Operations Office

Chief, Chicago Patent Group

Director, DOE-RRT (2)

Director, Reactor Programs Div., CH

Director, CH-INEL

President, Argonne Universities Association

Materials Science Division Review Committee:

G. S. Ansell, Rensselaer Polytechnic Inst.

R. W. Balluffi, Cornell U.

S. L. Cooper, U. Wiscons in

S. Doniach, Stanford U.

H. L. Falkenberry, Tennessee Valley Authority

C. Laird, U. Pennsylvania

D. Lazarus, U. Illinois

M. T. Simnad, General Atomic

A. R. C. Westwood, Martin Marietta Lahs. 